\title{
Crianças nascidas após o emprego de técnicas de reprodução assistida: aspectos maternos e resultados perinatais
}

\author{
Marcia de Freitas
}

Tese apresentada ao Programa de Pós-Graduação em Saúde Pública da Faculdade de Saúde Pública da Universidade de São Paulo para obtenção do título de Doutor em Saúde

Pública.

Área de Concentração: Saúde MaternoInfantil

Orientador: Prof. Dr. Arnaldo Augusto Franco de Siqueira

São Paulo

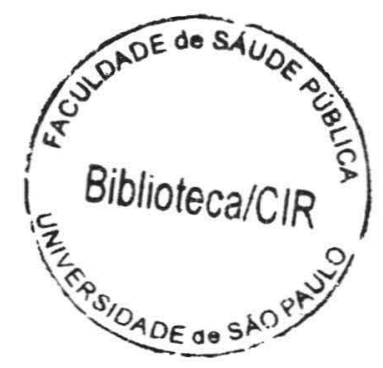


É expressamente proibida a comercializaçăo deste documento tanto na sua forma impressa como eletrônica. Sua reprodução total ou parcial é permitida exclusivamente para fins acadêmicos e científicos, desde que na reproduçăo figure a identificação do autor, título e ano da tese/dissertação.

$$
49034 / 2007 \text { doe }
$$


A minha mãe, em memória, a quem dedico meu doutorado.

Ao meu maior exemplo de vida, Marcelo que sempre me estimulou a dar este grande passo. Com muita sabedoria, discernimento, bom senso e dedicação esteve sempre caminhando ao meu lado me encorajando nas horas difíceis e me aplaudindo nos momentos de glória. Obrigada por ser meu marido, pelo apoio e o ensino diário. 


\section{AGRADECIMENTOS}

A todos que contribuíram para a realização deste trabalho, fica expressa aqui a minha gratidão, especialmente:

Ao Professor Arnaldo agradeço profundamente por ter assumido a orientação desta tese com um tema absolutamente novo, tendo-me brindado com importante colaboração em todo meu trabalho, presente em todos os momentos, mesmo quando ele estava doente, sempre me incentivando e me direcionando para alcançar meus objetivos.

Ao Prof. Dr. Jonathas Soares Borges, meu agradecimento especial, pelo infinito apoio, orientação e principalmente pela confiança durante 0 desenvolvimento do todas as etapas do meu doutorado.

A minha eterna mestra Profa. Dra. Conceição Aparecida de Matos Segre todo meu respeito e carinho, que tanto tem contribuído para que meus sonhos se tornem uma realidade.

Ao Prof. Dr. Sidney Glina por aceitar a participar da banca de defesa desta tese, e certamente suas sugestões servirão para meu crescimento, aprendizado e incentivo à pesquisa.

Ao Prof. Dr. Cláudio Leone agradeço as ricas sugestões a esse trabalho, assim como sua compreensão, estimulando-me sempre a seguir em frente.

A Dra. Alice D'Agostini Deustch que muito tem contribuído para meu crescimento profissional.

Aos meus colegas, pediatras, neonatologistas, obstetras e a toda a equipe multidisciplinar do HIAE pela compreensão e o carinho em me ajudar nos meus momentos de maior dificuldade.

Aos colegas do Ministério da Saúde de compreenderam e incentivaram essa jornada.

A minha GRANDE amiga Mirna que sobreviveu a mordida do meu cachorro, comemoração do seu aniversário em minha casa com o único objetivo de me ajudar a elaborar o "nosso doutorado".

Aos pacientes que participaram desta pesquisa, pois sem eles nenhuma dessas páginas estaria completa.

As grandes embriologistas Roberta e Françoise que tanto me ajudaram com o fornecimento de dados, literatura e com suas experiências. 
Ao Serviço de Epidemiologia - Gestão de Informação em Saúde do HIAE que me forneceram todo o banco de dados do berçário e da maternidade de todo o período de abrangência do meu trabalho.

A minha grande parceira Creusa que abriu mão de sua própria família para me ajudar nas atividades domésticas.

Aos pacientes que participaram desta pesquisa, pois sem eles nenhuma dessas páginas estaria completa

À todos aqueles que de forma direta ou indireta colaboraram para a realização desta tese, meu agradecimento. 
Resumo: Crianças nascidas após o emprego de técnicas de reprodução assistida: aspectos maternos e resultados perinatais

Introdução: Saúde Reprodutiva é um estado de completo bem-estar físico, mental e social em todas as matérias concernentes ao sistema reprodutivo, suas funções e processos, e não a simples ausência de doença ou enfermidade. Desde tempos remotos o homem pensou na possibilidade de fecundação fora do ato sexual. Atualmente é altamente divulgada e realizada. Encontram-se os procedimentos tanto de baixa complexidade (relação programada e inseminação artificial), como de alta complexidade (fertilização in vitro, transferência intratubária de gametas, injeção intracitoplasmática de espermatozóides). Contudo são poucos os trabalhos brasileiros demonstrando a repercussão materno-infantil desses procedimentos. Objetivo: Comparar as características maternas e resultados perinatais de crianças concebidas por diferentes modalidades de técnicas de reprodução assistida da Unidade de Reprodução Humana do Hospital Israelita Albert Einstein. Método: Estudo foi descritivo, retrospectivo para coleta dos dados e prospectivos para análise dos mesmos. utilizando dados de mulheres que foram submetidas às diferentes técnicas de reprodução assistida na Unidade de Reprodução Humana do Hospital Israelita Albert Einstein no período de janeiro de 1995 a dezembro de 2003. Foram selecionados para o estudo todos os casos de sucesso gestacional cujos partos ocorreram na própria Instituição. Resultados: Neste período o Serviço de Reprodução Humana base deste estudo realizou 2448 procedimentos, sendo FIVc 439 e ICSI 2009. Em média a taxa de gravidez variou de $25-30 \%$. Năo houve diferenças significativas entre os dois métodos estudados, em relaçăo aos resultados perinatais. Encontrou-se maior morbimortalidade entre os múltiplos em relação aos únicos. Conclusão: As técnicas de reprodução assistida não interferiram nos resultados perinatais. A prematuridade dos múltiplos foi o fator determinante de maior morbimortalidade.

Palavras-chave: fertilização in vitro, injeção intracitoplasmática de espermatozóides, gestação múltipla, prematuridade. 


\section{Abstract: Children born after assisted reproduction techniques: maternal aspects and perinatal results.}

Introduction: Reproductive health is a state of complete physical, mental and social well-being in all the subjects related to reproductive system and its functions and process, not the simple absence of disease or illness. From remote times, man thought in the possibility of fertilization without sexual intercourse. Presently, assisted reproduction has become widely known and performed. There is the less complex procedure (programmed sexual intercourse and artificial insemination) as.well as more complex procedures (in vitro fertilization, gamete intratubal transfer, intracytoplasmic sperm injection). Although, there are few Brazilian papers that demonstrate the maternal-child repercussions. Objective: To compare maternal characteristics and perinatal results of children conceived by different techniques of assisted reproduction of the Center of Human Reproduction of Hospital Israelita Albert Einstein. Methods: Retrospective for dates, prospective for analysis and descriptive study in women submitted to different techniques of assisted reproduction of the Center of Human Reproduction of Hospital Israelita Albert Einstein from January 1995 to December 2003. All the cases of pregnancy success and delivery that occurred at the institution were selected. Results: In the period from January 1995 to December 2003 at the Human Reproduction Service 2448 procedures were carried out, 439 IVF and 2009 ICSI. The pregnancy rate, on average, vary from $25-30 \%$. There is no significant different between the two methods studied to perinatal result. Major morbimortality was observed in multiples in relation to single birth. Conclusion: Assisted reproduction techniques did not interfere in perinatal results. Prematurity was the determinative factor to the bigger morbimortality of multiple births.

Keywords: in vitro fertilization; intracytoplasmic sperm injection; multiple pregnancy; prematurity. 


\section{Índice}

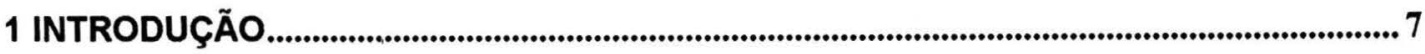

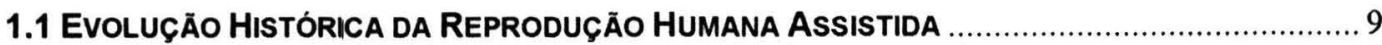

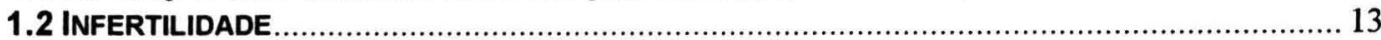

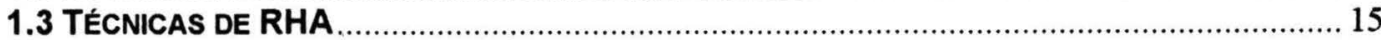

1.3.1 Técnicas de Baixa Complexidade Médica .................................................... 16

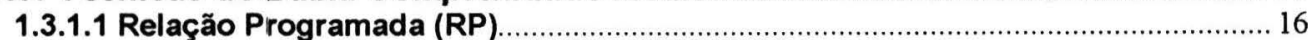

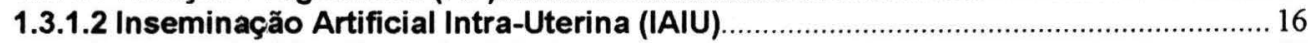

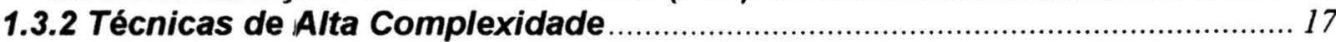

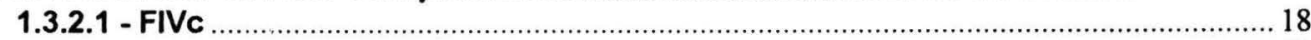

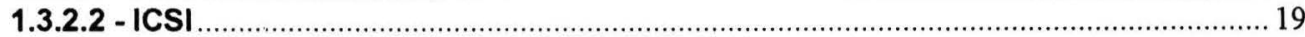

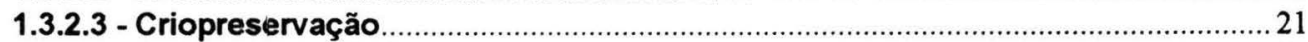

1.4 TAXAS DE SUCESSO NA RHA

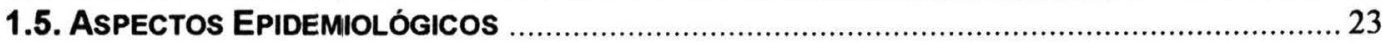

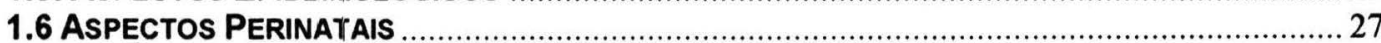

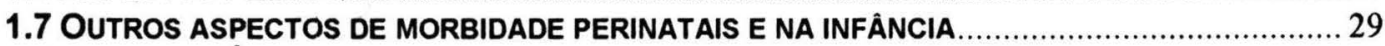

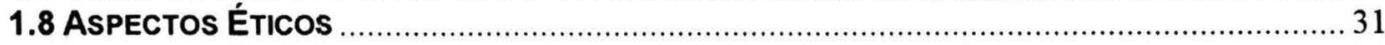

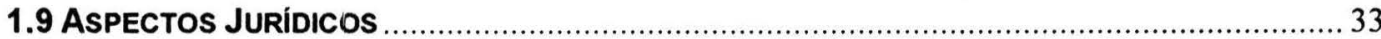

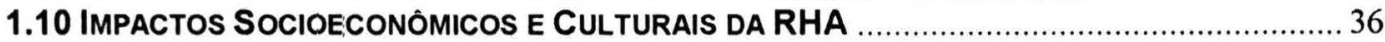

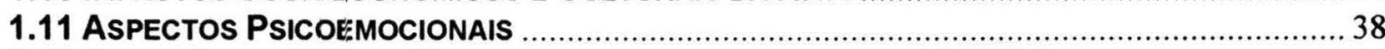

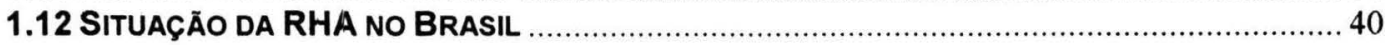

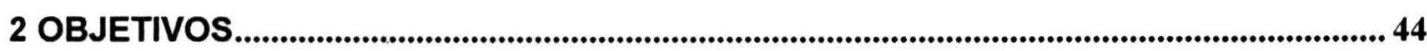

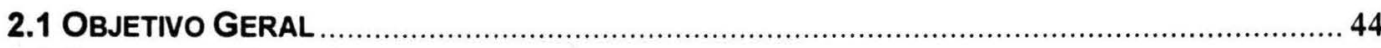

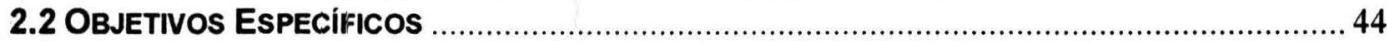

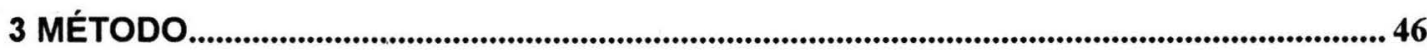

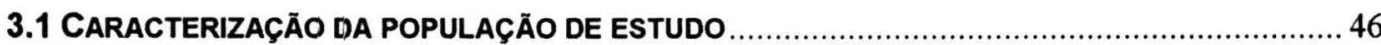

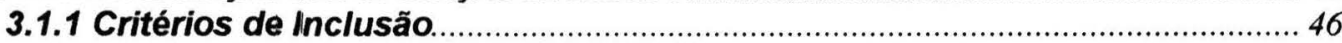

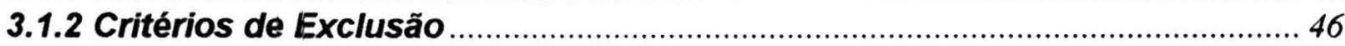

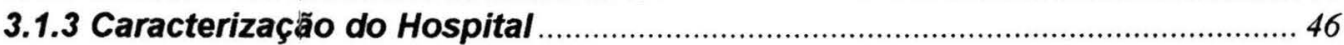

3.1.4 Caracterização da Unidade de Reprodução Humana do HIAE:........................4 47

3.1.5.1 Gestantes

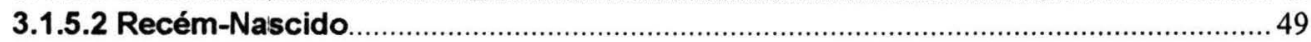

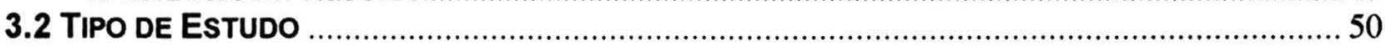

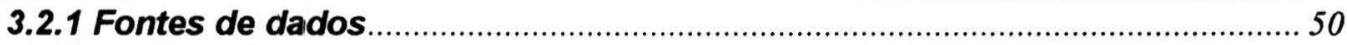

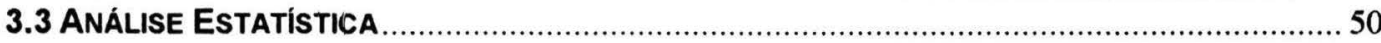

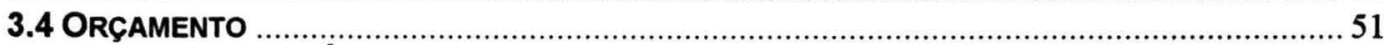

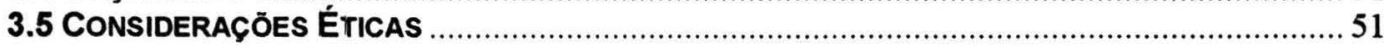

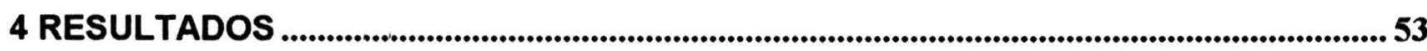

4.1 RESULtAdOS DAS PACIENTES QUE FIZERAM ALGUMA DAS TÉCNICAS DE RHA NO HIAE .... 53

4.2 CARACTERISTICAS GERAIS DAS PACIENTES QUE FIZERAM ALGUMA DAS TÉCNICAS DE RHA NO HIAE

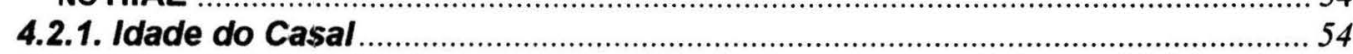

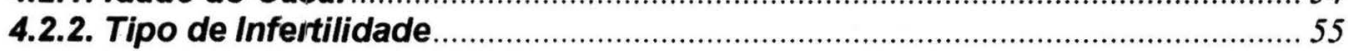

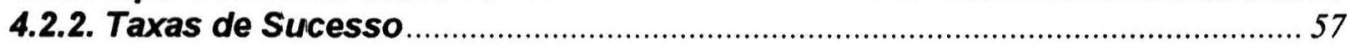

4.3 CARACTERIZAÇÃo dAS MULHERES QUE REALIZARAM O PARTO NO HIAE .........................58

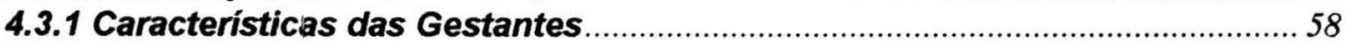

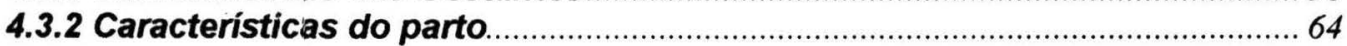

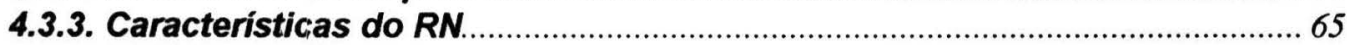

4.3.3.1 Malformação

4.3.3.2 Gemelaridade 


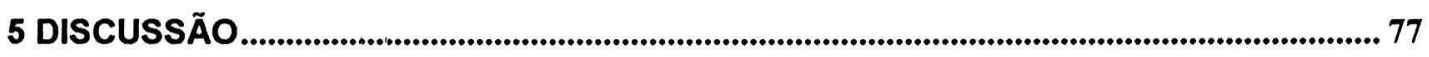

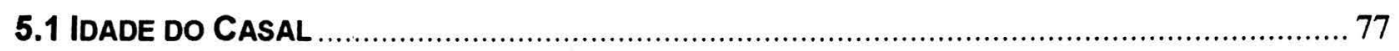

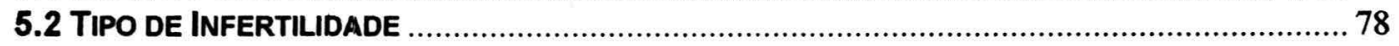

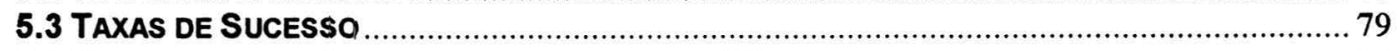

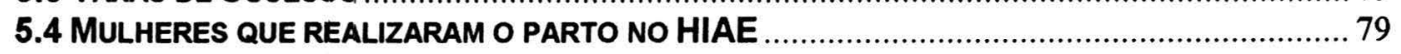

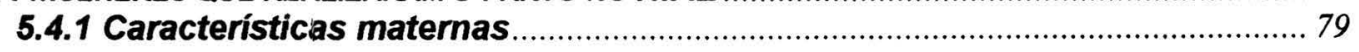

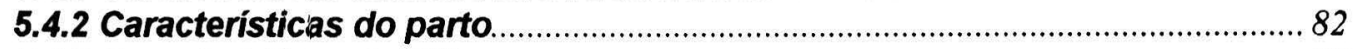

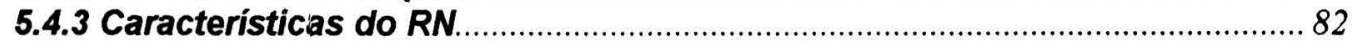

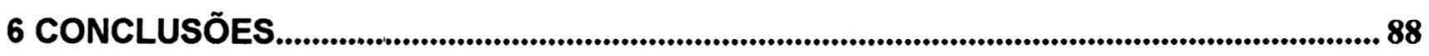

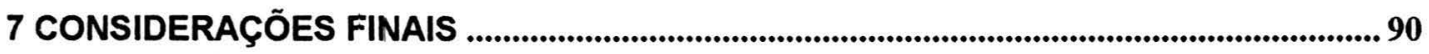

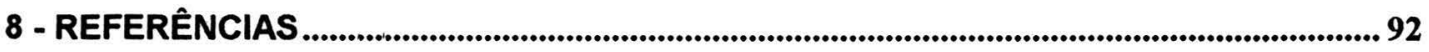




\section{Lista de Tabelas}

Tabela 1 - Distribuição da idade do casal segundo as pacientes que realizaram RHA. URHA-HIAE, 1995-2003

Tabela 2 - Presença do fator de infertilidade feminina das pacientes que realizaram RHA. URHA-HIAE, 1995-2003

Tabela 3 - Distribuição do fator de infertilidade feminina. URHA-HIAE 19952003

Tabela 4 - Presença do fator de infertilidade masculina dos parceiros das pacientes que realizaram RHA. URHA-HIAE, 1995-2003

Tabela 5 - Distribuição do fator de infertilidade masculina. URHA-HIAE 19952003 HIAE 1995-2003

Tabela 6 - Presença do fator de infertilidade sem causa de infertilidade aparente. URHA-HIAE, 1995-2003

Tabela 7 - Distribuiçăo de outros fatores de infertilidade. URHA-HIAE 19952003. HIAE 1995-2003

Tabela 8 - Taxa de Gravidez Bioquímica dos procedimentos realizados na URHA-HIAE, 1995 a 2003.

Tabela 9 - Taxa de Gravidez Clínica dos procedimentos realizados na URHA-HIAE, 1995 a 2003.

Tabela 10 - Taxa de Gravidez Efetiva dos procedimentos realizados no RHA no URHA- HIAE, 1995 a 2003.

Tabela 11 - Distribuição das Gestantes segundo a idade materna e idade gestacional. HIAE, 1995 a 2003 
Tabela 12 - Distribuição das gestantes segundo a presença de doenças antes da gravidez. HIAE, 1995 a 2003

Tabela 13 - Distribuição das gestantes segundo a presença de doenças durante a gravidez. HIAE, 1995 a 2003

Tabela 14 - Presença de ITU durante a gravidez. HIAE, 1995 a 2003

Tabela 15 - Presença de DHEG durante a gravidez. HIAE, 1995 a 2003

Tabela 16 - Presença de diabetes durante a gravidez. HIAE, 1995 a 2003

Tabela 17 - Presença de Internações durante a gravidez. HIAE, 1995 a 2003

Tabela 18 - Distribuição das gestantes segundo paridade. HIAE, 1995-2003.

Tabela 19 - Distribuição das gestantes segundo o número de abortos antes da gravidez. HIAE 1995-2003

Tabela 20 - Distribuição das gestantes segundo a o tipo de parto. HIAE, 1995-2003

Tabela 21 - Distribuição do número de RN por gestação. HIAE 1995-2003

Tabela 22 - Distribuição dos RN segundo o sexo. HIAE, 1995-2003.

Tabela 23 - Distribuição dos RN segundo a classificação da idade gestacional. HIAE 1995-2003.

Tabela 24 - Classificação do RN segundo o crescimento intra-uterino. HIAE, 1995-2003

Tabela 25 - Distribuição dos RN segundo o peso de nascimento. HIAE, 1995-2003

Tabela 26 - Características dos RN segundo variáveis peso, Apgar e tempo de internação. HIAE, 1995-2003 
Tabela 27 - Presença de doença pulmonar de membrana hialina grau IV. HIAE, 1995 a 2003

Tabela 28 - Presença de Hemorragias peri-intraventricular grau IV. HIAE, 1995 a 2003

Tabela 29 - Presença de septicemia. HIAE, 1995 a 2003

Tabela 30 - Presença de retinopatia da prematuridade. HIAE, 1995 a 2003

Tabela 31 - Presença de RN com malformação segundo idade materna. HIAE, 1995-2003

Tabela 32 - Distribuição RN com malformação segundo a idade materna. HIAE, 1995-2003

Tabela 33 - Distribuição dos tipos de malformações. HIAE, 1995-2003

Tabela 34 - Distribuição do número dos RN por gestação segundo a idade gestacional. HIAE, 1995-2003

Tabela 35 - Distribuição do número dos RN por gestação segundo peso de nascimento. HIAE, 1995-2003

Tabela 36 - Distribuição do número de RN por gestação segundo o tipo de alta. HIAE 1995-2003

Tabela 37 - Distribuição do número dos RN por gestação. HIAE, 1995-2003

Tabela 38 - Comparação entre RN por número por gestação. HIAE, 19952003 


\section{Lista de Gráficos}

Gráfico 1 - Distribuiçăo dos números de procedimentos de RHA no Centro de Reprodução Humana no HIAE, 1995 a 2003.

Gráfico 2 - Distribuiçăo do número de RN por tipo de gestação segundo a idade gestacional de nascimento. HIAE 1995-2003

Gráfico 3- Distribuição do número de RN por gestação segundo o tipo de alta. HIAE 1995-2003 


\section{Lista de Abreviaturas}

\begin{tabular}{|l|l|}
\hline BHCG & $\begin{array}{l}\text { Diagnóstico da gravidez dosando a gonadotrofina coriônica } \\
\text { humana }\end{array}$ \\
\hline CDC & Central Disease Control \\
\hline CREMESP & Conselho Regional de Medicina de São Paulo \\
\hline DHEG & Doença Hipertensiva Específica da Gravidez \\
\hline DNA & Ácido desoxirribonucléico \\
\hline DPMH & Doença Pulmonar de Membrana Hialina \\
\hline ESHRE & European Society of Human Reproduction and Embryology \\
\hline FIV & Fertilização in vitro \\
\hline FIVc & Fertilização in vitro clássica \\
\hline GIFT & Transferência Intratubária de Gametas \\
\hline HIV & Human Imunnedeficiency Virus \\
\hline HPIV & Hemorragia Peri Intra-Ventricular \\
\hline IAIU & Inseminação Artificial Intra-Uterina \\
\hline IBGE & Instituto Brasileiro de Geografia e Estatística \\
\hline IC & Intervalo de confiança \\
\hline ICSI & Injeção intracitoplasmática de espermatozóides \\
\hline IG & Idade Gestacional \\
\hline ITU & Infecção do Trato Urinário \\
\hline OMS & Organização Mundial de Saúde \\
\hline PGD & Diagnóstico Genético Pré-Implantacional \\
\hline Rede LARA & Rede Latino Americana de Reprodução Assistida \\
\hline RHA & Reprodução Humana Assistida \\
\hline RN & Recém-Nascido ou Recém-Nascidos \\
\hline ROP & Retinopatia da Prematuridade \\
\hline RP & Relação Programada \\
\hline RR & Risco relativo \\
\hline SBW & Síndrome de Beckwith-Wiedemann \\
\hline Sepse & Septicemia \\
\hline STT & Síndrome de transfusão feto-fetal \\
\hline
\end{tabular}




\begin{tabular}{|l|l|}
\hline SUS & Sistema Único de Saúde \\
\hline TPP & Trabalho de Parto Prematuro \\
\hline URHA-HIAE & $\begin{array}{l}\text { Unidade de Reprodução Humana Assistida do Hospital } \\
\text { Israelita Albert Einstein }\end{array}$ \\
\hline VACTERL & $\begin{array}{l}\text { um acrônimo para alterações vertebrais (V), atresia anal (A), } \\
\text { alterações cardíacas (C), atresia de esôfago ou fístula } \\
\text { traqueoesofágica (TE), anomalias renais (R) e anomalias de } \\
\text { extremidades (L, do inglês limb, membro) }\end{array}$ \\
\hline
\end{tabular}




\section{INTRODUÇÃO}




\section{Crianças nascidas após o emprego de técnicas de reprodução assistida: aspectos maternos e resultados perinatais}

\section{INTRODUÇÃO}

Segundo a Conferência Internacional sobre População e Desenvolvimento - Programa de Ação ${ }^{1}$ - $\$ 7.2$, a "Saúde Reprodutiva é um estado de completo bem-estar físico, mental e social em todas as matérias concernentes ao sistema reprodutivo, suas funções e processos, e não a simples ausência de doença ou enfermidade". A saúde reprodutiva implica, por conseguinte, que a pessoa possa ter uma vida sexual segura e satisfatória, tendo a capacidade de reproduzir e a liberdade de decidir sobre quantas vezes deseja fazê-lo. Está implícito, nessa última condição, o direito de homens e mulheres de serem informados e de terem acesso aos métodos eficientes, seguros, aceitáveis e financeiramente compatíveis de planejamento familiar. Da mesma forma, o acesso a outros métodos de regulação de fecundidade à sua escolha e que não contrariem as leis, bem como o direito de acesso a serviços apropriados de saúde que propiciem às mulheres as condições de passar em segurança pela gestação e parto, proporcionando aos casais uma chance melhor de ter um filho sadio.

Para um melhor entendimento sobre os Direitos Sexuais e Reprodutivos é necessário compreender que esse conceito, no âmbito internacional, o que remonta à primeira Assembléia Geral das Nações Unidas $-1948^{2}$, na qual se consideraram homens e mulheres iguais em dignidade. Entretanto, os direitos reprodutivos foram reconhecidos, pela primeira vez como Direitos Humanos, na Conferência Internacional de Direitos Humanos, celebrada em Teerã $-1968^{3}$.

Não obstante esses avanços, na Conferência Mundial de Direitos Humanos, de Viena -1993 fomos enfatizados que os direitos das mulheres e 
meninas constituem-se em Direitos Humanos inalienáveis ${ }^{3}$. A declaração e o programa de Ação de Viena adotado pela Conferência Mundial de Direitos Humanos, em 1993, declararam: "Todos os direitos humanos são universais, indivisiveis e interdependentes e estão relacionados entre si. A comunidade internacional deve tratar os Direitos Humanos de forma global e de maneira justa e eqüitativa, dando-Ihes, a todos o mesmo peso" ${ }^{4}$.

Este e outros postulados foram referendados mais adiante, na Conferência Internacional sobre População e Desenvolvimento no Cairo em 1994, assim como na Quarta Conferência Mundial sobre a Mulher - Beijing1995. O aporte dessas Conferências foi o reconhecimento de novos Direitos, entre eles os sexuais e reprodutivos e, principalmente, o estabelecimento de estratégias para a implementação de ações que têm como meta a eqüidade de gênero ${ }^{4,5}$.

Nesse contexto, surge a reprodução assistida definida no projeto de lei art. L 671-2 adotado pela Assembléia Nacional Francesa em 26 de Novembro de 19924: "A procriação medicamente assistida destina-se a responder ao projeto parental de um casal. Tem por objetivo exclusivo atenuar a esterilidade, cujo caráter patológico foi medicamente constatado, ou evitar a transmissão à criança de uma doença particularmente grave e incurável".

A Reprodução Humana Assistida (RHA) é, basicamente, a intervenção do homem no processo de procriação natural, com o objetivo de possibilitar que pessoas com problema de infertilidade e esterilidade satisfaçam o desejo de alcançar a maternidade ou a paternidade.

Ressalta-se que a esterilidade e a infertilidade são doenças devidamente registradas na Classificação Internacional de Doenças - CID 10 (pela OMS) $^{6}$ e, como tal, podem ser tratadas. 


\subsection{Evolução Histórica da Reprodução Humana Assistida}

Desde tempos remotos o homem pensou na possibilidade de fecundação fora do ato sexual ${ }^{7}$.

A mitologia é rica em casos de mulheres que engravidaram fora do ato sexual, como por exemplo: Ates - filho de Nana, filha do Rei Sangário, que teria colhido uma amêndoa e colocado em seu ventre (Grécia); Kwanyin - deusa que possibilitava a fecundidade das mulheres que Ihe prestassem culto (China); Vanijiin - deusa da fertilidade, mulheres que se dirigiam sozinhas a seu templo, retornavam grávidas (Japão); Maria, mãe de Jesus, (Bíblia); no Brasil é conhecida a lenda do boto que engravida as mulheres que the dirigem o olhar ${ }^{8}$.

Os avanços tecnológicos permitiram que o sonho místico viesse a se tornar realidade ${ }^{9,10,11}$.

Em meados do século XVIII, Ludwig Jacobi (alemão) fez tentativas de inseminação em peixes. Em 1755, Lazzaro Spallanzani (biólogo italiano) obteve resultados positivos na fecundação de mamíferos. Em 1799, John Hunter (médico e biólogo inglês) obteve êxito na fecundação por Inseminação Assistida em seres humanos. Em 1884, Pancoast (médico inglês) fez a primeira inseminação heteróloga. Em 1910, Elie Ivanof (russo) foi responsável pela descoberta da conservação do sêmen fora do organismo, por resfriamento.

Vencedor de Premio Nobel em 1924, o cientista Hans Spermann muito contribuiu para o estudo de reprodução. Em 1902, na Alemanha, produziu o primeiro clone animal. Obteve duas salamandras a partir de um embrião de salamandra de duas células associada a um fio de cabelo humano. 
Em 1940, o biólogo francês Jean Rostand descobre que o sêmen de animal pode ser conservado em baixas temperaturas e teriam surgido também nesse ano os primeiros bancos de sêmen nos EUA.

O ano de 1953 é marcado pela primeira inseminação artificial feita com sêmen congelado, onde os geneticistas ingleses James $\mathrm{B}$. Watson $\mathrm{e}$ Francis $\mathrm{H}$. C. Crick descobriram a estrutura em hélice de DNA, descoberta que deu origem à Genética Molecular e é considerado o marco inicial da Engenharia Genética.

Em 25 de julho de 1978, na Inglaterra, nasceu Louise Toy Brown, o primeiro bebê de proveta, marco da fertilização in vitro (FIV) e o evento mais importante em matéria de RHA, realizada por Patrick C. Steptoe e Robert Edwards ${ }^{11}$.

Em 1980 na Austrália foi criado o primeiro banco de embriões de seres humanos congelados ${ }^{12}$.

FERNANDEZ et al. ${ }^{13}$ (1985) publicam a ocorrência da primeira gestação obtida por transferência intratubária de gametas (GIFT), em 1984, no Chile.

Concomitantemente, o médico paulista Dr. Milton Nakamura tendo como colaborador Dr. Steptoe, realiza o primeiro procedimento de FIV com gestação no Brasil e assim nasce no dia 7 de outubro de 1984, Ana Paula Caldeira ${ }^{14}$.

Com o auxilio do micromanipulador, surge o procedimento de injeção intracitoplasmática de espermatozóide (ICSI), que completou a técnica do Dr. Edwards, até então a mais revolucionaria de todos os tempos. Em 1992, um grupo da Universidade Livre da Bélgica descreve a primeira gestação pelo método ${ }^{15}$.

Em 1994, foram relatadas as primeiras gestações de mulheres em período de menopausa na América Latina, por meio da técnica de FIVc e 
doação de oócitos. Nessa data, em Roma, uma mulher de 62 anos teve um filho por meio de RHA em homens azoospérmicos ${ }^{17}$.

Nesse período, começaram a ser desenvolvidas no mundo as técnicas para obtençăo de espermatozóides ${ }^{17}$.

Outro fato marcante na RHA foi o nascimento de Elizabetta, em 1995, em Roma, dois anos após a morte da sua mãe. 0 embrião foi transferido para o útero de sua tia, irmã de seu pai natural ${ }^{17}$.

O avanço incessante das ciências biomédicas e da biologia molecular possibilitou, na questão do diagnóstico pré-natal, a abertura de novos caminhos. Em 1990, dois grupos, separadamente, descreveram resultados de biópsias embrionárias antes da transferência para o útero. Começava a se desenvolver a técnica de Diagnóstico Genético Pré-Implantacional (PGD), que, no Brasil foi introduzida em 1997. Nessa data, um fato revoluciona a comunidade cientifica e a sociedade: o nascimento da ovelha Dolly, clonada pelos britânicos lan Wilmut e Keith Campbell ${ }^{18}$.

Em 1998, a revista Science publica um artigo do Grupo de Thomson (Madison, EUA), que relata a possibilidade de se obter células indiferenciadas (células-tronco - stem cells) a partir de embriões em estágios de blastocistos ${ }^{19}$.

Em julho de 2000, cientistas britânicos conseguiram desenvolver células hepáticas a partir de células precursoras do sangue. A descoberta é - primeiro grande passo para substituir a necessidade de transplantes, aumentando a aplicabilidade na clonagem de embriōes para fins terapêuticos.

No ano de 2001, na Universidade de São Paulo, o grupo coordenado pela professora Lygia da Veiga Pereira é o pioneiro na aquisição de células tronco e geração de modelos animais para doenças genéticas humanas ${ }^{20}$. 
Em continuidade ao processo histórico, em janeiro de 2005, o Departamento de Reprodução Humana do Canadá determinou normas mais rígidas e um regime regulatório para os procedimentos de $\mathrm{RHA} \mathrm{A}^{21}$.

Dois eventos importantes ocorreram em abril de 2007, quando uma advogada canadense conseguiu a primeira permissão para doar óvulos para a própria filha. A mulher congelou os seus próprios óvulos para que sua filha pudesse usá-los se resolvesse ter filhos, dando-lhe a oportunidade de ter uma criança com genes semelhantes aos dela, condição essa que seria impossível de forma natural pelo fato da menina ser portadora de Síndrome de Turner 22 .

Em junho de 2007 pesquisadores anunciaram, numa conferência em Lyon, França, o nascimento da primeira criança de FIV resultante de um óvulo amadurecido em laboratório e depois congelado, realizado pelo grupo de Hananel Holzer, do Centro de Reprodução da McGill, em Montreal ${ }^{22}$.

Esse novo procedimento será de grande importância para mulheres submetidas à quimio e radioterapia e àquelas que não conseguem engravidar com a fertilização in vitro (FIV clássica). Assim, dois grupos de mulheres poderão ser beneficiadas por essa técnica: as jovens com câncer que vão poder retirar seus óvulos antes da quimioterapia, que pode deixá-las inférteis, e as mulheres com a síndrome dos ovários policísticos. 0 procedimento não envolve hormônios para estimular a ovulação, utilizandose óvulos imaturos retirados de um ciclo natural da mulher. 


\subsection{Infertilidade}

A infertilidade é definida como a ausência de gestação clinica e hormonal após 12 meses de relações sexuais normais, sem o uso de método anticoncepcional (OMS). Pelo $\operatorname{CDC}^{23}$ estatisticamente $7-10 \%$ da população experimentará alguma forma de infertilidade. No Brasil estima-se que, mais de 3.000 .000 de mulheres casadas em idade fértil são inférteis, destas aproximadamente $12 \%$ residem no Estado de São Paulo. Com base nos mesmos dados do IBGE $^{24}$ sabe-se que $30 \%$ das mulheres com infertilidade necessitarão de RHA, o que corresponde no Brasil a mais de um milhão de mulheres.

Dados informados pelo Centro Nacional de Avaliação do Crescimento da Família em 2002 mostraram que das aproximadamente 62 milhões de mulheres em idade reprodutiva nesse ano, aproximadamente 1,2 milhões, ou $2 \%$, tinham o diagnóstico médico de infertilidade e $10 \%$ tiveram uma consulta com um médico de infertilidade em algum momento do passado. Adicionalmente, $7 \%$ dos casais em que a mulher encontrava-se em idade reprodutiva (2,1 milhões de casais) relataram que não tinham usado contraceptivos por 12 meses e a mulher não tinha engravidado ${ }^{25}$.

As causas atribuídas à infertilidade são várias. Como exemplo, a tendência atual da mulher adiar a gravidez para uma idade cada vez mais avançada, em função de sua entrada no mercado de trabalho e sua busca por realização profissional como prioridades, postergando o início da formação familiar a idades mais avançadas, nas quais sua fertilidade está diminuida ${ }^{26}$.

MENEZES ${ }^{27}$ (2005) comprovou que os rigorosos padrões de estética impostos às mulheres, tais como, peso ideal e juventude eterna, também têm contribuído para a infertilidade, já que o estresse dessas pressões pode levar à amenorréia e conseqüente interrupção da ovulação. 
Segundo dados da Organizaçăo Mundial de Saúde ${ }^{28}$ (OMS) em um estudo com 8.500 casais inférteis e utilizando critérios diagnósticos padrão para determinar as circunstâncias médicas que contribuiram para a infertilidade, constatou-se que em países desenvolvidos, o fator infertilidade feminina foi relatado em $37 \%$ de pares inférteis, o fator infertilidade masculina em $8 \%$ e, infertilidade mista, (masculina e feminina) em $35 \%$. Cinco por cento dos pares tiveram infertilidade sem causa aparente e $15 \%$ das mulheres engravidaram durante o estudo. Esse estudo ilustra a importância de avaliar o casal infértil, focalizando nos processos principais que afetam a fertilidade. Os processos principais que afetam a fertilidade feminina segundo o mesmo estudo e que explicaram $81 \%$ da infertilidade feminina foram: disfunção ovulatória (25\%), endometriose (15\%), aderências pélvicas $(12 \%)$, obstruções tubárias $(11 \%)$, outras anormalidades tubárias (11\%), hiperprolactinemia (7\%).

Já em paises em desenvolvimento a infertilidade feminina se deveu primeiramente ao fator tubo-peritonial, mais comumente desencadeado pela doença inflamatória pélvica e iatrogênica (laqueadura tubária), seguido do fator ovulatório ${ }^{26}$.

Quanto à infertilidade masculina, segundo diferentes estatísticas, é a primeira causa de um terço dos casais inférteis e associa-se ao fator feminino em outros 20\%. A vida sexual do casal é de grande relevância, muitas vezes descontinuada, principalmente por problemas sociais (como viagens profissionais, emprego e o tipo de ocupação). $O$ fator masculino tem como principais causadores: a criptorquidia, antecedentes cirúrgicos (vasectomia), orquite pós parotidite no pós púbere, seqüelas dos procedimentos utilizados no câncer de testículo ou até mesmo nos meninos com linfoma de Hodgkin, que apresentam espermogramas alterados prétratamento, indicando que a própria neoplasia condiciona alteração da espermatogênese. Ainda são referidas alterações do cariótipo (sendo a mais freqüente a sindrome de Klinefelter e microdeleçōes do cromossomo Y) ${ }^{26}$. 
Estudo realizado na Unidade de Reprodução Humana do Hospital Israelita Albert Einstein, encontrou que 25\% dos homens com menos de 5 milhões de espermatozóides por $\mathrm{ml}$ e $33 \%$ dos homens com azoospermias não-obstrutivas apresentam alguma alteração genética ${ }^{29}$.

Agentes poluentes industriais e do meio ambiente também estão relacionados com a alteração da fertilidade. A questão da gonadotoxicidade pode ser determinada por agentes químicos, físicos ou biológicos que possam alterar o sistema endócrino ou a espermatogênese, causando modificações na fisiologia normal da reprodução. $A$ interrupção do processo biológico normal pode ocorrer por ação direta do agente, ou de forma indireta, por meio de seus metabólitos ${ }^{30}$.

Muitas das causas de infertilidade, tidas como idiopáticas, são influenciadas pelo meio ambiente como: estilo de vida, uso de medicamentos, utilização ou contato com substâncias tóxicas (tabaco e metais), bem como a poluição do ar. $O$ estresse da vida moderna também pode provocar alterações hormonais, que por sua vez podem ter impacto sobre a fertilidade humana ${ }^{31}$.

\subsection{Técnicas de RHA}

A RHA consiste em um conjunto de técnicas, em que uma equipe multidisciplinar, tem participação estreita no acompanhamento do desenvolvimento folicular, detecção e indução da postura ovular ou até mesmo a realização do encontro dos gametas, assim como na otimização da fase lútea.

As indicações dessas técnicas estão diretamente ligadas às causas de infertilidade. 


\subsubsection{Técnicas de Baixa Complexidade Médica}

Apesar do grande número de procedimentos e técnicas diferentes, idealizados para a RHA, atualmente, a preferência absoluta recai sobre os métodos mais simples, com facilidade de repetição, que apresentem bons resultados e especialmente possam ser realizados em nível ambulatorial ${ }^{32}$.

\subsubsection{Relação Programada (RP)}

Entende-se RP como a orientação médica para a relação sexual, determinada pelo acompanhamento do período fértil da mulher. É o tratamento mais básico para infertilidade e muito se assemelha ao método natural. São analisados diversos aspectos do homem e da mulher submetidos ao tratamento: função tubária, desenvolvimentos folicular e endometrial, além de análise do sêmen ejaculado. Com resultados normais, pode-se tentar a gravidez com relação sexual com hora marcada. 0 referido procedimento pode incluir a indução da ovulação com medicações hormonais, a monitorização do crescimento dos folículos ovarianos e do desenvolvimento do revestimento uterino com ultra-sonografia, para se determinar o exato momento para a relação sexual. Suas principais indicações são: fator ovulatória e esterilidade sem causa aparente ${ }^{33,34,35}$.

\subsubsection{Inseminação Artificial Intra-Uterina (IAIU)}

Este tipo de inseminação, conhecido popularmente como inseminação artificial $^{30,33,34,35}$, é a técnica de introdução de espermatozóides preparados em laboratório no útero da mulher, com um pequeno cateter através do colo (entrada da cavidade uterina). O sêmen pode ser colhido do marido (ou companheiro) da paciente, ou de um doador anônimo, podendo ser fresco ou congelado, dependendo da situação de cada paciente. É uma outra técnica de baixa complexidade médica, determinada via de regra, quando 
realizada alguma tentativa de relação programada fracassada ou se houver alguma anormalidade pequena no muco cervical ou nos espermatozóides.

A indução da ovulação é feita, inicialmente, da mesma maneira que na RP, com o intuito de se produzir folículos múltiplos e liberar mais de um óvulo por ciclo reprodutivo. Ao mesmo tempo, há monitoração do tratamento por ultra-sonografia para medir o crescimento dos folículos e individualizar as doses do medicamento, colheita de sêmen e colocação através do colo uterino dos espermatozóides preparados, dentro da cavidade uterina, tudo para facilitar a fertilização. São indicados principalmente pelo fator masculino: de causa ejaculatória, de causa seminal leve e moderada, indicação para inseminação do sêmen do doador, do sêmen armazenado e para o fator feminino o cervical.

Os métodos de RHA de baixa complexidade são efetivos e consagrados no tratamento da infertilidade, entretanto sua eficácia apresenta significativa redução após varias tentativas sem sucesso. Restringe-se na realidade a três ou quatro tentativas, indicando-se uma técnica de alta complexidade na falha desse procedimento. Procedendo dessa forma, as técnicas de menor complexidade podem propiciar gestação em 30 a $50 \%$ dos casos (em 3 ou 4 tentativas), evitando assim procedimentos mais complexos e onerosos para grande parte dos casais ${ }^{32}$.

\subsubsection{Técnicas de Alta Complexidade}

São denominadas técnicas de alta complexidade os procedimentos de reprodução assistida que envolvem fertilização extracorpórea (fertilização in vitro - FIV). Pode ser a fertilização in vitro clássica (FIVc) ou a FIV com ICSI.

No conjunto de técnicas de alta complexidade, a FIV, com transferências de embriões, é um dos maiores avanços obtidos nas últimas décadas para a terapêutica de infertilidade conjugal. Ocupa, com certeza, 
lugar de destaque, já que permitiu a solução de um problema, até então insolúvel, a ausência tubária, além de contribuir para o desenvolvimento de um moderno e eficiente arsenal de drogas de indução ovulatória. Por outro lado, as técnicas de micromanipulação de gametas, como a ICSI, permitiram o tratamento da infertilidade masculina grave de maneira eficiente. Em continuidade a todos estes processos, iniciaram-se as pesquisas com o objetivo do tratamento direto dos gametas ("assisted hatching"), por defragmentação, e a prevenção de transmissão genética de afecções já

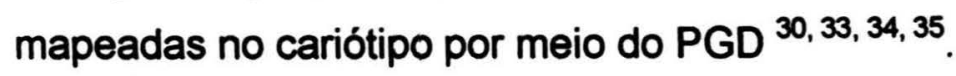

\subsubsection{1 - FIVc}

A FIV clássica, é comumente conhecida como "a técnica de bebê de proveta". A experiência inicial com FIVc envolveu mulheres com ausência ou obstruçăo das trompas, sem possibilidade de correção cirúrgica. Posteriormente tornou-se indicada para outras causas de infertilidade feminina, $\Theta$ até mesmo algumas masculinas, tiveram seu tratamento viabilizado por meio da FIVc, tais como: ausência ou obstruçăo tubária, insucesso de salpingólise e/ou reanastomose tubária, doenças pélvicas, endometriose grave (depois de tentativas de tratamento com procedimentos invasivos), falência ovariana (programa de ovodoação), oligoovulação, disovulias e/ou anovulias em falha de tratamentos anteriores, alguns fatores de infertilidade masculina moderados e infertilidade sem causa aparente ${ }^{11,36}$, $37,38,39,40,41,42$

No entanto, a opção por tratamentos mais conservadores deve ser considerada, principalmente nos casais com tubas pérvias e sem fator masculino mais acentuado (moderado ou grave). Causas de sub-fertilidade deverão ser tratadas antes de iniciadas as tentativas de FIVc, uma vez que não só as taxas de concepção natural, mas também as da própria FIVc 
podem ser melhoradas com tais cuidados. Deve-se ter sempre presente que a maior determinante de sucesso das técnicas de fertilização in vitro, FIVc ou mesmo com ICSI, é sem dúvida a idade da mulher ${ }^{43}$.

A FIVc é uma técnica de RHA em que a fertilização do óvulo pelo espermatozóide ocorre em laboratório de maneira espontânea. Os óvulos são identificados, classificados quanto à sua maturidade $e$ inseminados em meio de cultura especiais e incubados com $5 \% \mathrm{CO}_{2}$ na temperatura de $37^{\circ} \mathrm{C}$ a $90 \%$ de umidade.

O sêmen, antes da inseminação, passa por um processamento visando à separação dos espermatozóides do plasma seminal é o início do processo de capacitação. A fertilização é verificada 17 a 20 horas após a inseminação, na qual é observada a presença ou não dos pró-núcleos (feminino e masculino).

A clivagem embrionária e a classificaçăo dos pré-embriōes são vistas com mais de 24 horas de incubação. A transferência embrionária é realizada com 48 horas ( $2-4$ células), 72 horas (6-10 células) ou 120 horas após a verificação da fertilização, sendo que nesta última a fase embrionária observada é a de blastócito, que por apresentar maior taxa de implantação, permite a transferência de menor número de embriōes.

\subsubsection{2 - ICSI}

A ICSI está indicada quando o fator de infertilidade é masculino, ou quando o sucesso com outras técnicas, como a FIVc, é considerado improvável. Este fato pode ser devido ao encontro de menos de dois milhões de espermatozóides móveis por ejaculação, produção de anticorpos antiespermatozóide, falhas repetidas de fertilização com o esperma congelado pela técnica de FIVc, obstrução no trato reprodutivo masculino 
irreversível, morfologia anormal em mais 95\% espermatozóides e por defeitos específicos dos espermatozóides. A ICSI foi também bem sucedida nos homens com oligozooespermia grave e azoospermia, e nestes casos, os espermatozóides são obtidos por biópsias testiculares.

Nessa técnica de fertilização assistida é feita a injeção de um único espermatozóide no citoplasma do óvulo por meio de um aparelho especialmente desenvolvido contendo microagulhas para injeção (micromanipulador). Os óvulos são identificados, classificados quanto à sua maturidade e sofrem o processo de micromanipulação após 4 horas de incubação com $5 \%$ de $\mathrm{CO}_{2}$, temperatura de $37^{\circ} \mathrm{C}$ e $90 \%$ de umidade. Os espermatozóides passam pelo mesmo processamento descrito antes da injeção ${ }^{30,44}$. Os demais passos serão idênticos aos da fertilização clássica, anteriormente descrita.

Embora a ICSI represente um dos principais avanços na abordagem do fator masculino de infertilidade, existem considerações importantes relativas ao potencial de transmissão de anormalidades genéticas para a prole, uma vez que o processo de seleção natural dos espermatozóides, nestas circunstâncias é evitado. Ressalta-se também que as alteraçőes gênicas ou cromossômicas não interferem na morfologia dos espermatozóides nem no índice obtido com a RHA. Segundo PASCOLALLOTO ${ }^{45}$, os três fatores genéticos mais freqüentemente relacionados à infertilidade masculina são: as aberrações cromossômicas (mais freqüente a sindrome de Klinefelter -47 XXY-presente em $4,6 \%$ dos homens inférteis), mutações gênicas (a mais relevante delas e a que leva ao aparecimento da fibrose cística resultando em anormalidades do desenvolvimento das estruturas derivadas dos ductos de Woolf, secundariamente, em agenesia renal e aplasia e hipoplasia das vesículas seminais; e por microdeleçōes do cromossomo $\mathrm{Y}$.

As indicações das técnicas, em especial a da ICSI, devem ser muito precisas, pois conforme o médico urologista Dr. Sidney Glina no Jomal de Medicina, em 1999: 
"Seguramente, a ICSI foi o acontecimento mais maravilhoso para nós, que tratamos de homens inférteis. Mas esta arma deve ser usada com parcimónia e sabedoria e o casal tem que participar das decisóes e receber todas as informaçбes. Existem RHA tratamentos menos fantásticos, porém menos agressivos e que podem ajudar alguns casais" (GLINA, 2006, p.1)

Merece atenção na RHA uma "ferramenta coadjuvante" no tratamento da infertilidade: a criopreservaçăo.

\subsubsection{3 - Criopreservação}

Método de congelamento para a preservação de pré-embriōes e espermatozóides em nitrogênio líquido $\left(-196^{\circ}\right){ }^{30}, 47$. As células são protegidas dos danos causadas pelo congelamento e posterior descongelamento por substâncias chamadas de crioprotetores.

Esses crioprotetores, por meio do processo de osmose, entram na célula com conseqüente perda de água. 0 processo de congelamento pode ser realizado lentamente por vapor de nitrogênio líquido ou rapidamente por vitrificaçăo. 


\subsection{Taxas de Sucesso na RHA}

O maior determinante de sucesso das técnicas de FIVc ou com ICSI, é sem dúvida a idade da mulher. Em 2002, o registro americano mostrou que as taxas de nascidos vivos, por ciclo, em mulheres com idade inferior a 35 anos foi de $37 \%$, de 35 a 37 anos de $31 \%, 38$ a 40 anos $21 \%, 41$ a 42 anos $11 \%$ e acima de 42 anos $4 \%{ }^{48}$.

As taxas săo utilizadas para a avaliaçăo dos resultados das técnicas de RHA. Para o casal infértil o seu principal objetivo é alcançar uma gestação efetiva, ou seja, a que resulta em nascimento vivo.

No entanto, para o embriólogo e embriologistas, quando necessitam avaliar as práticas médicas, avanços nas técnicas de RHA, ou desenvolvimento de novos meios de cultura que resultaram em novos protocolos, essas taxas devem ser avaliadas em cada uma das fases dos procedimentos, ou seja, estimulação e monitoração ovarianas, coleta de óvulos, fertilizaçăo e cultura de embrião (taxa de fertilizaçăo) e transferência do embrião (taxa de transferência). A partir dessa fase podem ser evidenciados três tipos de gravidez: bioquímica-elevação dos níveis de betaHCG a partir do décimo dia após a transferência, gravidez clínica, onde se visualiza a presença de saco gestacional e batimento cardio-fetal pelo ultrasom; e a gravidez onde há a ocorrência do parto com o nascimento de uma criança viva). Para esses três tipos de gravidez as taxas podem ser calculadas tendo como o numerador a gestação e como denominador os ciclos iniciados ou número de embrióes transferidos ${ }^{49}$. 


\subsection{Aspectos Epidemiologicos}

A incidência de gestação gemelar espontânea é variável nos diferentes paises, sendo, por exemplo, baixa no Japão e alta na Nigéria ${ }^{50}$.

Nos Estados Unidos, a gestação dupla e tripla espontâneas ocorreram aproximadamente uma em cada 80 e uma em cada 8000 gestaçōes, respectivamente, sendo mais freqüentes na raça negra. Em 2002 , contudo, duplos e múltiplos nascimentos ( $\geq 3$ ) ocorreram em 31,1 e 1,8 por mil nascidos vivos respectivamente, ou seja, taxas muito superiores àquelas esperadas para o nascimento de duplos ou múltiplos espontâneos ${ }^{51}$.

No Brasil, entre 1984 e 1993, essa taxa ficou estável em 0,88\% em população de vários níveis socioeconómicos ${ }^{52}$.

É fato notório que a literatura médica vem registrando um aumento contínuo nas taxas de nascimentos gemelares a partir dos anos 70 até o momento. Em 2001, KIELY e KIELY ${ }^{53}$ (2001) relatam que, nos Estados Unidos subiram de 1,8\% em 1971 para aproximadamente $3 \%$.

No Brasil, segundo COLLETTO et al. ${ }^{54}$, analisando-se uma população de alto nivel, essa taxa atingiu 2,4\% no período de 1995 a 1998

Considerando-se dados do IBGE ${ }^{55, ",}$ pode-se verificar que houve uma alteração na curva demográfica do País quando se compara uma série histórica de nascimentos no período de 1984 a 2003. Enquanto o número de nascimentos, como um todo, elevou-se em $9,5 \%$, o número de triplos ou mais foi cinco vezes maior, quando se comparou o mesmo período.

Duas são as explicações possíveis: a interferência dos procedimentos de fertilizaçăo assistida e a idade materna mais elevada ${ }^{52,56}$.

*Nota de Rodape: Freitas, M. Figueira ASF, Segre CAM. Aspectos Demográficos na gemelaridade no Brasil (artigo năo publicado) 
Em relação aos procedimentos de RHA, tem-se verificado que o risco de gestação múltipla varia diretamente com o número de embriōes transferidos e também com o uso de drogas estimulantes do ovário, como as gonadrotofinas e o citrato de clomifene para indução da ovulação, dependendo da dose e da freqüência dos medicamentos. Outro fato importante para esta ocorrência foi o aumento e procura dos centros de infertilidade ${ }^{57}$.

Quanto à idade materna, estudo realizado na Suécia mostrou que mulheres acima de 39 anos tinham maior chance para o nascimento de gemelares. Observou-se, também, que essa probabilidade era três vezes maior quando foram comparadas mulheres em faixas etárias de 45 a 49 anos e 35-39 anos, enquanto para mulheres na faixa etária de 50 a 54 anos, um em cada três nascimentos podia ser gemelar. Considerando-se o nascimento de triplos, as mulheres acima de 45 anos tinham chance cem vezes maior de uma gestação tripla quando comparadas a gestantes adolescentes ${ }^{58}$.

Segundo POTER et al. ${ }^{59}$ (2002) as gestações múltiplas constituem sério motivo de preocupação, tanto para obstetras como para neonatologistas, por apresentarem condiçōes de risco quer seja para as gestantes como para seus filhos, como por exemplo, resultarem em um elevado número de crianças internadas em unidades de terapia intensiva neonatal.

Por outro lado, a mortalidade nos recém-nascidos (RN) de gestações múltiplas registra taxas 4 a 6 vezes mais elevadas que nas únicas $e$ aumenta proporcionalmente ao número das crianças ${ }^{52,53,59}$.

Em relação aos gemelares nativivos, há que se assinalar a ocorrência de aumento de $50 \%$ de RN de baixo peso e de $90 \%$ em gestações triplas, além de um aumento de RN com restrição de crescimento intra-uterino $e$ suas complicaçōes como a ocorrência de doenças crônicas da criança $\Theta$ do adulto $^{51,60}$. 
Apesar da maioria das publicações destacar que um dos maiores problemas dessas técnicas está relacionado com o maior número de gestações múltiplas, duplas e triplas, o que aumenta consideravelmente as complicaçőes maternas, fetais e do RN, nas gestaçőes únicas também pode haver problemas.

$\mathrm{Na}$ Alemanha um estudo de coorte multicêntrico, controlado e prospectivo avaliou informações sobre mais de 3.000 gestaçőes obtidas por ${ } \mathrm{CSS}^{61}$. Seus resultados mostraram que: entre as gestaçōes únicas, o risco relativo (RR) de complicaçőes obstétricas foi significativamente maior do que entre os casos com gestaçőes naturais, usadas como controle para: sangramento vaginal antes e após $28^{a}$ semana da gravidez (RR 3,8; IC 95\% 2,8-5,2), placenta prévia (RR: 6,4; IC 95\% : 4,0-10,2), oligoidrâmnio (RR: 2,1; IC 95\%: 1,5-3,0), insuficiência placentária (RR: 3,7; IC 95\%: 2,7-5,0), descolamento prematuro de placenta RR 1,8; IC 95\%:1,2-2,6), trabalho de parto prematuro (RR: 2,6; IC95\%: 2,3-2,2), anemia (RR: 1,7; IC 95\%: 1,51,8), pré-eclâmpsia (RR: 1,3; IC 95\%: 1,1-1,5) e parto pré-termo (RR: 1,8; IC 95\%: 1,5-2,1). Quando esses autores avaliaram todas as gestações, incluindo as múltiplas e não somente aquelas com feto único, o excesso de risco em relação ao grupo controle esteve presente para as mesmas complicaçőes, agregando-se somente a incompetência istmo-cervical, devido provavelmente às gestações múltiplas em maior número $(23,5 \%$ versus $1,0 \%$ ), que se associariam a maior freqüência do problema. Outra complicação que tem sido associada aos procedimentos de RHA é o diabetes gestacional. Vários autores têm mostrado que, entre mulheres grávidas por procedimentos de RA, a taxa de diabete gestacional chegou a $21 \%$, sendo significativamente mais alta que nos grupos utilizados como controle (habitualmente partos e gestaçōes espontâneas da mesma instituição ou da mesma região geográfica) ${ }^{62,63}$.

Neste último estudo, também se identificou, entre mulheres submetidas à FIV, aumento do risco de hipertensão induzida pela gravidez. Explicação para o risco aumentado para essas complicações poderiam ser 
alteraçōes endometriais e endócrinas reconhecidamente presentes nestas mulheres. Quanto à maior freqüência de incompetência istmo-cervical, poder-se-ia discutir a validade da qualidade do diagnóstico, considerando que na realidade, não existiria alteração estrutural dos mecanismos de contençăo fetal, congênita ou adquirida, mas apenas incapacidade de impedir o nascimento prematuro por absoluta falta de espaço no interior da matriz, para as gestaçōes de mais de um feto ${ }^{62,63}$.

Finalmente, outra complicação, exclusiva das gestaçőes monocoriônicas, a síndrome de transfusão feto-fetal (STT), que ocorre em até $15 \%$. Nesses casos existem anastomoses placentárias que conectam as circulações dos gêmeos. A STT se estabelece quando um fluxo preferencial ocorre nas anastomoses artério-venosas tornando um feto doador e o outro receptor de maior volume sanguineo. O feto doador torna-se hipovolêmico, com menos diurese produzindo menor quantidade de líquido amniótico, o que vai levar ao oligoâmnio. O feto receptor, hipervolêmico, produz mais diurese $e$ desenvolve polihidrâmnio, levando a complicações como o trabalho de parto prematuro, a rotura prematura das membranas, a hidropsia e/ou o óbito de um ou de ambos os fetos. Quanto mais precoce o desenvolvimento da síndrome, pior o prognóstico fetal. Estima-se que quando ocorre abaixo de 26 semanas de gestação, a mortalidade pode chegar a $90 \%$. 62,63 .

Entre casais inférteis, independentemente de terem sido submetidos ou não a técnicas de RHA, os resultados indicam que essas gestações devem ser sempre acompanhadas em clínicas de pré-natal especializado em assistência de gestações de alto risco ${ }^{64}$.

Embora, ainda hoje, não seja possivel separar efetivamente os riscos da RHA tanto para as mães quanto para os RN, daqueles secundários aos problemas básicos causadores da infertilidade, esses problemas devem ser amplamente discutidos com os pais que procuram a RHA. Na tentativa de minimizar esses efeitos adversos, algumas medidas têm sido propostas, como a reduçăo do número de embriőes transferidos em cada procedimento. 
No entanto há ainda falhas significativas no conhecimento que devem ser sanadas, quer no campo das ciências básicas como no campo da epidemiologia ${ }^{34}$.

\subsection{Aspectos Perinatais}

Dentre os diferentes aspectos destaca-se o nascimento de mais uma criança, considerado um problema de saúde pública, devido aos riscos causados às mães, às crianças e pelo alto custo gerado ao sistema público de saúde. Os riscos da gravidez múltipla são muitos. Para a măe, podemos citar a pré-eclámpsia, o diabetes gestacional, o rompimento do colo uterino e o parto prematuro. Enquanto que para as crianças, o maior risco é o da prematuridade, em especial o prematuro extremo. Além deste podem ser citados: restrição de crescimento intra-uterino; necessidade de educação especial; dificuldades de comportamento e de socializaçăo. A mortalidade perinatal aumenta quatro vezes para a gestaçăo gemelar e seis vezes para a trigemelar.

GUNBY e DAYA ${ }^{65}$ (2005) em estudo retrospectivo, a partir de registros de $90 \%$ dos centros de reproduçăo assistida no Canadá, no período de janeiro a dezembro de 2001, avaliaram os resultados das RHA aplicadas. Analisaram 2247 gestaçőes relacionadas às variáveis óbitos fetais, mortalidade neonatal, mortalidade perinatal, idade gestacional (IG) média, partos prematuros (< 37 semanas) e partos com IG < 34 semanas. Encontraram aumento da taxa de mortalidade perinatal de 2,4\%, mesmo em fetos únicos, em relaçăo à populaçăo geral. Constataram também, resultados estatisticamente significativos quanto ao aumento de mortalidade perinatal, sendo $3,7 \%$ nas gestações de duplos e valores que superam $6,8 \%$.em triplos. 
As taxas mais elevadas de anomalias congênitas, são em sua grande maioria, resultados dos efeitos adversos dos nascimentos múltiplos. Nos gêmeos monozigótocos (um zigoto: idênticos) existe uma probabilidade duas a três vezes maior de defeitos estruturais do que nos gêmeos dizigóticos (dois zigotos: não idênticos) ou nos únicos $66,67,68$.

Acham-se incluidas malformações maiores (aquelas que ocorrem no inicio morfogêneses) ou seqüências de malformações, anormalidades causados por alteraçōes vasculares (também mais comuns em gêmeos monozigóticos). As seguintes malformações ocorrem com freqüência aumentada nos gêmeos idênticos: anencefalia; holoprosencefalia; teratoma sacrococcígeo; sirenomelia; e a associação VACTERL [um acrônimo para alterações vertebrais (V), atresia anal (A), alterações cardiacas (C), atresia de esófago ou fístula traqueoesofágica (TE), anomalias renais (R) e anomalias de extremidades ( $L$, do inglês limb, membro)]. Na maioria das vezes somente um gêmeo é afetado pela malformação. Em $5 \%$ a $20 \%$ dos casos em que os gêmeos são concordantes para o defeito, um gêmeo é afetado com maior gravidade.

KATAGIRI et al. ${ }^{69}$ (2007) encontraram taxas elevadas de desordens epigenéticas tais como o síndrome de Angelman e a síndrome de BeckwithWiedemann (SBW) em crianças concebidas por RHA. Anormalidades do peso foram relatadas, também, em animais clonados. Os fatores possíveis subjacentes a esses achados incluem características inerentes do gameta, influência da cultura in vitro e peculiaridades dos métodos de RHA. É importante determinar precocemente se tais anormalidades epigenéticas estão presentes nas crianças atualmente concebidas por RHA, para considerar a saúde das gerações seguintes. 


\subsection{Outros aspectos de morbidade perinatais e na infância}

Como outras alterações podemos citar a maior incidência de casos de câncer; há hipóteses que a gravação defeituosa (defective imprinting) pode ter um papel no desenvolvimento de alguns cânceres da infância, tais como - tumor de Wilms, a retinoblastoma, e o rabdomiosarcoma embrionário. Esses fenômenos epigenéticos de gravação (epigenetic phenomenon of imprinting) são alteraçőes na mudança de expressão de um gene sem modificações na sequaéncia de bases do DNA) e podem ser afetados pela RHA, em especial pelos procedimentos mais invasivos tais como $|C S|^{70,} 71$, 72

Relatório realizado na Holanda constatou que todos os novos casos de retinoblastoma diagnosticados no período de novembro de 2000 a fevereiro de 2002 ocorreram em crianças nascidas por RHA. No entanto, ressaltam que, apesar do possível aumento da doença, esse estudo deve ser revisto ${ }^{73}$.

Há relatos de um possível risco aumentado do câncer ovariano e de mamas em mulheres que receberam terapia de gonadotrofinas ou com clomifeno $^{74,75,76}$.

Os efeitos da hiperestimulação ovariana, os procedimentos de RHA, os fatores de infertilidade materna e paterna, as diferentes afecçōes especificas da gravidez, ou ainda uma combinação desses fatores, podem levar ao nascimento de RN pré-termo, baixo peso ao nascer, ou pequenos para idade gestacional, ou até mesmo nas gestações únicas, com RHA, existe um risco mais elevado do nascimento de prematuros elou de RN de baixo peso quando comparadas às gestações espontâneas ${ }^{57}$.

Estudo com dados populacionais (Departamento de Reproduçăo Humana dos Estados Unidos), incluíram 42.000 crianças concebidas por RHA no período de 1996 a 1997 e 3 três milhões nascimentos da populaçăo geral nacional. Constataram que RN de baixo peso ao nascer eram 
significativamente mais comuns entre os RN de termo, mas não nos múltiplos concebidos por RHA, comparados com a população geral (únicos $6.5 \%$ e $2.5 \%$ RR $2.6,95 \% \mathrm{Cl} 2.4-2.7)^{23}$. O pré-termo com baixo peso também é significativamente maior entre os únicos, mas não nos nascimentos de múltiplos por RHA (para os únicos $6.6 \%$ e $4.7 \%$ RR 1.4, $95 \% \mathrm{Cl} 1.3-1.5)^{77}$.

KÄLLÉN et al. ${ }^{78}$ (2005) afirmam que os nascimentos múltiplos são os principais responsáveis pelo aumento da incidência de internaçőes hospitalares, em virtude da prematuridade e do perfil dos pais, que levariam seus filhos mais vezes aos hospitais.

SODERSTROM-ANTTILA ${ }^{79}$ (2001) revisou os trabalhos que acompanharam o desenvolvimento neuropsicomotor de crianças nascidas por oócitos doados, e apesar do pequeno número de estudos e de crianças avaliadas, os obtiveram resultados que sugerem desenvolvimento normal e boas relações parentais nessas famílias.

BONDUELLE et al. ${ }^{80}$ (2003) não encontraram diferenças no desenvolvimento neuropsicomotor em crianças nascidas por FIVc ou ICSI, após aplicação da escala de Bayley aos dois anos de idade, sem o conhecimento prévio da técnica pelo pesquisador. 0 estudo também mostrou que a pontuação obtida pela Escala, foi igual à da população geral e mais baixa em gémeos, principalmente prematuros, tanto para FIVc quanto para ICSI e compativeis com o esperado para a populaçăo de prematuros nascidos sem técnicas de reprodução assistida. 


\subsection{Aspectos Éticos}

Em 1987 a Igreja Católica publicou um documento "Instruçăo sobre o respeito à vida humana nascente e a dignidade da procriaçăo" estabelecendo a sua posição sobre esses assuntos ${ }^{81}$.

A partir de 1990, inúmeras sociedades médicas em vários países estabeleceram diretrizes éticas e leis, para as tecnologias reprodutivas. A Inglaterra, por exemplo, estabeleceu os limites legais para a reproduçăo assistida em 1990, com base nas proposiçőes do Warenock Report ${ }^{82}$.

No Brasil, o Conselho Federal de Medicina, por meio da Resoluçăo CFM 1358/92, instituiu as Normas Éticas para a utilização das Técnicas de Reproduçăo Assistida, em $1992^{83}$.

Os aspectos éticos mais importantes que envolvem questőes de reproduçăo humana săo os seguintes: os relativos à utilizaçăo do consentimento informado, à seleçăo de sexo, à doaçăo de espermatozóides, óvulos, pré-embriőes e embriōes, à seleção de embriōes com base na evidência de doenças ou problemas associados; à maternidade substitutiva, à reduçăo embrionária, à clonagem, à pesquisa e criopreservaçăo (congelamento) de embriőes. Um importante questionamento que deve ser amplamente discutido é o da utilizaçăo dessas técnicas de reproduçăo medicamente assistida em casais sem problemas de infertilidade ${ }^{84}$. Uma demanda já encaminhada a vários serviços é a utilizaçăo para fins de proteção do parceino de uma mulher portadora do vírus HIV (human imunnedeficiency virus). Técnicas de reproduçăo seriam utilizadas com o objetivo de proteger o parceiro de uma eventual contaminaçăo e permitiria ao casal ter filhos. Essa situaçăo, no passado, quando năo existiam terapêuticas adequadas nem profilaxia para o RN, era formalmente contraindicada, pois exporia um terceiro a um grande risco então existente. Com o desenvolvimento atual do tratamento, o risco de transmissão vertical foi muito reduzido, levando a uma rediscussão desse tema por parte dos profissionais, portadores, parceiros e Comitês de Bioética ${ }^{85}$. 
Uma área bastante complexa é a que envolve aspectos reprodutivos de casais homossexuais. Casais homossexuais femininos podem solicitar que um serviço de reprodução assistida possibilite a geraçăo de uma criança, em uma das parceiras, utilizando sêmen de doador. O médico deve realizar esse procedimento equiparando essa solicitação à de um casal heterossexual? Ou deve ser dada uma abordagem totalmente diversa? A própria questăo de adoçăo de crianças por homossexuais tem sido admitida em vários países, inclusive no Brasil.

As reflexões utilizadas na RHA podem ser transpostas às questōes de adoçăo (reproduçăo legalmente assistida)? A adoçăo, com as suas inúmeras maneiras de realizaçăo, desde as legais ou oficialmente mediadas pelo Estado, até as realizadas de maneira informal, inclusive com forte componente comercial, comporta um grande questionamento ético. A seleção de crianças por parte dos futuros pais adotivos, o estabelecimento de critérios sociais por parte das autoridades, a invasão de privacidade que os pretendentes sofrem em suas vidas, com a finalidade de preservar possivelmente o melhor bem-estar para a criança adotada, săo algumas questőes que merecem reflexão ${ }^{85}$.

Por fim, uma outra questão que está propondo desafios éticos é a do prosseguimento de gestações em mães com diagnóstico de morte encefálica. Já existem casos relatados, no Brasil e em outros países, de situaçōes onde a paciente ou seus familiares, solicitam que todas as medidas de suporte vital sejam utilizadas para que a gestação possa resultar em uma criança viável. As equipes médicas podem atender a uma demanda dessas? Como fica o critério de morte encefálica nessas situações? A paciente, já considerada morta, continua sendo paciente, ou o seu feto é que assume este status? Nesse caso, quando é que a mãe será considerada morta? Essas questões merecem ser refletidas e discutidas nos seus aspectos mais amplos. 


\subsection{Aspectos Jurídicos}

Considerando que o nascimento do primeiro bebê de proveta foi um marco histórico no uso das tecnologias reprodutivas no Brasil, o início do debate legislativo foi tardio, sobretudo se levarmos em conta o fato de que o país carece de uma regulamentação de caráter nacional. Durante os primeiros sete anos de uso das novas tecnologias reprodutivas, não houve qualquer norma de controle dos procedimentos, sendo raros os registros ou dados sobre esse periodo ${ }^{9,86,87}$.

Somente em 1993 foi proposto o primeiro projeto de lei sobre o tema no país. Conduzido pela Câmara dos Deputados, esse projeto foi o que mais diretamente se inspirou no Warenock Report e o que mais intensamente representou os interesses da classe médica no país ${ }^{87}$.

Sendo assim, o deputado Luiz Moreira autor do primeiro projeto de lei no país sobre tecnologias reprodutivas, baseou-se na resolução do CFM $1358 / 92^{88}$. Na época, acreditava-se que não haveria problemas na transformação da resolução em projeto, nem tampouco na transformação desse, por conseguinte, em lei.

Na atualidade são três os projetos de lei em tramitação no Congresso Nacional Brasileiro ${ }^{89}$,

Para fins do presente trabalho, iremos denominá-los pela cronologia de proposição. $01^{\circ}$ - Projeto de Lei 3638-A foi proposto em 1993, e é de autoria do deputado federal Luiz Moreira; $02^{\circ}$ - Projeto de Lei 2855 foi proposto em 1997, de autoria do deputado federal, Confúcio Moura e o $3^{\circ}-$ Projeto de Lei 90/99, proposto em 1999 e de autoria do ex-governador do Ceará o médico Lúcio Alcảntara.

Em março de 2004, a Comissão sobre Acesso e Uso do Genoma Humano da Secretária de Ciência, Tecnologia e Insumos Estratégicos (MS) apresentou uma Nota Técnica visando demonstrar os resultados das 
discussões das modernas biotecnologias no âmbito da RHA no país. Seu objetivo foi difundir informações nesse campo da ciência e subsidiar os Poderes Legislativo e Executivo, tendo em vista a tramitação no Congresso Nacional de Projetos de lei regulamentando as técnicas de reprodução ${ }^{90}$.

Após anos de tramitação no Congresso Nacional, foi aprovada a Lei 11.105, em 24 de março de 2005. A Lei de Biossegurança em seu artigo $5^{\circ}$, veio permitir a utilizaçăo de células-tronco embrionárias, obtidas de embriōes humanos produzidos por fertilização in vitro, para os fins de pesquisa e terapia. Impõe, é certo, algumas condições, como o congelamento por no mínimo três anos, a aquiescência dos genitores e a aprovação do Comitê de Ética correspondente ${ }^{91}$.

O Ministério da Saúde lançou também em 2005, a Política Nacional de Direitos Sexuais e Direitos Reprodutivos, que teve como base 0 documento "Direitos Sexuais e Direitos Reprodutivos: uma prioridade de governo" e que previa ações voltadas ao planejamento familiar para o periodo de 2005 a $2007^{92}$.

A Política de Direitos Sexuais e Reprodutivos tem três eixos principais de ação, voltados ao planejamento familiar: a ampliação da oferta de métodos anticoncepcionais reversíveis (não-cirúrgicos); a ampliação do acesso à esterilizaçăo cirúrgica voluntária; $e$ a introdução de reprodução humana assistida no Sistema Único de Saúde (SUS).

A Política Nacional de Atenção Integral de Reprodução Humana no âmbito do SUS foi instituida por meio da Portaria GM/MS 426 de 22 de março de 2005, que determina a viabilização das técnicas de reprodução assistida não apenas para a infertilidade, mas também para o controle de doenças de transmissão vertical e/ou horizontal. Essa última finalidade deveu-se ao desenvolvimento de terapias anti-retovirais, onde os indivíduos contaminados saíram de uma situação de quase morte de uma doença crônica, e com isso começaram a aspirar uma vida normal, casar e ter filhos. A união de três situações, o desenvolvimento das técnicas de RHA, a 
sobrevida de individuos infectados e a utilização de anti-retrovirais na gestação, reduzindo o risco de transmissão vertical, permitiram a esses individuos a realizaçăo do sonho de gerar a sua própria descendência, minimizando os riscos. Sensibilizados por essas questões e considerando a necessidade de regulamentar a atenção em RHA aos casais inférteis, aos portadores de doenças genéticas e aos portadores de doenças infectocontagiosas, em especial os portadores do vírus HIV e das hepatites virais, 0 Ministério da Saúde (Secretária de Atenção à Saúde) editou a Portaria n. 388 de 6 de julho de 2005, com a intenção de definir quais os critérios para o credenciamento de Centros de Reprodução Humana que poderiam tratar esses casais, pois a contaminação hospitalar entre pacientes tem sido descrita para o HIV e em técnicas de reprodução assistida para hepatite B e C. A contaminação cruzada em tanques de criopreservação de tecidos foi demonstrada, assim como a transmissão ocupacional hospitalar para HIV, hepatites B e $\mathrm{C}^{93}$.

Porém muitas foram às controvérsias em relação à viabilidade dessa Portaria, apesar de ainda não estar em vigor, principalmente quanto ao aspecto financeiro e em relação à paciente portadora de HIV, conforme discutido por especialistas reunidos no Conselho Regional de Medicina de São Paulo (CREMESP) em 2005, para debater sobre o tema Reprodução assistida para portadores de HIV, os infectologistas Guido Carlos Levi e Vicente Amato Neto, coordenados pelo conselheiro e também infectologista Caio Rosenthal, discutem a operacionalidade dessas técnicas e concluem que apesar de ser um programa com estrutura elogiável, louvável e ético, o Ministério da Saúde tem verba limitada, com necessidades gigantescas em termos de saúde pública, não sendo então uma prioridade de ação diante de tantas outras como por exemplo verba para medicamentos no tratamento da tuberculose e AIDS $^{94}$.

Ainda no Jornal de Medicina do Conselho Federal de Medicina, no item "polêmica", médicos ressaltam uma infindável gama de problemas éticos tais como a "redução de embriões" e os riscos decorrentes da 
reprodução assistida relacionados à gemelaridade e à prematuridade, elevando o número de seqüelas principalmente de origem cerebral ${ }^{95}$.

\subsection{Impactos Socioeconómicos e Culturais da RHA}

ZEGERS-HOCHSCHILD ${ }^{44}$ afirma que uma porção muito pequena da população mundial tem acesso ao tratamento de infertilidade de alta complexidade como os da reprodução assistida. Essa iniqüidade no acesso à saúde reprodutiva é especialmente manifesta em países em desenvolvimento, onde os recursos destinados a essa área são escassos e se distribuem de forma pouco eqüitativa. Em paises onde tratamentos de infertilidade estão garantidos por lei, como é o caso dos paises da Europa, Austrália e Israel, a reprodução assistida é um direito a que todas as pessoas têm acesso na idade reprodutiva, independente de sua condição social e econômica. Quando o Estado garante esse direito, fixa certas regras como, por exemplo, o limite de idade para fazer o tratamento, assim como 0 número de máximo de embriōes que podem ser transferidos nos tratamentos de reprodução assistida. Dessa maneira os gastos suportados pelo Estado nos tratamentos de infertilidade se vêem compensados por uma economia global, que na etapa neonatal reduz os gastos decorrentes da prematuridade extrema associada à gestação múltipla. Quando o acesso ao tratamento de infertilidade não é parte das políticas governamentais, como é o caso dos países da América Latina, as pessoas que podem fazer um tratamento complexo são aquelas com capacidade econômica própria ou possuidoras de seguros de saúde, que aceitam cobri esse tipo de tratamento. É este cenário que faz com que o mercado regule o tratamento, pois não existem regras em relação ao número de embriōes transferidos, ou partos de gestação múltipla. Estes geram gastos neonatais que se elevam de maneira desproporcional e săo cobertos pelo Estado, ou pelos sistemas de seguros 
privados. Assim, os fundos destinados aos tratamentos saem de fontes diferentes das destinadas a cobrir o parto e a etapa neonatal.

A cobertura de reprodução assistida é baixa nos paises da América do Norte e Latino Americanos comparados aos paises da Europa. Por sua vez, o número de embriões transferidos na Europa é metade do que nas Américas, o que indica que a multigestação global e a extrema prematuridade são muito superiores nas Américas. A taxa de nascimentos triplos e múltiplos nas Américas flutua entre 3,8 a7,8\% comparada com 0,2 a $0,4 \%$ em países do norte da Europa. Isso traz conseqüências neonatais que não só afetam a economia global e familiar como também a qualidade biológica dos descendentes. A solução dos problemas de acesso à tecnologia reprodutiva assim como a maneira de se regular a sua prática, só serão possiveis na medida em que os médicos, legisladores, grupos de mulheres, de homens e empresas de saúde trabalharem juntos num projeto comum.

Os tratamentos iniciados durante 2002 nos paises europeus com técnicas de reprodução assistida estão informados na sexta edição do relatório ESHRE. Os dados foram coletados principalmente dos registros nacionais já existentes. De 25 países, 631 clínicas relataram 324238 ciclos do tratamento com: FIVc 122.634, ICSI 135.048; transferência de embriões congelados, 57.162; gameta doado 7.677; diagnóstico pré-implantação, 1.563; e maturação in vitro 154. Para FIVc a taxa clínica da gravidez por aspiração e por transferência foi de 26.0 e $29.5 \%$, respectivamente. Para ICSI as taxas correspondentes foram 27.2 e $29.4 \%$. Esses dados são melhores do que os de 2001. Depois da realização das técnicas FIV e ICSI a distribuição de transferência $1,2,3$ e de 4 ou mais embriōes foram 13,7; 54,$8 ; 26,9$ e $4.7 \%$, respectivamente. Comparados com o ano 2001 , menos embriőes foram transferidos, mas diferenças enormes existiram entre os países. A distribuição de partos únicos, de gêmeos e dos triplos para FIVc e ICSI foi de $75.5,23.2$ e 1.3\%, respectivamente, o dá uma taxa total de partos múltiplos de $24.5 \%$, comparada com os $25.5 \%$ no ano 2001 . O percentual de 
partos de gestações triplas depois FIVc e ICSI variaram zero a $5.2 \%$ entre os países ${ }^{47}$.

Dados de Registro dos Estados Unidos do ano de 2003 reportaram que de 122.872 ciclos de RHA, provenientes de 399 clínicas, ocorreu o nascimento de 48,756 crianças. Isso representa uma taxa de sucesso (nascidos vivos por transferência) de $34.7 \%$ sendo desses $66 \%$ de únicos, $31 \%$ de duplos e $3 \%$ de triplos ou mais, ou seja, cerca de $34 \%$ dos nascidos vivos foram de gestação múltipla. Isso representa aproximadamente $1 \%$ de todos os partos e $18 \%$ de todas as partos de múltiplos dos Estados Unidos $^{23}$. Na Dinamarca, o país da Europa com a maior proporção de nascimentos por RHA, 4,2\% de todos os nascimentos em 2002 foram resultado de $\mathrm{RHA}^{47}$.

Enquanto que na Rede Latino Americana de Reprodução Assistida (Rede LARA) participaram 12 paises, incluindo o Brasil, foram 21.034 ciclos iniciados, 20.012 aspirações, 18.647 transferências que resultaram em 5887 gestações ( $31,6 \%$ das transferências resultaram em gestações), $78,7 \%$ das gestações terminaram em um ou mais RN vivos por parto. Nasceram 6268 crianças sendo 3120 únicos (49,8\%), 2338 gemelares $(37,3 \%) 731$ triplos $(11,7 \%)$ e 79 quádruplos $(1,3 \%)^{96}$.

Os problemas da RHA são inúmeros e bastante complexos. Em face dos dados expostos, ainda é difícil se fazer uma avaliação precisa dos impactos socioeconômicos e culturais considerando-se, principalmente, as enormes diferenças entre os países onde sua prática é reconhecida.

\subsection{Aspectos Psicoemocionais}

Sabe-se ainda que os resultados favoráveis da reprodução assistida dependem de vários fatores, incluídos os aspectos psicoemocionais. 0 
diagnóstico de infertilidade causa um impacto negativo no bem-estar emocional.

A dificuldade de um casal para engravidar e/ou a descoberta de algum tipo de infertilidade é um processo muito sofrido, incluindo sentimentos de impotência que interferem na capacidade de seguir adiante para concretizar suas expectativas. Esse aspecto influi muito na vida de ambos, alterando de modo significativo a estima, trazendo sentimentos de culpa, incapacidade, raiva, depressão, decepção, angústia, frustração, tristeza, ansiedade, distúrbios sexuais e de relacionamento, comportamentos obsessivos e, dependendo da forma como eles lidam com este problema, somatizações variadas.

A idéia da infertilidade normalmente se generaliza e os casais sentem-se inférteis para a vida como um todo, quer seja na relação do casal, nas relações familiares e sociais e em alguns casos em nível profissional.

MELAMED et al. ${ }^{97}$ (2005) realizaram um importante estudo para avaliar as expectativas e reações emocionais dos casais submetidos às técnicas de reproduçăo assistida e concluíram que, mesmo após terem sido informados sobre as reais chances das RHA, a maior parte dos casais acreditam na chance de $100 \%$ da gestação. Quando os casais que se confrontam com o fracasso na primeira tentativa podem apresentar diversas reações, alguns mantêm o propósito de gerar um filho biológico e lutam para torná-lo realidade, enquanto outros permanecem imobilizados diante da dor.

Ressaltam ainda a importância do profissional de saúde mental na equipe interdisciplinar dos serviços de RA, já que a condição de infertilidade traz consigo uma gama de aspectos emocionais que podem influenciar no resultado final do tratamento ${ }^{97}$. 


\subsection{Situação da RHA no Brasil}

A infertilidade é condição médica desabilitante. Por ser considerado como tratamento elitista não faz parte da cobertura da grande maioria dos planos de saúde e, portanto, sem reembolso. O grande desafio para os pacientes que procuram 0 serviço de infertilidade é o convencimento dos governantes de que a infertilidade é um problema de saúde, que afeta emocionalmente o casal, e que deveria ser incluída no Plano Nacional de Saúde.

Dos 117 centros de RHA brasileiros, apenas seis Instituições oferecem 0 tratamento totalmente gratuito e três oferecem 0 serviço gratuitamente com a medicação paga pelo casal. Há ainda um serviço público de infertilidade no Rio de Janeiro, que disponibiliza apenas os exames para diagnosticar a causa da infertilidade ${ }^{96}$. Essa situação ainda se agrava quando se observa que além do insuficiente número de centros de RHA públicos para a demanda, $80 \%$ desses estão concentrados no Estado de São Paulo e distribuídos de maneira não equânime no Estado e no País.

No entanto, o Brasil é um dos líderes mundiais em número de tratamentos de RHA e em especial quanto ao crescente número de gestações múltiplas: $42 \%$ das gestações por técnicas de RHA resultam em gêmeos, trigêmeos ou mais. Esses dados podem ser evidenciados pelos relatórios das Instituições de reprodução humana no mundo ${ }^{96}$.

Nos EUA, segundo o relatório de 2004, dos 411 centros que participaram (47 paises) foram iniciados 127.977 ciclos, que geraram $33,7 \%$ de gestação clínica e destas, $82,1 \%$ efetivaram a gravidez com o parto. Ainda o mesmo relatório mostrou que $26,7 \%$ foram partos múltiplos ${ }^{35}$.

O relatório do Centro Tecnologia de Reprodução Assistida da Europa cujos resultados nacionais dos registros foram publicados pela Sociedade Européia de Reprodução Humana e Embriologia de 2003, mostrou que 
houve 365103 procedimentos que resultaram em $23,1 \%$ gestações múltiplas $^{47,98}$.

Em relação à América Latina, as informações fornecidas pela RedeLara que coleta dados de 12 paises, inclusive do Brasil, em 2004, mostrou que nosso país realizou quase a metade dos procedimentos (total: 24.588 procedimentos, Brasil: 10.804 procedimentos). Ressalta-se que estão cadastrados nesta Rede apenas 55 centros dos 117 existentes no país ${ }^{96}$.

Outro fator alarmante no Brasil é o fato de que as técnicas de reprodução assistida são regulamentadas apenas pelas normas éticas definidas pela resolução do Conselho Federal de Medicina ${ }^{83}$.

Esta falta de legislação no país, em especial relacionada ao número de pré embriōes transferidos, fez com que as gestações múltiplas, aumentassem exponencialmente no Brasil, gestações essas consideradas um problema de saúde pública, devido aos riscos causados às mães, às crianças e ao sistema público de saúde pelo alto custo.

Dado o importante impacto da gestação múltipla na densidade demográfica e na economia do país, muito em breve a taxa de múltiplos vai determinar o grau de desenvolvimento humano de um país ${ }^{99}$.

COLLETTO et al. ${ }^{56}$ (2003) analisaram dados dos nascimentos nos anos de 1990, 1996 e 1999 em São Paulo. Para esse estudo foram escolhidos os hospitais Amparo Maternal, Servidor Público Estadual, Santa Catarina e Albert Einstein, em ordem crescente do nível socioeconômico de seus pacientes. Para efeito de comparação, o levantamento mostrou que, se no começo dos anos $90 \circ$ Hospital Albert Einstein registrava proporcionalmente quase 0 dobro de nascimentos de gêmeos computados no Amparo Maternal ( $0,85 \%$ contra $1,41 \%)$, no final da década essa diferença havia quadruplicado $(0,73 \%$ e 2,94\%). Em relação à distribuiçăo dos pesos das crianças ao nascer verificou-se que a proporção de únicos nascidos com peso inferior a 2.500 gramas e 1.500 gramas variou de $8,1 \%$ 
no Amparo Maternal a 4,6\% no Albert Einstein. Já no caso dos gêmeos, a proporção de crianças nascidas abaixo do peso ideal se mostrou bem alta e foi praticamente à mesma nesses dois hospitais $(61,3 \%)$. Isso mostra que, mesmo com o aumento do nivel socioeconómico, não houve diminuição do risco maior representado pela gestação múltipla.

Apesar da modalidade ser relativamente recente, diversas organizaçőes internacionais voltadas para a reprodução assistida (CDC ${ }^{23}$, ESHRE ${ }^{47}$ e Rede Lara ${ }^{96}$ ), têm publicado relatórios e artigos referentes aos resultados perinatais das RHA. Porém, mesmo sabendo-se da relevåncia do assunto, em especial no Brasil que se destaca mundialmente pelo número de Centros de Reprodução Humana, há poucos estudos sobre a evolução dessas crianças, fato este de extrema importância para a complementação e continuidade da assistência prestada, desde o inicio do tratamento da infertilidade à mãe até o seu nascimento. Faz-se mister, contudo, um acompanhamento do desenvolvimento e crescimento em todas as fases destas crianças, ou seja, no período neonatal, infância e adolescência.

Para um conhecimento mais profundo das principais repercussões epidemiológicas, de um grupo específico de mulheres que realizaram algumas das técnicas de reprodução assistida e seus conceptos, o presente trabalho se propōe a estudar algumas variáveis que possam influenciar em alguns eventos obstétricos e perinatais, com ênfase na avaliaçăo de crianças no período neonatal imediato nascidas em um hospital privado, de nivel terciário, que é referência para o atendimento de gestante e RN de risco. 
OBJETIVOS 


\section{OBJETIVOS}

\subsection{Objetivo Geral}

Comparar as características maternas e resultados perinatais de crianças concebidas por diferentes modalidades de técnicas de reprodução assistida na Unidade de Reprodução Humana do Hospital Israelita Albert Einstein

\subsection{Objetivos Especificos}

- Caracterizar as mulheres submetidas às técnicas de reprodução humana segundo as variáveis, idade materna causas de infertilidade e tipo de técnica utilizada.

- Descrever a evolução dos recém-nascidos, concebidos por diferentes modalidades de técnicas de reprodução assistida, desde o nascimento até sua alta do berçário, analisando peso, idade gestacional, os principais problemas durante a sua internação na Instituição. 


\section{MÉTODO}




\section{MÉTODO}

\subsection{Caracterização da população de estudo}

Mulheres que foram submetidas às diferentes técnicas de reprodução assistida na Unidade de Reprodução Humana Assistida do Hospital Israelita Albert Einstein (URHA - HIAE) no período de janeiro de 1995 a dezembro de 2003.

Foram selecionados para revisão de prontuário todos os casos de sucesso gestacional com evolução para o parto. Salienta-se que apesar de todos os procedimentos para o tratamento de infertilidade terem ocorrido na URHA - HIAE, nem todos os partos ocorreram no próprio hospital, o que limitou a amostra uma vez que não será possivel acessar os dados de partos ocorridos em outras Instituições.

\subsubsection{Critérios de Inclusão}

Todas as mulheres submetidas às técnicas de RHA na URHA - HIAE, no período de 1995 a 2003 e cujos partos ocorreram no HIAE.

\subsubsection{Critérios de Exclusão}

Partos ocorridos fora do HIAE.

\subsubsection{Caracterização do Hospital}

O Hospital Israelita Albert Einstein (HIAE) é um hospital privado de nível terciário na Região Sul do Município de São Paulo no Distrito do Morumbi.

O Departamento Materno-Infantil está integrado ao HIAE. É oferecido uma assistência médica e interdisciplinar integral à gestação, parto, puerpério e recém-nascidos. Os serviços são executados na área de 
obstetrícia na medicina-fetal, unidade de pronto-atendimento de ginecologia e obstetrícia, centro obstétrico e maternidade (inaugurada em 25 de maio de 1971). E na área de neonatologia no berçário de normais, cuidados intermediários e unidade de terapia intensiva neonatal.

A população usuária do Departamento Materno Infantil do Hospital é de alto nível socioeconômico, provenientes de clinicas privadas, com demanda espontânea e todas as mães tiveram assistência pré-natal. As gestantes são encaminhadas à Maternidade por seus obstetras, sem vínculo empregatício com o hospital.

\subsubsection{Caracterização da Unidade de Reprodução Humana do HIAE:}

A população usuária do URHA-HIAE pode ter sido dirigido à Instituição por procura espontânea, ou encaminhada de outros serviços ou por obstetras. Atendida na URHA-HIAE, é realizada uma avaliação do casal infértil. Inicia-se a propedêutica do casal com problemas de infertilidade quando após um ano de relações sexuais bem distribuídas ao longo do ciclo menstrual sem uso de métodos contraceptivos e ausência de gravidez neste período.

A investigação inicial do casal parte de uma história clinica bem detalhada e o exame físico minucioso, especialmente na área genital. Quanto aos exames complementares para a investigação da fertilidade masculina, foi recomendado à realização do espermograma, dosagens hormonais, provas funcionais visando avaliar a capacidade dos espermatozóides em percorrer $\circ$ trajeto genital feminino, biópsias testiculares e exames de imagens (ultra-som transretal). Em relação à investigação da fertilidade feminina, os exames especificos para este fim são: histerossalpingografia, avaliação seriada do muco cervical, teste póscoito, ultra-som endovaginal, biópsia endometrial e dosagens hormonais, complementados ainda por estudos genéticos ou de imagens específicos, e em uma pesquisa mais avançada foi ser realizado a video-laparoscopia, 
vídeo-histeroscopia, salpingoscopia e mais recentemente a histerossonossalpingografia.

Uma vez feito o diagnóstico da causa de infertilidade foi decidido pelo médico qual a melhor técnica de reprodução assistida a ser realizada. Para este trabalho abordou-se apenas as técnicas de Fertilização in vitro clássica (FIVc) e a Fertilização in vitro com Injeção Intracitoplasmática de Espermatozóide (ICSI).

No laboratório de fertilização in vitro foram manipulados os gametas masculino e feminino, com o propósito de promover a fertilização, formação de pré-embrião e transferência, com o intuito de obter a gestação. Para que isso ocorresse foi necessária uma série de minuciosos detalhes, pois o laboratório é o componente mais importante para o sucesso de todo o trabalho. Todos foram considerados cuidadosamente, desde a sua localização, layout, tipos de equipamentos e materiais.

Em virtude da fragilidade das células dos gametas e pré-embriões, o ambiente laboratorial deve ser limpo, com o mais estrito controle de qualidade, além de profissionais qualificados, denominados embriologistas.

Ainda foi de fundamental importância selecionar o pré-embrião mais viável para a transferência. Dentre os inúmeros critérios usados no processo de seleção destacou-se a avaliação não-invasiva do zigoto ao blastocisto em microscópio invertido em aumento de 400X.

\subsubsection{Caracterização da Assistência Prestada no Hospital HIAE}

\subsubsection{Gestantes}

A gestante encaminhada ao hospital, foi atendida na triagem obstétrica, onde se realizou o diagnóstico do trabalho de parto e avaliação da vitalidade fetal. Encaminhada ao pré-parto, avaliada pelo seu obstetra e supervisionada por enfermeiras obstetrizes, quando o seguimento clínico do 
parto é feito rotineiramente por um método de avaliação fetal denominado cardiotocografia.

Após a realização do parto, a paciente foi transferida para um leito da maternidade. No caso de alguma complicação materna, as pacientes foram encaminhadas para a UTI de Adulto do próprio Hospital.

\subsubsection{Recém-Nascido}

$\mathrm{Na}$ sala de parto o $\mathrm{RN}$ foi avaliado pelo médico neonatologista e submetido aos procedimentos de reanimação de acordo com o caso. No caso de gestação múltipla estarão presentes na sala de parto um neonatologista e uma enfermeira obstetriz para cada RN.

Posteriormente o neonatologista e a enfermeira obstétrica realizaram a identificação, o exame físico sumário, as medidas antropométricas, os procedimentos legais e a classificação por peso e idade gestacional.

Todos os RN foram encaminhados à Unidade Neonatal e distribuidos aos setores correspondentes, segundo o grau e natureza dos cuidados necessários.

Os RN encaminhados para UTI Neonatal contaram com a presença e avaliação de equipe multidisciplinar composta por fisioterapeuta, farmacêutica, nutricionista, psicóloga, além da equipe médica e de enfermagem, está última na relação de 1 enfermeira para 2 pacientes, nos casos de maior gravidade 1 enfermeira para cada paciente.

Por ocasião da alta todos os pais receberam um resumo de alta com os dados de nascimento, principais diagnósticos durante a permanência no berçário e as condiçōes do RN na alta.

Em relação às afecções estudadas, considerou-se para o trabalho as formas mais graves das doenças, cujos diagnósticos foram feito: Doença Pulmonar de Membrana Hialina (DPMH) quadro clínico e radiológico, Hemorragia Peri Intra-Ventricular (HPIV) quadro clinico e ultra-som de cérebro, Retinopatia da Prematuridade (ROP) fundo de olho e Sepse quadro clinico e laboratorial. 


\subsection{Tipo de Estudo}

Estudo foi descritivo, retrospectivo para coleta dos dados e prospectivos para análise dos mesmos.

\subsubsection{Fontes de dados}

Os dados utilizados no estudo foram obtidos das seguintes fontes de informação:

- Banco de dados fornecidos pelo URHA-HIAE.

- Livro de registro dos partos realizados na Instituição

- Prontuários maternos e dos RN do Hospital (SAME)

- Prontuários digitalizados do Sistema de Informação do Hospital HIAE (Medtrack)

- Banco de dados fornecido pelo Serviço de Epidemiologia HIAE.

\subsubsection{Variáveis de Estudo}

As variáveis relacionadas para o presente estudo foram subdivididas e agrupadas em:

- Variáveis referentes às técnicas de reprodução assistida

- Variáveis maternas

- Variáveis paternas

- Variáveis do recém-nascido desde o nascimento e durante a internação no berçário

\subsection{Análise Estatística}

As informações coletadas foram colocadas em um banco de dados em ACCESS, sendo exportados os relatórios em EXCEL.

A comparação entre duas variáveis categóricas, do tipo grupos da amostra e incidência de determinada característica, foi feita pelo teste de qui-quadrado. Quando a variável em estudo era quantitativa como, por exemplo, o peso do RN, tempo de internação (em dias), etc. utilizou-se o 
teste de Mann-Whitney para a comparação entre dois grupos e o KruskalWallis para a comparação entre três ou mais grupos.

O nivel de significância adotado foi de $5 \%$ e todos os testes foram realizados pelo programa estatístico SPSS V11.5.

\subsection{Orçamento}

A presente pesquisa e a análise decorrente resultante neste trabalho foi integralmente custeadas com recursos próprios do pesquisador, sem ônus para a Instituição.

\subsection{Considerações Éticas}

O trabalho foi apreciado e aprovado pela Comissão de Ética em Pesquisa do Hospital Israelita Albert Einstein e pelo Comitê de Ética em Pesquisa da Faculdade de Saúde Pública da Universidade de São Paulo. 
RESULTADOS 


\section{RESULTADOS}

\subsection{Resultados das pacientes que fizeram alguma das técnicas de RHA} no HIAE

Neste período o Serviço de Reprodução Humana base deste estudo procedeu a 2.448 procedimentos com duas modalidades de técnicas de reprodução assistida, FIV e ICSI, com o procedimento de ICSI, houve uma diminuição da FIV, conforme mostra Gráfico 1.

Gráfico 1 - Distribuição dos números de procedimentos de RHA no Centro de Reprodução Humana no HIAE, 1995 a 2003

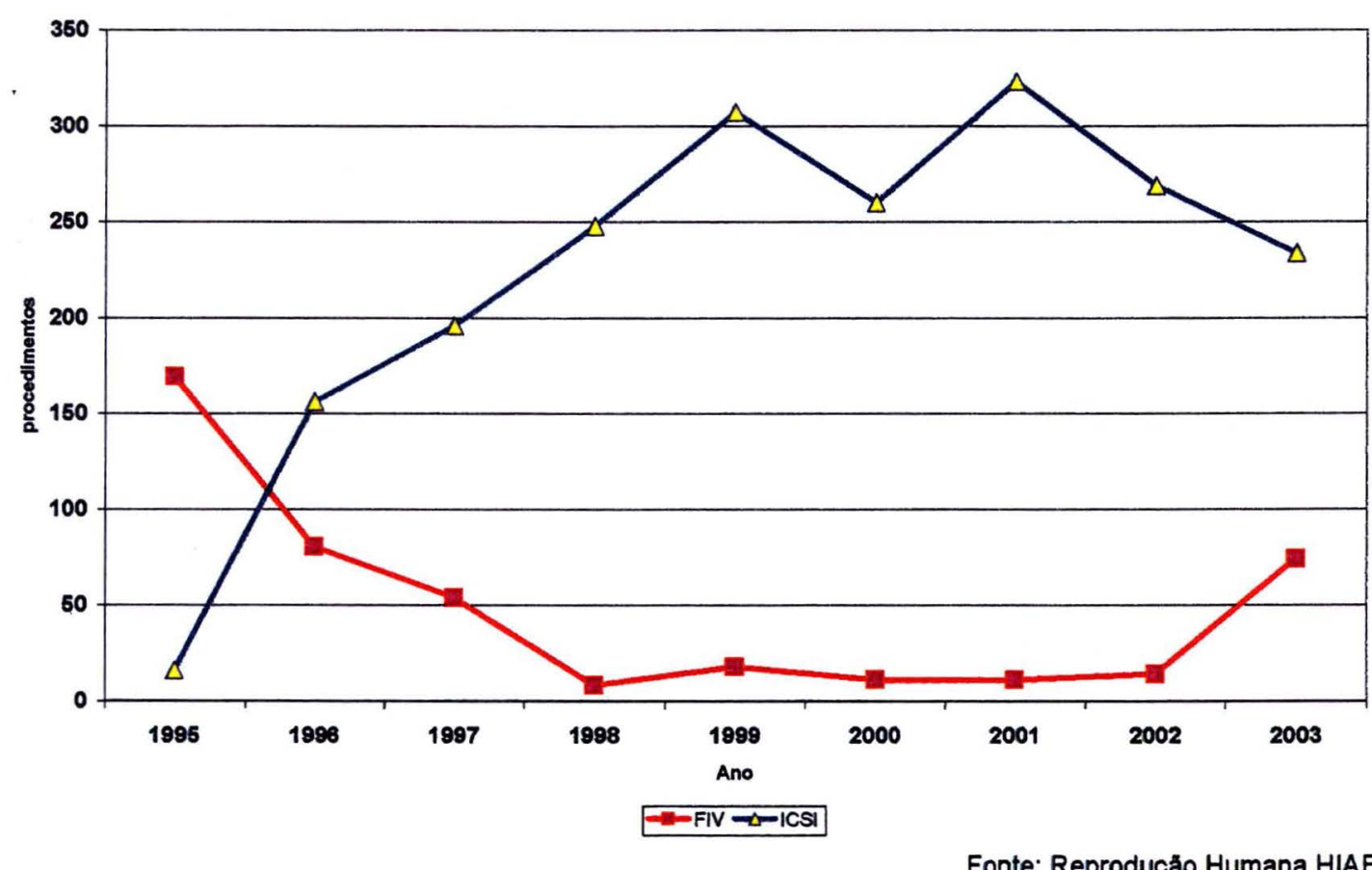

Observa-se no Gráfico 1 que a partir do ano de 1997 houve um aumento do número de procedimentos de ICSI, com o seu maior percentual no ano de 2001 , onde este percentual alcançou $96 \%$ de todos os procedimentos realizados neste ano.

A amostra do estudo foi composta de 238 gestantes que realizaram alguma das técnicas de RHA no HIAE e deram à luz na mesma Instituição. 


\subsection{Características gerais das pacientes que fizeram alguma das técnicas de RHA no HIAE}

\subsubsection{Idade do Casal}

Sabendo-se que a idade do casal é um fator determinante no sucesso do tratamento, em especial a idade materna, a Tabela 1 compara idade entre as mulheres e os entre os homens que realizaram RHA no HIAE.

Tabela 1 - Distribuição da idade do casal segundo as pacientes que realizaram RHA. URHA-HIAE, 1995-2003

\begin{tabular}{llcccccc}
\hline $\begin{array}{l}\text { Idade do } \\
\text { casal }\end{array}$ & Grupo & $\mathbf{N}$ & Mediana & Média & $\begin{array}{c}\text { Desvio } \\
\text { Padrão }\end{array}$ & $\begin{array}{c}\text { Mann- } \\
\text { Whitney } \\
(\mathbf{Z})\end{array}$ & $\mathbf{P}$ \\
\hline \multirow{2}{*}{ Mulheres } & $\mathrm{HIAE}^{\mathrm{a}}$ & 238 & 34 & 33,8 & 4,1 & $-3,885$ & $<0,001$ \\
\cline { 2 - 8 } & $\mathrm{RA}^{\mathrm{b}}$ & 2169 & 35 & 35,1 & 5,1 & & \\
\cline { 2 - 8 } Homens & $\mathrm{HIAE}^{\mathrm{a}}$ & 224 & 37 & 37,5 & 5,5 & $-1,876$ & 0,061 \\
& $\mathrm{RA}^{\mathrm{b}}$ & 2047 & 38 & 38,7 & 6,9 & & \\
\hline
\end{tabular}

Mulheres $-Z=-3,885 ; P<0,001$

Homens $-Z=-1,876 ; P=0,061$

Fonte: URHA- HIAE

a - mulheres tratadas no URHA-HIAE e parto no HIAE

b - mulheres tratadas no URHA e que não engravidaram ou realizaram parto no HIAE

A Tabela 1 mostra que quando se compara a idade da mulher e a idade do homem entre os pacientes do HIAE e do RA observa-se que as mulheres da amostra RA têm idade significativamente maior que na amostra HIAE

Da mesma forma, os homens mostram idade aparentemente maior na amostra RA do que na amostra HIAE. O teste de Mann-Whitney não foi significativo, porém com um resultado próximo ao limite do nível de significância de $5 \%$. 


\subsubsection{Tipo de Infertilidade}

As tabelas 2,3 , e 4 demonstram a existência do fator de infertilidade feminino, masculino ou sem causa aparente.

Tabela 2 - Presença do fator de infertilidade feminina das pacientes que realizaram RHA. URHA-HIAE, 1995-2003

\begin{tabular}{lcccccc}
\hline Infertilidade & \multicolumn{2}{c}{ HIAE } & \multicolumn{2}{c}{ RA } & \multicolumn{2}{c}{ Total } \\
\cline { 2 - 7 } Feminina & $\mathbf{N}$ & $\mathbf{\%}$ & $\mathbf{N}$ & $\%$ & $\mathbf{N}$ & $\%$ \\
\hline Não & 138 & 58,0 & 1265 & 57,2 & 1403 & 57,3 \\
Sim & 100 & 42,0 & 945 & 42,8 & 1045 & 42,7 \\
\hline Total & $\mathbf{2 3 8}$ & $\mathbf{1 0 0 , 0}$ & $\mathbf{2 2 1 0}$ & $\mathbf{1 0 0 , 0}$ & $\mathbf{2 4 4 8}$ & $\mathbf{1 0 0 , 0}$ \\
\hline Fonte: URHA-HIAE & \multicolumn{7}{c}{0,$05 ; \mathrm{P}=0,8256$}
\end{tabular}

Tabela 3 - Distribuiçăo do fator de infertilidade feminina. URHA-HIAE 19952003

\begin{tabular}{lcccccc}
\hline $\begin{array}{l}\text { Causas da } \\
\text { Infertilidade }\end{array}$ & \multicolumn{2}{c}{ HIAE } & \multicolumn{2}{c}{ RA } & \multicolumn{2}{c}{ Total } \\
\cline { 2 - 7 } Feminina & $\mathbf{N}$ & $\%$ & $\mathbf{N}$ & $\%$ & $\mathbf{N}$ & $\%$ \\
\hline Fator Tubário & 53 & 53,0 & 475 & 50,3 & 528 & 50,5 \\
Fator ovulatório & 30 & 30,0 & 325 & 34,4 & 355 & 34,0 \\
Múltipla Feminino & 17 & 17,0 & 145 & 15,3 & 162 & 15,5 \\
\hline Total & $\mathbf{1 0 0}$ & $\mathbf{1 0 0 , 0}$ & $\mathbf{9 4 5}$ & $\mathbf{1 0 0 , 0}$ & $\mathbf{1 . 0 4 5}$ & $\mathbf{1 0 0 , 0}$ \\
\hline Fonte: URHA-HIAE & & & & & &
\end{tabular}

Tabela 4 - Presença do fator de infertilidade masculina dos parceiros das pacientes que realizaram RHA. URHA-HIAE, 1995-2003

\begin{tabular}{lcccccc}
\hline Infertilidade & \multicolumn{2}{c}{ HIAE } & \multicolumn{2}{c}{ RA } & \multicolumn{2}{c}{ Total } \\
\cline { 2 - 7 } Masculina & $\mathbf{N}$ & $\%$ & $\mathbf{N}$ & $\%$ & $\mathbf{N}$ & $\%$ \\
\hline Não & 162 & 68,1 & 1.567 & 70,9 & 1.729 & 70,6 \\
Sim & 76 & 31,9 & 643 & 29,1 & 719 & 29,4 \\
\hline Total & $\mathbf{2 3 8}$ & $\mathbf{1 0 0 , 0}$ & $\mathbf{2 . 2 1 0}$ & $\mathbf{1 0 0 , 0}$ & $\mathbf{2 . 4 4 8}$ & $\mathbf{1 0 0 , 0}$ \\
\hline
\end{tabular}

Fonte: URHA-HIAE

$$
\chi^{2}=0,083 ; P=0,361
$$


Tabela 5 - Distribuição do fator de infertilidade masculina. URHA-HIAE 19952003 HIAE 1995-2003

\begin{tabular}{lcccccc}
\hline \multirow{2}{*}{ Infertilidade Masculina } & \multicolumn{2}{c}{ HIAE } & \multicolumn{2}{c}{ RA } & \multicolumn{2}{c}{ Total } \\
\cline { 2 - 7 } & $\mathbf{N}$ & $\%$ & $\mathbf{N}$ & $\%$ & $\mathbf{N}$ & $\%$ \\
\hline Oligozooespermia & 50 & 65,8 & 394 & 61,3 & 444 & 62,0 \\
Azoospermia não & & & & & & \\
obstrutiva & 15 & 19,7 & 156 & 24,3 & 168 & 23,5 \\
Azoospermia obstrutiva & 11 & 14,5 & 93 & 14,5 & 104 & 14,5 \\
\hline Total & $\mathbf{7 6}$ & $\mathbf{1 0 0 , 0}$ & $\mathbf{6 4 3}$ & $\mathbf{1 0 0 , 0}$ & $\mathbf{7 1 6}$ & $\mathbf{1 0 0 , 0}$ \\
\hline Fonte: URHA-HIAE & & & & & &
\end{tabular}

Tabela 6 - Presença do fator de infertilidade sem causa de infertilidade aparente. URHA-HIAE, 1995-2003

\begin{tabular}{|c|c|c|c|c|c|c|}
\hline \multirow{2}{*}{$\begin{array}{l}\text { Sem cauda de } \\
\text { infertilidade } \\
\text { aparente }\end{array}$} & \multicolumn{2}{|c|}{ HIAE } & \multicolumn{2}{|c|}{ RA } & \multicolumn{2}{|c|}{ Total } \\
\hline & $\mathbf{N}$ & $\%$ & $\mathbf{N}$ & $\%$ & $\mathbf{N}$ & $\%$ \\
\hline Não & 216 & 90,8 & 2.064 & 93,4 & 2.280 & 93,1 \\
\hline Sim & 22 & 9,2 & 146 & 6,6 & 168 & 6,9 \\
\hline Total & 238 & 100,0 & 2.210 & 100,0 & 2.448 & 100,0 \\
\hline
\end{tabular}

Tabela 7 - Distribuição de outros fatores de infertilidade. URHA-HIAE 19952003. HIAE 1995-2003

\begin{tabular}{lcccccc}
\hline \multirow{2}{*}{ Infertilidade } & \multicolumn{2}{c}{ HIAE } & \multicolumn{2}{c}{ RA } & \multicolumn{2}{c}{ Total } \\
\cline { 2 - 7 } & $\mathbf{N}$ & $\%$ & $\mathbf{N}$ & $\%$ & $\mathbf{N}$ & $\%$ \\
\hline Infertilidade Feminina & 32 & 51,6 & 368 & 59,0 & 400 & 58,3 \\
Masculino & & & & & & \\
Sem Infertilidade & 22 & 35,5 & 146 & 23,4 & 168 & 24,5 \\
aparente & 8 & 12,9 & 110 & 17,6 & 118 & 17,2 \\
Ignorado & $\mathbf{6 2}$ & $\mathbf{1 0 0 , 0}$ & $\mathbf{6 2 4}$ & $\mathbf{1 0 0 , 0}$ & $\mathbf{6 8 6}$ & $\mathbf{1 0 0 , 0}$ \\
\hline Total & & & & & &
\end{tabular}

Fonte: URHA-HIAE

Observa-se nas Tabelas 2,4 e 6 a presença ou não do fator de infertilidade feminina, masculina e sem causa aparente para as duas amostras. Não foi observada diferença significativa entre elas. 
Destaca-se também a presença de endometriose como causa da infertilidade dessas mulheres (26 gestantes - 10,9\%)

As Tabelas 3, 5 e 7 descrevem as causas de infertilidade, observa-se que tanto para HIAE como para RA as causas femininas foram maiores que as masculinas,. Este resultado deve-se a no grupo RA incluir toda a amostra de pacientes que realizam algumas das técnicas de RHA com ou sem sucessos.

\subsubsection{Taxas de Sucesso}

Tabela 8 - Taxa de Gravidez Bioquímica dos procedimentos realizados na URHA-HIAE, 1995 a 2003.

\begin{tabular}{lcc}
\hline Taxa de Gravidez Bioquimica & FIV & ICSI \\
\hline PE transferidos & 359 & 1712 \\
BHCG + & 116 & 482 \\
Taxa de gravidez & $32,3 \%$ & $28,2 \%$ \\
\hline Fonte: URHA-HIAE & &
\end{tabular}

Tabela 9 - Taxa de Gravidez Clínica dos procedimentos realizados na URHA-HIAE, 1995 a 2003.

\begin{tabular}{lcc}
\hline Taxa de Gravidez Clínica & FIV & ICSI \\
\hline PE transferidos & 359 & 1712 \\
Saco Gestacional + presença de & 104 & 413 \\
Batimento Cardio Fetal & $29,0 \%$ & $24,1 \%$ \\
Taxa de gravidez Clínica & &
\end{tabular}

$$
\chi^{2}=1,994 ; P=0,158
$$


Tabela 10 - Taxa de Gravidez Efetiva dos procedimentos realizados no RHA no URHA- HIAE, 1995 a 2003.

\begin{tabular}{|c|c|c|}
\hline Taxa de Gravidez Efetiva & FIV & ICSI \\
\hline PE transferidos & 359 & 1712 \\
\hline Bebe em Casa & 81 & 303 \\
\hline Taxa de gravidez & $22,6 \%$ & $17,7 \%$ \\
\hline
\end{tabular}

As Tabelas 8,9 e 10 mostram a taxa de sucesso por tipo de gravidez. Observa-se que não houve diferença significativa entre as técnicas.

Apesar do resultado estatístico encontrado na amostra, ressalta-se um decréscimo de cada fase de evolução de gravidez. O que chama a atenção é um decréscimo de aproximadamente $30 \%$ da gravidez bioquímica para a gravidez efetiva.

\subsection{Caracterização das mulheres que realizaram o parto no HIAE}

\subsubsection{Características das Gestantes}

Para as variáveis maternas usaram-se os dados apenas uma vez, devido à gestação múltipla. Comparou-se as variáveis internação materna, aborto, idade gestacional, nas duas técnicas de reprodução assistida.

Os dados foram analisados de uma amostra de 238 gestantes. A técnica de reproduçăo assistida utilizada por estas pacientes foi de 45 casos de FIV e 193 casos ICSI.

Segundo os dados levantados de prontuários da maternidade em relação à profissão a mais encontrada foi advogada $(9,3 \%)$ e administradora de empresa (6,8\%). Em relação à escolaridade, elevado número de anos de estudo, sendo $76,4 \%$ da amostra com nível superior. A condição casada representou o estado civil de $77,0 \%$ das gestantes. 
Afecções maternas durante a gestação ocorreram em 17,6\% das pacientes da amostra. Essas afecções geraram $31,1 \%$ das internações no HIAE. 
Tabela 11 - Distribuição das gestantes segundo a idade materna e idade gestacional. HIAE, 1995 a 2003

\begin{tabular}{lccccccc}
\hline Idade & Técnica & N & Mediana & Média & $\begin{array}{c}\text { Desvio } \\
\text { padrão }\end{array}$ & $\begin{array}{c}\text { Mann- } \\
\text { Whitney } \\
(\mathbf{Z})\end{array}$ & Prob. \\
\hline Idade & FIVC & 45 & 34 & 34,00 & 4,47 & $-0,073$ & 0,942 \\
Materna & ICSI & 193 & 34 & 33,89 & 4,06 & & \\
Idade & FIVC & 45 & 38 & 37,7 & 1,95 & $-0,717$ & 0,473 \\
Gestacional & ICSI & 193 & 37,5 & 37,41 & 2,59 & & \\
\hline
\end{tabular}

A população incluida neste estudo foi composta de gestantes com média de idade de 34 anos para FIV e 33,89 anos para ICSI. As médias de idades gestacionais superaram 37 semanas em ambas as técnicas. Estatisticamente, a média da idade materna e da idade gestacional não diferem significativamente nas duas técnicas estudadas quando testadas pelo Mann-Whitney, conforme mostra a Tabela 11.

Tabela 12 - Distribuição das gestantes segundo a presença de doenças antes da gravidez. HIAE, 1995 a 2003

\begin{tabular}{lcccccc}
\hline Doenças & \multicolumn{2}{c}{ FIVc } & \multicolumn{2}{c}{ ICSI } & \multicolumn{2}{c}{ Total } \\
\cline { 2 - 7 } $\begin{array}{l}\text { antes da } \\
\text { gravidez }\end{array}$ & $\mathbf{N}$ & $\%$ & $\mathbf{N}$ & $\%$ & $\mathbf{N}$ & $\%$ \\
\hline Não & 43 & 95,6 & 172 & 89,1 & 215 & 90,3 \\
Sim & 2 & 4,4 & 21 & 10,9 & 23 & 9,7 \\
\hline Total & $\mathbf{4 5}$ & $\mathbf{1 0 0 , 0}$ & $\mathbf{1 9 3}$ & $\mathbf{1 0 0 , 0}$ & $\mathbf{2 3 8}$ & $\mathbf{1 0 0 , 0}$ \\
\hline \multicolumn{7}{c}{$=1,73 ; P=0,188$}
\end{tabular}

Observa-se na Tabela 12 que doenças prévias a gravidez ocorreram em $9,7 \%$ das gestantes, porém não foram estatisticamente significantes quando comparadas por técnicas de RHA.

Nessas pacientes o hipotiroidismo foi à doença com maior freqüência $(3,4 \%)$, seguido de abortamentos de repetição $(0,8 \%)$.

Em relação às doenças ocorridas durante o procedimento de RHA encontrou-se um caso de síndrome de hiperestimulação ovariana. 
Tabela 13 - Distribuição das gestantes segundo a presença de doenças durante a gravidez. HIAE, 1995 a 2003

\begin{tabular}{|c|c|c|c|c|c|c|}
\hline \multirow{2}{*}{$\begin{array}{l}\text { Doenças durante } \\
\text { a gravidez }\end{array}$} & \multicolumn{2}{|c|}{ FIVc } & \multicolumn{2}{|c|}{ ICSI } & \multicolumn{2}{|c|}{ Total } \\
\hline & $\mathbf{N}$ & $\%$ & $\mathbf{N}$ & $\%$ & $\mathrm{~N}$ & $\%$ \\
\hline Não & 39 & 86,7 & 157 & 81,3 & 196 & 82,4 \\
\hline Sim & 6 & 13,3 & 36 & 18,7 & 42 & 17,6 \\
\hline Total & 45 & 100,0 & 193 & 100,0 & 238 & 100,0 \\
\hline
\end{tabular}

$\mathrm{Na}$ Tabela 13 verifica-se que afecções maternas durante a gravidez ocorreram em $17,6 \%$ das pacientes da amostra. Nota-se que também não houve diferença estatística entre as técnicas de RHA estudas em relação a esta variável.

Tabela 14 - Presença de ITU durante a gravidez. HIAE, 1995 a 2003

\begin{tabular}{lcccccc}
\hline \multirow{2}{*}{ ITU } & \multicolumn{2}{c}{ FIVC } & \multicolumn{2}{c}{ ICSI } & \multicolumn{2}{c}{ Total } \\
\cline { 2 - 7 } & $\mathbf{N}$ & $\%$ & $\mathbf{N}$ & $\%$ & $\mathbf{N}$ & $\%$ \\
\hline Não & 44 & 97,8 & 178 & 92,2 & 222 & 93,3 \\
Sim & 1 & 2,2 & 15 & 7,8 & 16 & 6,7 \\
\hline Total & $\mathbf{4 5}$ & $\mathbf{1 0 0 , 0}$ & $\mathbf{1 9 3}$ & $\mathbf{1 0 0 , 0}$ & $\mathbf{2 3 8}$ & $\mathbf{1 0 0 , 0}$ \\
\hline & $\chi^{2}=1,79 ;$ & $P=0,1806$ & & &
\end{tabular}

Tabela 15 - Presença de DHEG durante a gravidez. HIAE, 1995 a 2003

\begin{tabular}{|c|c|c|c|c|c|c|}
\hline \multirow{2}{*}{ DHEG } & \multicolumn{2}{|c|}{ FIVc } & \multicolumn{2}{|c|}{ ICSI } & \multicolumn{2}{|c|}{ Total } \\
\hline & $\mathbf{N}$ & $\%$ & $\mathbf{N}$ & $\%$ & $\mathbf{N}$ & $\%$ \\
\hline Não & 42 & 93,3 & 182 & 94,3 & 224 & 94,1 \\
\hline Sim & 3 & 6,7 & 11 & 5,7 & 14 & 5,9 \\
\hline Total & 45 & 100,0 & 193 & 100,0 & 238 & 100,0 \\
\hline
\end{tabular}


Tabela 16 - Presença de diabetes durante a gravidez. HIAE, 1995 a 2003

\begin{tabular}{lcccccc}
\hline \multirow{2}{*}{ Diabetes } & \multicolumn{2}{c}{ FIVc } & \multicolumn{2}{c}{ ICSI } & \multicolumn{2}{c}{ Total } \\
\cline { 2 - 7 } & $\mathbf{N}$ & $\%$ & $\mathbf{N}$ & $\%$ & $\mathbf{N}$ & $\%$ \\
\hline Não & 43 & 95,6 & 185 & 95,9 & 228 & 95,8 \\
Sim & 2 & 4,4 & 8 & 4,1 & 10 & 4,2 \\
\hline Total & $\mathbf{4 5}$ & $\mathbf{1 0 0 , 0}$ & $\mathbf{1 9 3}$ & $\mathbf{1 0 0 , 0}$ & $\mathbf{2 3 8}$ & $\mathbf{1 0 0 , 0}$ \\
\hline & $\chi^{2}=0,01 ; \mathrm{P}=0,9281$ & & &
\end{tabular}

Dada à importância e a maior freqüência das doenças ITU, DHEG e diabetes foram estudadas individualmente. As tabelas 14,15 e 16 mostram as principais afecções ocorridas durante a gestação. Nota-se uma vez mais que não houve significância estatística dessas doenças quando comparadas às técnicas de RHA.

Tabela 17 - Presença de Internações durante a gravidez. HIAE, 1995 a 2003

\begin{tabular}{lcccccc}
\hline \multirow{2}{*}{ Internações } & \multicolumn{2}{c}{ FIVc } & \multicolumn{2}{c}{ ICSI } & \multicolumn{2}{c}{ Total } \\
\cline { 2 - 7 } & $\mathbf{N}$ & $\%$ & $\mathbf{N}$ & $\mathbf{0}$ & $\mathbf{N}$ & $\%$ \\
\hline Não & 36 & 80,0 & 128 & 66,3 & 164 & 68,9 \\
Sim & 9 & 20,0 & 65 & 33,7 & 74 & 31,1 \\
\hline Total & $\mathbf{4 5}$ & $\mathbf{1 0 0 , 0}$ & $\mathbf{1 9 3}$ & $\mathbf{1 0 0 , 0}$ & $\mathbf{2 3 8}$ & $\mathbf{1 0 0 , 0}$ \\
\hline \multicolumn{3}{c}{$\chi^{2}=3,19 ; \mathrm{P}=0,742$} & & & &
\end{tabular}

Nota-se na tabela 17 que apesar de não haver diferenças estatísticas entre as técnicas houve a ocorrência de $31,1 \%$ de internações.

A causa mais freqüência de internação $(11,3 \%)$ foi por trabalho de parto prematuro (TPP) seguido de amniorrexe prematura $(6,7 \%)$. Apesar da afecção incompetência istmo-cervical corresponder em apenas a $2,5 \%$ das causas de internação para realização de circlagem, esteve presente em $100 \%$ das pacientes que tiveram TPP. 
Tabela 18 - Distribuição das gestantes segundo paridade. HIAE, 1995-2003.

\begin{tabular}{lcccccc}
\hline Número de & \multicolumn{2}{c}{ FIVc } & \multicolumn{2}{c}{ ICSI } & \multicolumn{2}{c}{ Total } \\
\cline { 2 - 7 } \multicolumn{1}{c}{ Gestação } & $\mathbf{N}$ & $\mathbf{\%}$ & $\mathbf{n}$ & $\mathbf{\%}$ & $\mathbf{N}$ & $\mathbf{\%}$ \\
\hline Primigesta & 26 & 57,8 & 115 & 59,6 & 141 & 59,2 \\
Secundigesta & 10 & 22,2 & 48 & 24,9 & 58 & 24,4 \\
Tercigesta & 5 & 11,1 & 27 & 14,0 & 32 & 13,4 \\
Multipara $(\geq 4)$ & 4 & 8,9 & 3 & 1,6 & 7 & 2,9 \\
\hline Total & $\mathbf{4 5}$ & $\mathbf{1 0 0 , 0}$ & $\mathbf{1 9 3}$ & $\mathbf{1 0 0 , 0}$ & $\mathbf{2 3 8}$ & $\mathbf{1 0 0 , 0}$ \\
\hline & $\chi^{2}=7,024 ; P=0,071$ & & &
\end{tabular}

Tabela 19 - Distribuição das gestantes segundo o número de abortos antes da gravidez. HIAE 1995-2003

\begin{tabular}{ccccccc}
\hline $\begin{array}{c}\text { Número de } \\
\text { Abortos }\end{array}$ & \multicolumn{2}{c}{ FIVc } & \multicolumn{2}{c}{ ICSI } & \multicolumn{2}{c}{ Total } \\
\cline { 2 - 7 } & $\mathbf{n}$ & $\%$ & $\mathbf{n}$ & $\%$ & $\mathbf{N}$ & $\%$ \\
\hline 0 & 28 & 62,2 & 144 & 74,6 & 172 & 72,3 \\
1 & 13 & 28,9 & 31 & 16,1 & 44 & 18,5 \\
$\geq 2$ & 4 & 8,9 & 18 & 9,3 & 22 & 9,2 \\
\hline Total & $\mathbf{4 5}$ & $\mathbf{1 0 0 , 0}$ & $\mathbf{1 9 3}$ & $\mathbf{1 0 0 , 0}$ & $\mathbf{2 3 8}$ & $\mathbf{1 0 0 , 0}$ \\
\hline & $\chi^{2}=4,030 ; P=0,133$ & & &
\end{tabular}

Nas Tabelas 18 e 19 observa-se, em relação à paridade, 59,2\% das gestantes foram primigestas. Abortos ocorreram em mais de $20 \%$ na população geral do estudo. No entanto a paridade e o número de abortos não foram estatisticamente diferentes para as duas diferentes técnicas de RHA. 


\subsubsection{Características do parto}

As tabelas 20 e 21 mostram o tipo de parto realizado e o número de RN por gestação.

Tabela 20 - Distribuição das gestantes segundo a o tipo de parto. HIAE, 1995-2003

\begin{tabular}{lcccccc}
\hline \multirow{2}{*}{ Parto } & \multicolumn{2}{c}{ FIVc } & \multicolumn{2}{c}{ ICSI } & \multicolumn{2}{c}{ Total } \\
\cline { 2 - 7 } & $\mathbf{N}$ & $\%$ & $\mathbf{N}$ & $\mathbf{\%}$ & $\mathbf{N}$ & $\%$ \\
\hline Cesárea & 41 & 91,1 & 178 & 92,2 & 219 & 92,0 \\
Normal & 2 & 4,4 & 12 & 6,2 & 14 & 5,9 \\
Fórceps & 2 & 4,4 & 3 & 1,6 & 5 & 2,1 \\
\hline Total & $\mathbf{4 5}$ & $\mathbf{1 0 0 , 0}$ & $\mathbf{1 9 3}$ & $\mathbf{1 0 0 , 0}$ & $\mathbf{2 3 8}$ & $\mathbf{1 0 0 , 0}$ \\
\hline & $\chi^{2}=1,651 ; \mathbf{P}=0,438$
\end{tabular}

Observa-se na Tabela 20 a predominância do parto cesáreo nas gestantes dos dois grupos, que ocorreu em $92,0 \%$ de toda amostra. O tipo de parto não diferiu estatisticamente nos dois tipos de técnicas de RHA conforme mostrado pelo teste de qui-quadrado.

Tabela 21 - Distribuição do número de RN por gestação. HIAE 1995-2003

\begin{tabular}{lcccccc}
\hline \multirow{2}{*}{ Tipo de gestação } & \multicolumn{2}{c}{ FIVc } & \multicolumn{2}{c}{ ICSI } & \multicolumn{2}{c}{ Total } \\
\cline { 2 - 7 } & $\mathbf{N}$ & $\%$ & $\mathbf{n}$ & $\%$ & $\mathbf{n}$ & $\%$ \\
\hline Única & 27 & 60,0 & 137 & 71,0 & 164 & 68,9 \\
Duplo & 15 & 33,3 & 51 & 26,4 & 66 & 27,7 \\
Trigemelar ( ${ }^{*}$ quadrigêmeo) & 3 & 6,7 & $5^{\star}$ & 2,6 & 8 & 3,4 \\
\hline Total & $\mathbf{4 5}$ & $\mathbf{1 0 0}$ & $\mathbf{1 8 8}$ & $\mathbf{1 0 0}$ & $\mathbf{2 3 8}$ & $\mathbf{1 0 0}$ \\
\hline \multicolumn{2}{c}{$\chi^{2}=3,071 ; \mathrm{P}=0,215$} & & & & &
\end{tabular}

Verificou-se na tabela um alto percentual de gestações múltiplas $(31,1 \%)$ não sendo estatisticamente significante quando comparadas por técnicas. 


\subsubsection{Características do RN}

Tabela 22 - Distribuição dos RN segundo o sexo. HIAE, 1995-2003.

\begin{tabular}{|c|c|c|c|c|c|c|}
\hline \multirow{2}{*}{ Sexo do RN } & \multicolumn{2}{|c|}{ FIVc } & \multicolumn{2}{|c|}{ ICSI } & \multicolumn{2}{|c|}{ Total } \\
\hline & $\mathbf{N}$ & $\%$ & $\mathbf{N}$ & $\%$ & $\mathbf{N}$ & $\%$ \\
\hline Feminino & 32 & 47,8 & 129 & 50,6 & 161 & 50,0 \\
\hline Masculino & 35 & 52,2 & 126 & 49,4 & 161 & 50,0 \\
\hline Total & 67 & 100,0 & 255 & 100,0 & 322 & 100,0 \\
\hline
\end{tabular}

Na população do estudo, segundo a razão masculino/feminino para cada técnica, foi de 1.09 para os RN de FIVc e 0, 97 para os RN de ICSI. A Tabela 22 mostra que não houve diferença significativa na incidência entre os sexos feminino e masculino.

Tabela 23 - Distribuição dos RN segundo a classificação da idade gestacional. HIAE 1995-2003.

\begin{tabular}{lcccccc}
\hline $\begin{array}{c}\text { Classificação pela Idade } \\
\text { Gestacional no } \\
\text { Nascimento }\end{array}$ & \multicolumn{2}{c}{ FIVc } & \multicolumn{2}{c}{ ICSI } & \multicolumn{2}{c}{ Total } \\
\cline { 2 - 7 } & $\mathbf{N}$ & $\%$ & $\mathbf{N}$ & $\%$ & $\mathbf{N}$ & $\%$ \\
\hline Pré-termo (<37 semanas) & 21 & 31,3 & 95 & 37,3 & 116 & 36,0 \\
Termo ( $\geq 37$ semanas) & 46 & 68,7 & 160 & 62,7 & 206 & 64,0 \\
\hline Total & $\mathbf{6 7}$ & $\mathbf{1 0 0 , 0}$ & $\mathbf{2 5 5}$ & $\mathbf{1 0 0 , 0}$ & $\mathbf{3 2 2}$ & $\mathbf{1 0 0 , 0}$ \\
\hline \multicolumn{1}{c}{$\chi^{2}=0,805 ; \mathrm{P}=0,370$} & & & & &
\end{tabular}

A Tabela 23 mostra um elevado número de RN classificados como pré-termo ( $36 \%$ da amostra). Observou-se também que para essa variável não foram encontradas diferenças significativas entre os dois procedimentos. 
Tabela 24 - Classificação do RN segundo o crescimento intra-uterino. HIAE, 1995-2003

\begin{tabular}{lccccccc}
\hline $\begin{array}{c}\text { Classificação do RN de } \\
\text { acordo com o } \\
\text { crescimento intra- } \\
\text { uterino (Peso/ldade } \\
\text { gestacional) }\end{array}$ & FIVc & $\mathbf{N}$ & $\%$ & $\mathbf{N}$ & $\%$ & $\mathbf{N}$ & $\%$ \\
\cline { 2 - 8 } & 58 & 86,6 & 225 & 88,2 & 283 & 87,9 \\
AIG & 5 & 7,5 & 18 & 7,1 & 23 & 7,1 \\
GIG & 4 & 6,0 & 12 & 4,7 & 16 & 5,0 \\
PIG & $\mathbf{6 7}$ & $\mathbf{1 0 0 , 0}$ & $\mathbf{2 5 5}$ & $\mathbf{1 0 0 , 0}$ & $\mathbf{3 2 2}$ & $\mathbf{1 0 0 , 0}$ \\
\hline Total & & & & & & & \\
\hline
\end{tabular}

$\mathrm{Na}$ Tabela 24 pode ser evidenciado que $7,1 \%$ dos $\mathrm{RN}$ acima do percentil 90 da curva de crescimento (GIG) e $5 \%$ abaixo do percentil 10 (PIG). Não houve diferença significativa entre os três grupos de crescimento intra uterino com as técnicas utilizadas. Nota-se que RN AIG representaram um percentual bastante expressivo na maioria dos grupos analisados.

Encontro-se, durante a analise, dois RN de tamanho excessivamente grande (peso $\geq 4500 \mathrm{~g}$ ), ambos filhos de mãe diabética.

Tabela 25 - Distribuição dos RN segundo o peso de nascimento. HIAE, 1995-2003

\begin{tabular}{lcccccc}
\hline \multirow{2}{*}{ Peso RN } & \multicolumn{2}{c}{ FIVC } & \multicolumn{2}{c}{ ICSI } & \multicolumn{2}{c}{ Total } \\
\cline { 2 - 7 } & $\mathbf{N}$ & $\%$ & $\mathbf{n}$ & $\%$ & $\mathbf{N}$ & $\%$ \\
\hline$<1.000 \mathrm{~g}$ & - & - & 9 & 3,5 & 9 & 2,8 \\
entre 1000 e 1499g & 3 & 4,5 & 3 & 1,2 & 6 & 1,9 \\
entre 1500 a 2499g & 19 & 28,4 & 75 & 29,4 & 94 & 29,2 \\
2500g ou mais & 45 & 67,2 & 168 & 65,9 & 213 & 66,1 \\
\hline Total & $\mathbf{6 7}$ & $\mathbf{1 0 0 , 0}$ & $\mathbf{2 5 5}$ & $\mathbf{1 0 0 , 0}$ & $\mathbf{3 2 2}$ & $\mathbf{1 0 0 , 0}$ \\
\hline \multicolumn{2}{c}{$\chi^{2}=5,501 ; \mathbf{P}=0,139$} & & & &
\end{tabular}

Verificou-se na amostra, conforme mostra a Tabela 25, que 33,9\% $(n=109)$ RN nasceram com peso menor de $2500 \mathrm{~g}$, sendo que $13,7 \% \quad(n=15)$ destes RN tiveram seu peso menor de $1500 \mathrm{~g}$. Observou-se também, que em relação ao peso do nascimento, não se encontrou diferença significativa entre as duas técnicas de RHA. 
Tabela 26 - Características dos RN segundo variáveis peso, Apgar e tempo de internaçăo. HIAE, 1995-2003

\begin{tabular}{|c|c|c|c|c|c|c|c|}
\hline Variável & R.A & $\mathbf{N}$ & Mediana & Média & $\begin{array}{l}\text { Desvio } \\
\text { Padrão }\end{array}$ & $\begin{array}{l}\text { Mann- } \\
\text { Whitney } \\
\text { (Z) }\end{array}$ & $\mathbf{P}$ \\
\hline \multirow{2}{*}{$\begin{array}{l}\text { Peso do } \\
\text { RN no } \\
\text { nascimento }\end{array}$} & $|\mathrm{CS}|$ & 255 & 2740,00 & 2704,08 & 745,40 & \multirow[b]{2}{*}{$-0,136$} & \multirow[b]{2}{*}{0,892} \\
\hline & FIVc & 67 & 2680,00 & 2726,27 & 622,20 & & \\
\hline \multirow{2}{*}{$\begin{array}{l}\text { Peso na } \\
\text { alta }\end{array}$} & ICSI & 240 & 2535,00 & 2596,59 & 733,11 & \multirow{2}{*}{$-0,194$} & \multirow{2}{*}{0,847} \\
\hline & FIVc & 61 & 2540,00 & 2614,26 & 505,30 & & \\
\hline \multirow{2}{*}{ Apgar 1} & ICSI & 248 & 9,00 & 8,23 & 1,556 & \multirow{2}{*}{$-0,523$} & \multirow{2}{*}{0,601} \\
\hline & FIVc & 64 & 9,00 & 9,45 & 10,33 & & \\
\hline \multirow{2}{*}{ Apgar 5} & ICSI & 248 & 10,00 & 9,31 & 1,42 & \multirow{2}{*}{$-0,909$} & \multirow{2}{*}{0,363} \\
\hline & FIVc & 64 & 10,00 & 9,44 & 1,32 & & \\
\hline \multirow{2}{*}{$\begin{array}{l}\text { Dias de } \\
\text { Internação }\end{array}$} & ICSI & 255 & 3,00 & 7,85 & 15,92 & \multirow{2}{*}{$-1,522$} & \multirow{2}{*}{0,128} \\
\hline & FIVc & 67 & 4,00 & 11,72 & 45,52 & & \\
\hline
\end{tabular}

$\mathrm{Na}$ tabela 26 observa-se que as variáveis: peso (nascimento e alta), Apgar (1 e 5 minutos) e número de dias de internação, foram comparadas pelo teste de Mann-Whitney em ambas técnicas, observa-se pelo valor de $P$, que nenhuma dessas variáveis apresentou diferença significativa entre as duas técnicas. Deve ser ressaltado que em média os RN nasceram com peso superior a $2500 \mathrm{~g}$, elevadas notas de Apgar e um menor tempo de internação.

Tabela 27 - Presença de doença pulmonar de membrana hialina grau IV. HIAE, 1995 a 2003

\begin{tabular}{lcccccc}
\hline Membrana & \multicolumn{2}{c}{ FIVc } & \multicolumn{2}{c}{ ICSI } & \multicolumn{2}{c}{ Total } \\
\cline { 2 - 7 } Hialina & $\mathbf{N}$ & $\%$ & $\mathbf{N}$ & $\%$ & $\mathbf{N}$ & $\%$ \\
\hline Não & 67 & 100,0 & 248 & 97,3 & 315 & 97,8 \\
Sim & - & - & 7 & 2,7 & 7 & 2,2 \\
\hline Total & $\mathbf{6 7}$ & $\mathbf{1 0 0 , 0}$ & $\mathbf{2 5 5}$ & $\mathbf{1 0 0 , 0}$ & $\mathbf{3 2 2}$ & $\mathbf{1 0 0 , 0}$ \\
\hline \multicolumn{7}{c}{1,$880 ; \mathrm{P}=0,170$} \\
$\chi^{2}$
\end{tabular}


Tabela 28 - Presença de Hemorragias peri-intraventricular grau IV. HIAE, 1995 a 2003

\begin{tabular}{|c|c|c|c|c|c|c|}
\hline \multirow{2}{*}{$\begin{array}{l}\text { Hemorragias peri- } \\
\text { intraventricular }\end{array}$} & \multicolumn{2}{|c|}{ FIVc } & \multicolumn{2}{|c|}{ ICSI } & \multicolumn{2}{|c|}{ Total } \\
\hline & $\mathbf{N}$ & $\%$ & $\mathbf{N}$ & $\%$ & $\mathbf{N}$ & $\%$ \\
\hline Não & 67 & 100,0 & 252 & 98,8 & 319 & 99,1 \\
\hline Sim & - & - & 3 & 1,2 & 3 & 0,9 \\
\hline Total & 67 & 100,0 & 255 & 100,0 & 322 & 100,0 \\
\hline
\end{tabular}

Tabela 29 - Presença de septicemia. HIAE, 1995 a 2003

\begin{tabular}{lcccccc}
\hline \multirow{2}{*}{ Sepse } & \multicolumn{2}{c}{ FIVc } & \multicolumn{2}{c}{ ICSI } & \multicolumn{2}{c}{ Total } \\
\cline { 2 - 7 } & $\mathbf{N}$ & $\%$ & $\mathbf{N}$ & $\%$ & $\mathbf{N}$ & $\%$ \\
\hline Não & 67 & 100,0 & 249 & 97,6 & 316 & 98,1 \\
Sim & - & - & 6 & 2,4 & 6 & 1,9 \\
\hline Total & $\mathbf{6 7}$ & $\mathbf{1 0 0 , 0}$ & $\mathbf{2 5 5}$ & $\mathbf{1 0 0 , 0}$ & $\mathbf{3 2 2}$ & $\mathbf{1 0 0 , 0}$ \\
\hline & \multicolumn{1}{c}{$\chi^{2}=1,606 ; \mathrm{P}=0,205$} & & &
\end{tabular}

Tabela 30 - Presença de retinopatia da prematuridade. HIAE, 1995 a 2003

\begin{tabular}{lcccccc}
\hline \multirow{2}{*}{ ROP } & \multicolumn{2}{c}{ FIVc } & \multicolumn{2}{c}{ ICSI } & \multicolumn{2}{c}{ Total } \\
\cline { 2 - 7 } & $\mathbf{N}$ & $\%$ & $\mathbf{N}$ & $\%$ & $\mathbf{N}$ & $\%$ \\
\hline Não & 67 & 100,0 & 253 & 99,2 & 320 & 99,4 \\
Sim & - & - & 2 & 0,8 & 2 & 0,6 \\
\hline Total & $\mathbf{6 7}$ & $\mathbf{1 0 0 , 0}$ & $\mathbf{2 5 5}$ & $\mathbf{1 0 0 , 0}$ & $\mathbf{3 2 2}$ & $\mathbf{1 0 0 , 0}$ \\
\hline & $\chi^{2}=0,520 ; P=0,467$ & & &
\end{tabular}

As tabelas $27,28,29$ e 30 mostram o número das principais doenças ocorridas durante a internação do RN no berçário.

Por opção do pesquisador considerou apenas as formas de maior gravidades das doenças selecionadas, o que explica o reduzido número dessas afecções quando observados o número de RN prematuros

Nota-se que apesar de não ter sido encontrado nenhuma das doenças estudadas na técnica FIVc, ambos os procedimentos não se mostraram significantemente diferentes. 


\subsubsection{Malformação}

Tabela 31 - Presença de RN com malformação segundo idade materna. HIAE, 1995-2003

\begin{tabular}{lcccccc}
\hline \multirow{2}{*}{$\begin{array}{l}\text { Idade materna } \\
\text { (anos) }\end{array}$} & \multicolumn{3}{c}{ Não } & \multicolumn{2}{c}{ Sim } & \multicolumn{2}{c}{ Total } \\
\cline { 2 - 6 } & $\mathbf{N}$ & $\%$ & $\mathbf{N}$ & $\%$ & $\mathbf{N}$ & $\%$ \\
\hline$<25$ anos & 12 & 4,2 & 2 & 5,9 & 14 & 4,3 \\
26 a 30 & 47 & 16,3 & 6 & 17,6 & 53 & 16,5 \\
$31-35$ & 135 & 46,9 & 12 & 35,3 & 147 & 45,7 \\
$>35$ anos & 94 & 32,6 & 14 & 41,2 & 108 & 33,5 \\
\hline TOTAL & $\mathbf{2 8 8}$ & $\mathbf{8 9 , 4}$ & $\mathbf{3 4}$ & $\mathbf{1 0 , 6}$ & $\mathbf{3 2 2}$ & $\mathbf{1 0 0 , 0}$ \\
\hline \multicolumn{2}{c}{$\chi^{2}=1,793 ; \mathrm{P}=0,617$}
\end{tabular}

Nota-se na Tabela 31 que o avanço da idade materna é seguido por um maior número de malformações.

Tabela 32 - Distribuição RN com malformação segundo a idade materna. HIAE, 1995-2003

\begin{tabular}{|c|c|c|c|c|c|c|}
\hline \multirow{3}{*}{$\begin{array}{l}\text { Idade } \\
\text { materna } \\
\text { (anos) }\end{array}$} & \multicolumn{4}{|c|}{ Malformação } & \multirow{2}{*}{\multicolumn{2}{|c|}{ Total }} \\
\hline & \multicolumn{2}{|c|}{ FIVc } & \multicolumn{2}{|c|}{ ICSI } & & \\
\hline & $\mathbf{N}$ & $\%$ & $\mathbf{N}$ & $\%$ & $\mathbf{N}$ & $\%$ \\
\hline$<25$ anos & 2 & 100,0 & - & - & 2 & 5,9 \\
\hline 26 a 30 & - & - & 6 & 100,0 & 6 & 17,6 \\
\hline $31-35$ & 3 & 25,0 & 9 & 75,0 & 12 & 35,3 \\
\hline$>35$ anos & 4 & 28,6 & 10 & 71,4 & 14 & 41,2 \\
\hline TOTAL & 9 & 26,5 & 25 & 73,5 & 34 & 100,0 \\
\hline
\end{tabular}

FIVc $\chi^{2}=2,400 ; P=0,494$

ICSI $\chi^{2}=2,293 ; P=0,514$

Apesar do evidente aumento do número de malformações com o aumento da idade materna, em especial acima de 35 anos, não se evidenciou estatisticamente diferença entre as técnicas de RHA. 
Tabela 33 - Distribuição dos tipos de malformações. HIAE, 1995-2003

\begin{tabular}{|c|c|c|c|c|}
\hline Classificação & tipo de malformação & FIV & $\mid \mathrm{CSI}$ & Total \\
\hline \multirow{3}{*}{$\begin{array}{l}\text { cardiopatias } \\
\text { congênitas }\end{array}$} & Cardiopatia congênita complexa & 3 & 3 & 6 \\
\hline & Cardiopatia congênita e rim ectópico & - & 1 & 1 \\
\hline & Estenose Aórtica & 1 & - & 1 \\
\hline \multirow{5}{*}{$\begin{array}{l}\text { malformações do } \\
\text { aparelho genital }\end{array}$} & criptorquidia bilateral, prega assimétrica & - & 1 & 1 \\
\hline & criptorquidia direita & - & 1 & 1 \\
\hline & criptorquidia e prega única nas mãos & - & 1 & 1 \\
\hline & Hipospádia (grau I) & 1 & - & 1 \\
\hline & Hipospádia balânica & 1 & - & 1 \\
\hline \multirow{3}{*}{$\begin{array}{l}\text { malformações de } \\
\text { extremidades }\end{array}$} & $\begin{array}{l}\text { agenesia de antebraço e com coto distal } \\
\text { aberto no cotovelo }\end{array}$ & - & 1 & 1 \\
\hline & Pé torto congênito & - & 2 & 2 \\
\hline & Polidactilia & 1 & - & 1 \\
\hline \multirow{3}{*}{$\begin{array}{l}\text { malformações de } \\
\text { orelha }\end{array}$} & apêndice auricular $D$ & - & 1 & 1 \\
\hline & $\begin{array}{l}\text { cup ear - } \\
\text { malformacão do pavilhão auricular - }\end{array}$ & - & 1 & 1 \\
\hline & $\begin{array}{l}\text { septação de lóbulo de orelha em } 1 / 3 \\
\text { médio }\end{array}$ & - & 1 & 1 \\
\hline \multirow{2}{*}{$\begin{array}{l}\text { síndrome e/ou } \\
\text { seqüência }\end{array}$} & Síndrome de Down & - & 1 & 1 \\
\hline & Síndrome de Vacterl & - & 2 & 2 \\
\hline \multirow{2}{*}{$\begin{array}{l}\text { malformações do tubo } \\
\text { neural }\end{array}$} & Hidrocefalia, meningomielocele corrigida & - & 1 & 1 \\
\hline & meningomielocele lombar & - & 1 & 1 \\
\hline \multirow{2}{*}{$\begin{array}{l}\text { malformações } \\
\text { gastrointestinal }\end{array}$} & atresia de esôfago com fístula distal & - & 1 & 1 \\
\hline & malformações específicas do intestino & - & 1 & 1 \\
\hline \multirow{2}{*}{ malformações renais } & cisto renal & - & 1 & 1 \\
\hline & mega-ureter e rim multicístico & - & 1 & 1 \\
\hline \multirow{2}{*}{$\begin{array}{l}\text { malformações do } \\
\text { couro cabeludo }\end{array}$} & aplasia cútis & - & 1 & 1 \\
\hline & lesão hipocrômica em couro cabeludo & 1 & - & 1 \\
\hline \multirow{2}{*}{ outras malformações } & artéria umbilical única & - & 1 & 1 \\
\hline & Fenda labial e fenda palatina & 1 & - & 1 \\
\hline malformaçø̃es da pele & apêndice cutâneo supramanilar & - & 1 & 1 \\
\hline Total & & 9 & 25 & 34 \\
\hline
\end{tabular}

$\mathrm{Na}$ Tabela 33 observa-se uma descrição das malformações encontradas nos RN do estudo. Malformações cardíacas lideram o grupo. Chama-se atenção o encontro de malformações maiores, como no caso da Seqüência de VACTERL e das cardiopatias congênitas complexas 


\subsubsection{Gemelaridade}

Em vista da importância da variável gemelaridade para a Saúde Pública, mereceu uma analise pelo número de RN em cada gestação.

A amostra foi composta de 238 gestantes que resultaram em 322 RN vivos. Conforme já informado pela Tabela

Tabela 34 - Distribuição do número dos RN por gestação segundo a idade gestacional. HIAE, 1995-2003

\begin{tabular}{ccccccccc}
\hline \multirow{2}{*}{$\begin{array}{c}\text { Idade } \\
\text { Gestacional }\end{array}$} & \multicolumn{2}{c}{ Único } & \multicolumn{2}{c}{ Duplo } & \multicolumn{2}{c}{ Trigêmeo* } & \multicolumn{2}{c}{ Total } \\
\cline { 2 - 10 } & $\mathbf{N}$ & $\%$ & $\mathbf{N}$ & $\%$ & $\mathbf{N}$ & $\%$ & $\mathbf{N}$ & $\%$ \\
\hline 28 & 1 & 0,6 & 4 & 3,0 & 3 & 12,0 & 8 & 2,5 \\
$29-36$ & 149 & 90,3 & 54 & 40,9 & 5 & 20,0 & 208 & 64,6 \\
$\geq 37$ & 15 & 9,1 & 74 & 56,1 & 17 & 68,0 & 106 & 32,9 \\
\hline Total & $\mathbf{1 6 5}$ & $\mathbf{1 0 0 , 0}$ & $\mathbf{1 3 2}$ & $\mathbf{1 0 0 , 0}$ & $\mathbf{2 5}$ & $\mathbf{1 0 0 , 0}$ & $\mathbf{3 2 2}$ & $\mathbf{1 0 0 , 0}$ \\
\hline \multicolumn{4}{c}{$\chi^{2}=95,561 ;$} \\
* P<0,001 & & & & & \\
\end{tabular}


Gráfico 2 - Distribuição do número de RN por tipo de gestação segundo a idade gestacional de nascimento. HIAE 1995-2003

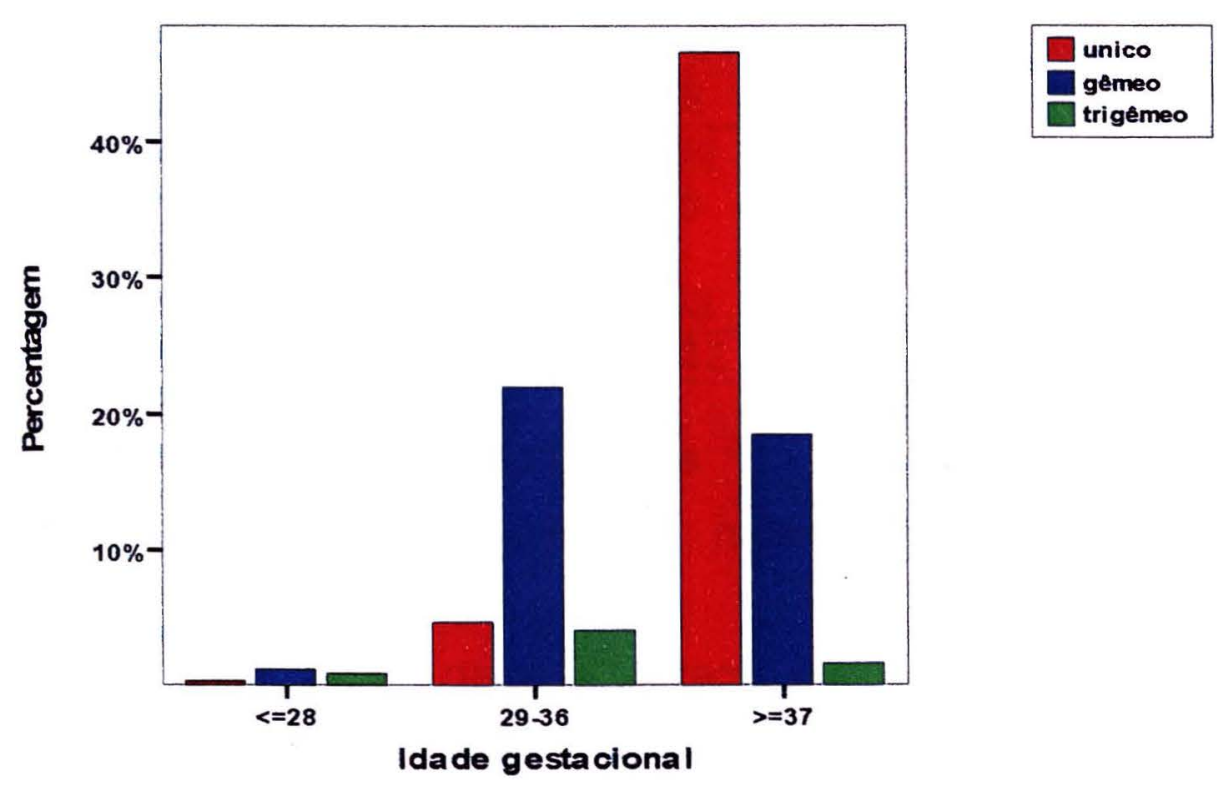

Evidencia-se nas Tabelas 34 e Gráfico 2 que a prematuridade (idade gestacional $\leq 37$ semanas) foi aumentada à medida que se elevem os números de conceptos nascidos por uma gestação. 
Tabela 35 - Distribuição do número dos RN por gestação segundo peso de nascimento. HIAE, 1995-2003

\begin{tabular}{|c|c|c|c|c|c|c|c|c|}
\hline \multirow{2}{*}{ Peso RN } & \multicolumn{2}{|c|}{ Único } & \multicolumn{2}{|c|}{ Gêmeo } & \multicolumn{2}{|c|}{ Trigêmeo* } & \multicolumn{2}{|c|}{ Total } \\
\hline & $\mathbf{N}$ & $\%$ & $\mathbf{N}$ & $\%$ & $\mathbf{N}$ & $\%$ & $\mathbf{N}$ & $\%$ \\
\hline$<1.000 \mathrm{~g}$ & 10 & 6,1 & 69 & 52,3 & 15 & 60,0 & 94 & 29,2 \\
\hline entre 1000 e $1499 \mathrm{~g}$ & 1 & 0,6 & 5 & 3,8 & 3 & 12,0 & 9 & 2,8 \\
\hline entre 1500 a $2499 \mathrm{~g}$ & 1 & 0,6 & & 0,0 & 5 & 20,0 & 6 & 1,9 \\
\hline $2500 \mathrm{~g}$ ou mais & 153 & 92,7 & 58 & 43,9 & 2 & 8,0 & 213 & 66,1 \\
\hline Total & 165 & 100,0 & 132 & 100,0 & 25 & 100,0 & 322 & 100,0 \\
\hline $\begin{array}{l}\chi^{2}=141,898 \\
-\quad \text { acrescidos }\end{array}$ & $<0,00$ & 0 & & & & & & \\
\hline
\end{tabular}

Entre o número de RN de cada gestação quando comparados com o peso do RN. No entanto RN com peso menor de que $1000 \mathrm{~g}$ corresponderam a $60 \%$ dos $\mathrm{RN}$ de parto trigemelar

Tabela 36 - Distribuição do número de RN por gestação segundo o tipo de alta. HIAE 1995-2003

\begin{tabular}{|c|c|c|c|c|c|c|}
\hline \multirow{2}{*}{$\begin{array}{l}\text { Número de } \\
\text { Gestação }\end{array}$} & \multicolumn{2}{|c|}{ Vivo } & \multicolumn{2}{|c|}{ Óbito } & \multicolumn{2}{|c|}{ Total } \\
\hline & $\mathbf{N}$ & $\%$ & $\mathbf{N}$ & $\%$ & $\mathbf{N}$ & $\%$ \\
\hline Únicos & 165 & 100,0 & - & - & 165 & 100,0 \\
\hline Gêmeos & 124 & 93,9 & 8 & 6,1 & 132 & 100,0 \\
\hline Trigêmeos & 17 & 81,0 & 4 & 19,0 & 21 & 100,0 \\
\hline Quádruplos & 4 & 100,0 & - & - & 4 & 100,0 \\
\hline Total & 310 & 96,3 & 12 & 3,7 & 322 & 100,0 \\
\hline
\end{tabular}


Gráfico 3- Distribuição do número de RN por gestação segundo o tipo de alta. HIAE 1995-2003

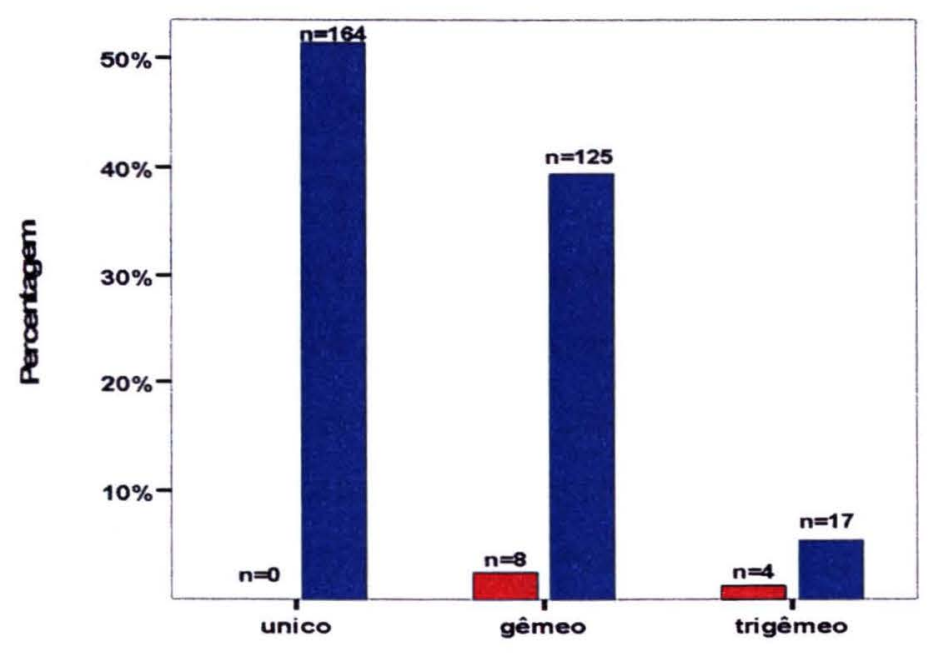

Morta lida de

Obito

Vivo

Na tabela 36 e Gráfico fica evidente as repercussões da gestação múltipla para os resultados neonatais. Não se observou óbitos nos RN de gestação única que praticamente concentraram-se nos RN de parto trigemelar. 
Tabela 37 - Distribuição do número dos RN por gestação. HIAE, 1995-2003

\begin{tabular}{lccccc}
\hline Gemelaridade & N & $\begin{array}{c}\text { Permanência } \\
\text { Mediana }\end{array}$ & $\begin{array}{c}\text { Permanência } \\
\text { Média }\end{array}$ & $\begin{array}{c}\text { Desvio } \\
\text { padrão }\end{array}$ & $\begin{array}{c}\text { Kruskal- } \\
\text { Wallis }\end{array}$ \\
\hline Únicos & 165 & 3 & 7,76 & 30,923 & \\
Duplo Gemelar & 132 & 4 & 8,02 & 15,486 & 66,832 \\
Trigemelar & 21 & 6 & 16,14 & 24,198 & $\mathrm{P}<0,0001$ \\
Quádruplos & 4 & 27 & 27 & - & \\
\hline \multicolumn{5}{r}{$\chi^{2}=51,229 ; P<0,001$} &
\end{tabular}

$\mathrm{Na}$ Tabela 37 observamos que o tempo de internação aumenta conforme aumenta o número de RN por gestação Quando se compara o tempo de internação entre os RN número de RN por gestação encontra-se um relação estatisticamente significante entre o tempo de permanência e os quatro grupos de por meio do teste de Kruskal-Wallis,

Tabela 38 - Comparação entre RN por número por gestação. HIAE, 19952003

\begin{tabular}{lcc}
\hline Comparação & $\begin{array}{c}\text { Diferença entre } \\
\text { Rank médio }\end{array}$ & Valor de P \\
\hline único vs. gêmeo & $-55,347$ & $<0,001$ \\
único vs. Trigêmeo & $-128,08$ & $<0,001$ \\
único vs. Quádruplo & $-172,48$ & $<0,001$ \\
Gêmeo vs. Trigêmeo & $-72,737$ & $<0,01$ \\
Gêmeo vs. Quádruplo & $-117,13$ & $<0,05$ \\
trigêmeo vs. Quádruplo & $-44,39$ & Ns \\
\hline
\end{tabular}

$\mathrm{Na}$ Tabela 38 o teste de comparações múltiplas de Dunn mostrou que existem diferenças significativas entre a comparação de cada dois grupos, com exceção de trigêmeos com quádruplos 
DISCUSSÃO 


\section{DISCUSSÃO}

0 presente trabalho estudou as mulheres que procuraram 0 tratamento de infertilidade na URHA-HIAE. Além disso foram selecionadas as pacientes cujo parto ocorreu também nessa Instituição.

Verificou-se na série histórica do total de procedimentos realizados na URHA-HIAE, um aumento na utilização da técnica ICSI.

\subsection{Idade do Casal}

Sabendo-se que a idade é um fator preponderante para infertilidade constatou-se, pelo estudo, a existência de um elevado percentual de mulheres com idade a superior a 35 anos, o mesmo se verificando com a idade dos homens.

Apesar disso, as diferenças nas médias de idade foram pouco superiores a um ano. Essa significância deve-se mais ao grande número de casos no RA onde praticamente qualquer diferença encontrada torna-se significativa. De toda forma, homens e mulheres dos dois grupos são mais velhos do que seriam observados na população geral ${ }^{101}$.

Quanto às repercussões da idade paterna avançada nos RN ainda não estão completamente esclarecidas.

Uma revisão da literatura sobre a qualidade do sêmem associado com a idade masculina entre homens de 30 anos comparados a homens de 50 anos de idade, encontrou diminuição do volume do sêmen ( 3 a $22 \%$ ), na mobilidade do esperma ( 3 a $37 \%$ ), e no percentual de esperma normal ( 4 a $18 \%$ ), mas não na concentração do esperma ${ }^{102}$.

Estudos mostram também que a idade paterna está associada com o aumento de mutações autossômicas dominantes (exemplo, acondroplasia; síndromes de Apert, Waardenburg, Crouzon, Pfeiffer e Marfan) que poderiam resultar em anomalias congênitas para os seus descendentes ${ }^{30}$. 


\subsection{Tipo de Infertilidade}

A infertilidade de causa feminina tem sido muito mais estudada na literatura em relação à masculina ${ }^{31}$. Observou-se no presente estudo, que analisou tanto causas femininas como masculinas que houve predomínio das causas ligadas à infertilidade feminina.

LASS $^{103}$ (1999) refere que o fator masculino correspondeu a $23 \%$ dos seus casos e o fator tubário a $24 \%$, referindo a infertilidade de causa não esclarecida em 12\%. Em 2006 dados do $\mathrm{CDC}^{23}$ referiu o fator tubário como responsável por $12,3 \%$, ० fator feminino de um modo geral (incluindo $\circ$ tubário) responsável por $32,9 \%$ dos casos, o fator masculino como responsável por $18,8 \%$ e a infertilidade mista por $17,9 \%$ dos casos.

No presente trabalho os dados se mostraram semelhantes aos do CDC.

Dentre as causas de infertilidade feminina as características peculiares a cada população podem interferir sobre os diferentes fatores, porém, o fator tubo peritonial, a iatrogênia e o fator ovulatório colocam-se como os mais freqüentes ${ }^{33,36}$.

No presente trabalho houve predomino do fator tubário.

Entre os fatores de infertilidade masculina na população em estudo a grande maioria se deveu à azoospermia, conforme referido na literatura ${ }^{46}$. 


\subsection{Taxas de Sucesso}

SCHIEVE et al. ${ }^{49}$ em 2002 relatam que a taxa de sucesso, ou seja, de ciclos iniciados que resultaram em gravidez, com RN, foi de $24,9 \%$. Em publicação de Rede $\operatorname{LARA}^{96}$ (2004) a taxa de parto por transferência de embriões frescos para FIV, ICSI e FIV+ICSI foi de $24,5 \%$.

As taxas de sucesso efetivo no presente trabalho foram inferiores às relatadas, contudo alguns fatores podem explicar esse achado como a idade das mulheres e a paridade, devendo-se salientar a transferência média de menos de três embriōes.

\subsection{Mulheres que realizaram o parto no HIAE}

\subsubsection{Características maternas}

A idade média das mulheres, por ser fator de sucesso, foi analisada no presente estudo, tendo se detectado que a média do grupo se localizou entre 30 e 40 anos. Contudo a média de idade materna para gêmeos foi maior, correspondendo também uma taxa de sucesso menor. A média de idade mais avançada implicou também na ocorrência de gestantes que já apresentavam importantes antecedentes ginecológicos e obstétricos, contudo sem diferenças entre as técnicas de RHA.

Embora as taxas de nascimento totais tenham diminuído globalmente entre as mulheres ${ }^{25}$, também há uma evidência que as mulheres também retardam a maternidade. Em idades de 40 a 44 anos, como um exemplo, o número das mulheres primigestas era 15.8/1000 em 2002, comparativamente aos com os $15.1 / 1.000$ em $1960^{96}$. Fica evidente, que na atualidade, que as mulheres em países desenvolvidos estão tendo menos filhos, ou os têm, ocorre num período mais tardio da vida e muitas optam, 
por não ter filhos. No entanto a maternidade após os 35 anos ainda é um desafio $^{104}$.

Teoricamente, as mulheres mais velhas teriam os mesmos riscos de complicações da gravidez que mulheres mais novas, mas seu risco é mais elevado de alguns desses problemas, como por exemplo, para os abortos espontâneos. Mulheres acima de 35 anos têm esta condição aumentada principalmente por perdas de fetos com trissômias e euploidias, resultado de um declínio na qualidade do oócito ${ }^{96}$.

Das doenças que ocorrem na gestação deve-se assinalar que a RHA é por si só importante causa de morbidade materna ${ }^{105}$. Entre essas: sangramento vaginal após 28 semanas, placenta prévia; oligoidrâmnio; insuficiência placentária e a síndrome de hiperestimulação ovário.Essa última afecção também foi encontrada no atual trabalho.

A explicação para este número aumentado de complicações poderia estar ligada às alterações endometriais, sabidamente presente nessas mulheres $^{105}$.

SHEVELL et al. ${ }^{105}(2005)$ após um estudo comparativo entre 36.062 mulheres que engravidaram espontaneamente, mulheres que usaram indução de ovulação e pacientes que realizaram FIV, constataram que a indução a ovulação estava associada estatisticamente com o aumento de descolamento prematuro de placenta, perda fetal após 24 semanas e diabetes gestacional. Enquanto que nas pacientes que realizaram FIV, houve uma associação estatisticamente significativa, com o aumento de préeclâmpsia, hipertensão gestacional, descolamento prematuro de placenta, placenta prévia e maior risco de parto cesáreo.

Sabendo-se que a situação de saúde materna influencia diretamente o desenvolvimento fetal e a saúde do neonato, verificou-se, por meio da atual pesquisa, que a alta incidência das afecções maternas durante a gestação além do risco para a própria gestante, poderia comprometer o resultado 
perinatal. Essas afecções geraram aproximadamente $20 \%$ das internações no HIAE, verificando-se que as gestantes que realizaram ICSI foram internadas mais freqüentemente que aquelas com FIV.

Trabalho de parto prematuro foi a principal causa de internação das gestantes no HIAE no presente estudo. Riscos maternos, nessa situação, estão especialmente associados com internações prolongadas durante a gestação, onde são administradas à paciente terapia com tocolíticos e esteróides, aumentando as chances de ocorrência de edema agudo de pulmão.

Outra afecção de grande importância é a anemia, que pode ocorrer agudamente na gestação ou até mesmo no puerpério, com necessidade muitas vezes de transfusões sanguíneas para suprir a alta demanda hemopoiética ${ }^{106}$.

Hipertensão e pré-eclâmpsia ocorrem muito freqüentemente na gestação múltipla. BURKMAN et al. ${ }^{75}$ constataram $24 \%$ de eclâmpsia grave, em gestações triplas com 20 semanas de idade gestacional, incluindo a forma mais grave dessa doença onde ocorre hemólise e com testes de função hepática elevada. Ainda pode-se incluir nas complicações maternas o polidrâmnio, que pode ocorrer em $12 \%$ das gestações múltiplas, além de aumentar o risco de parto prematuro. Outras afecções que também estão associadas à gestação múltipla são a hiperêmese gravídica, e o refluxo gastro-esofágico ${ }^{107}$.

Considerando-se o número de abortos, não houve diferenças significativas entre as técnicas aqui estudadas. 


\subsubsection{Características do parto}

No presente estudo observou-se uma elevada freqüência de parto cesáreo nas mulheres submetidas à RHA, embora sem diferenças significativas entre as duas técnicas estudadas. Prende-se a vários fatores desde aqueles relatados de risco materno, até a decisões do próprio casal $^{108}$.

À medida que aumenta o número de fetos, com gestações trigemelares ou mais, o parto cesáreo tem sua indicação aumentada, pois permite redução do intervalo entre os nascimentos e conseqüentemente às complicações para o segundo e terceiro fetos, assim como, menor número de casos de tocotraumatismos e hipóxia ${ }^{108}$.

Observou-se que embora o número de gestações dupla e trigemelar estivessem acima do encontrado em pacientes não submetidas à RHA, a gestação múltipla não mostrou diferenças significativas entre as duas técnicas ${ }^{54,56}$.

\subsubsection{Características do RN}

O RN de gestação de RHA tem sido objeto de inúmeros estudos ${ }^{76,79,}$ 109,110 .

Pode se dizer que "O ADMIRÁVEL MUNDO NOVO DA REPRODUÇÃO ASSISTIDA" trouxe repercussões que configuraram uma nova realidade a ser avaliada em toda a sua magnitude, como por exemplo, as implicações da prematuridade e da gestação múltipla.

Não houve diferença quanto ao sexo dos RN em relação às técnicas de RHA, o que está de acordo com outros trabalhos publicados em especial ,o de BONDUELLE ${ }^{80}$, em 2002. No entanto em uma população dinamarquesa houve predomínio do sexo masculino no procedimento de 
$\mid \mathrm{CSS}{ }^{47}$. Em trabalho de uma população voluntária de uma empresa houve predomínio do sexo masculino na técnica ICSI (esperma não ejaculado). Há que se salientar portanto, a existência de controvérsias quanto às diferenças de proporções entre os sexos segundo as técnicas de RHA utilizadas.

Em relação à população geral, observa-se um aumento da incidência de prematuridade, não somente entre os múltiplos, como também entre os RN de parto único concebidos de técnicas de RHA ${ }^{109}$.

No momento do nascimento, pela sua fragilidade física e imunológica, os RN apresentam diferentes níveis de maturidade, como conseqüência da idade gestacional.

Sabe-se que a relação entre a idade gestacional e o peso de nascimento reflete a adequação do crescimento intra-uterino. A determinação dessa relação permite a previsão da mortalidade e morbidade neonatal subseqüentes, e o reconhecimento dos problemas clínicos do RN será facilitado, possibilitando maior rapidez no estabelecimento de uma terapêutica e melhorando o resultado perinatal ${ }^{87}$. Assim, dois RN com o mesmo peso de nascimento, mas com idades gestacionais diferentes, podem ter diferentes riscos de morte. Segundo BERTAGNON ${ }^{109}$ (1991), o RN prematuro, pequeno para idade gestacional tem um risco 7,8 vezes maior de apresentar qualquer morbidade neonatal quando comparado ao prematuro adequado para idade gestacional.

No trabalho em tela, apesar do critério "termo" não pressupor a maturidade plena do concepto, a maioria das crianças foi classificada como RN de termo ( $>37$ semanas de idade gestacional), sem diferenças significativas entre os dois procedimentos analisados. Todavia, em termos de comparação, deve-se salientar que a taxa de prematuridade no Brasil,segundo o IBGE ${ }^{24}$, é aproximadamente cinco vezes menor do que a taxa encontrada no presente estudo. 
O número de crianças com restrição de crescimento intra-uterino não mostrou diferença entre as duas técnicas aqui estudadas. KAZAURA et al. (2002), também não referem diferença significativa entre as técnicas de RHAO ${ }^{110}$.

A gestação múltipla está associada a maiores riscos para mulheres, fetos e RN, merecendo atenção especial de obstetras e neonatologistas. $E$ fato bem conhecido que a gestação múltipla ocorre com muita freqüência nas pacientes submetidas às técnicas a RHA quer seja pela idade materna, ou como derivada das próprias técnicas ${ }^{52,56}$. A gestação múltipla (gemelares, trigemelares e mais) não mostrou diferença entre os 2 tipos de técnicas no presente estudo, embora a ocorrência de gemelar e trigemelar fosse bastante acima do encontrado em pacientes não submetidas à RHA ${ }^{29}$, 54

Evidências epidemiológicas mostram que a duração da gestação de gemelares é menor quando comparada com gestações únicas ${ }^{111}$.

Em relação aos $\mathrm{RN}$, em geral, parecem não estar associadas às complicações graves, em especial as relacionadas ao desenvolvimento neuro-psico-motor, no RN de termo que nasceu de algumas das técnicas de RHA. No entanto, o mesmo não ocorre nas gestações múltiplas, onde se encontram os dois maiores fatores de risco para ocorrência de seqüelas neurológicas, a prematuridade e o baixo peso de nascimento. Dentre as afecções neurológicas no RN, ganham destaque a paralisia cerebral, hemorragia intraventricular e as alterações motoras e cognitivas. Além de todas as complicações já mencionadas, já foi observada maior incidência de algumas neoplasias. Encontra-se também uma elevada incidência de malformações maiores ${ }^{112}$.

Outros estudos constataram um aumento de anomalias congênitas.como, anomalias do tubo neural, do coração, de extremidades e doenças como o Tumor de Wilms, associadas ao avanço da idade paterna 113,114 
Entretanto existem estudos recentes que contestam essas afirmativas, pois encontraram os mesmos riscos que na população geral para anomalias congênitas ${ }^{115}$.

No presente estudo, não houve diferenças significativas em relação ao boletim Apgar de $1^{\circ}$. e $5^{\circ}$. minutos entre os $\mathrm{RN}$, quanto ao tempo de permanência e nem em relação ao peso de alta, podendo-se inferir que a evolução na unidade neonatal tenha sido semelhante entre os RN analisados segundo as duas técnicas estudadas.

Analisando os RN múltiplos como um grupo único, independente da técnica, verificou-se que não houve diferença significativa quanto às variáveis: presença de doença de membranas hialinas (DMH), hemorragia intracraniana (HIV), retinopatia (ROP), sepse e prematuridade.

Houve diferença segundo o peso de nascimento e idade gestacional, como seria de se esperar.

As doenças relacionadas à prematuridade mostraram que houve maior número entre gêmeos e trigêmeos em relação aos únicos. $O$ nascimento prematuro explica essa ocorrência.

Os efeitos benéficos na adaptação respiratória do RN com 39 semanas de idade gestacional, foi evidenciado em um amplo estudo com mulheres submetidas à cesárea eletiva, sem testar a maturidade fetal do pulmão. Constatou-se que a realização desse procedimento está associada ao risco da admissão do RN na unidade de cuidados especiais por problemas respiratórios: o risco era de $11.4 \%$ em 37 semanas; 6.2 em 38 semanas; e $1.5 \%$ em 39 semanas de idade gestacional ${ }^{116}$.

O encontro de malformações foi não significativo entre únicos e gemelares, embora represente número elevado em relação ao relatado para uma população geral. 
Em relação à mortalidade perinatal, foram encontradas na amostra deste estudo, diferenças significativas entre os gêmeos e trigêmeos quando comparados aos únicos, como seria esperado segundo o que já foi exposto em relação aos riscos da gemelaridade. Não houve óbitos em RN de gestação única.

Estudo realizado pelo Centro Nacional de Estatísticos para Saúde dos Estados Unidos, incluindo 11 milhões de RN de gestações únicas e aproximadamente 300.000 nascimentos de gêmeos, mostrou que a taxa de mortalidade perinatal foi menor, para os únicos, quando realizada entre 39 a 41 semanas (aproximadamente 1 morte fetal e 1 neonatal por 1000 nascimentos), mas para gêmeos essa mesma taxa foi melhor quando da realização do parto entre 37 a 39 semanas (3-4 mortes fetais e 2 neonatais por 1000 nascimentos) . 0 estudo constatou ainda que na gestação de 39 semanas, o risco da morte fetal em uma gravidez gemelar excedia o risco da morte neonatal ${ }^{117}$.

Em resumo, apesar de todos os benefícios que a RHA trouxe para casais inférteis, ainda são necessários muitos estudos para que se possa estabelecer um consenso a respeito. 
CONCLUSÕES 


\section{CONCLUSÕES}

1. As mulheres submetidas à RHA no HIAE apresentaram , na média, idade avançada e a principal causa de infertilidade foi a feminina.

2. Verificou-se que a utilização da técnica de ICSI tem aumentado com, diminuição da técnica de FIV.

3. Os RN não diferiram, segundo as técnicas estudadas, quanto ao peso de nascimento, vitalidade ao nascer avaliada pélo boletim Apgar de $1^{\circ}$ e $5^{\circ}$ minutos, classificação do peso pela idade gestacional, peso de alta e tempo de permanência hospitalar.

4. Encontrou-se elevada proporção de malformações entre os RN. Foram encontradas diferenças significativas entre múltiplos e únicos em relação a doenças neonatais (DPMH, HIC) e mortalidade.

5. Proporcionalmente houve aumento de malformações conforme a idade da mãe foi maior 


\section{CONSIDERAÇÕES FINAIS}




\section{CONSIDERAÇÕES FINAIS}

Essa conclusão reforça a idéia que a utilização de ambas as técnicas deve ser baseadas de acordo com as indicações médicas e as normas propostas nos protocolos dos serviços.

A grande questão a ser analisada é o número de embriőes implantados. Se por um lado aumenta a taxa de sucesso de gravidez, por outro lado aumentam exponencialmente os riscos para os RN.

Dado ao escopo do estudo, não foi possível avaliar os efeitos tardios e possíveis seqüelas no conjunto dos RN. Isto reforça a necessidade de estudos que levem em conta 0 acompanhamento especializado, dessas crianças, nos primeiros anos de vida.

Como foi visto, há um número crescente de crianças nascidas por meio das técnicas de RHA, e essa tendência tende a se manter ou aumentar.

Esse estudo mostrou, que as varias alteraçoes encontrada, como a prematuridade extrema, problemas respiratórios, gestações múltiplas (especialmente as trigemelares ou mais), têm importante repercussão no futuro do RN.

Evidencio-se também, a falta de estudos e a pequena casuística do aumento da incidência de malformações, das doenças genéticas citadas, causas de infertilidade e conseqüências da manipulação dos gametas (como mutações) entre outras necessidades.

O Brasil ostenta uma posição de liderança na América Latina, mas mesmo assim são muito raros os estudos de follow-up seja das mães ou dos bebês.

Por tudo isso, a autora recomenda a implantação de serviços de acompanhamento das crianças nascidas de reprodução assistida. 


\section{REFERENCIAS}




\section{8 - REFERÊNCIAS}

1. CREMESP - Conselho Regional de Medicina de São Paulo. Resolução 1358/92. Brasília, 1992. Direitos sexuais e reprodutivos [texto na Internet] 2006 [citado 2006 jan10]. Disponível em:

http://www.cremesp.org.br/manual/etica gineco obst/etica gineco obst etr capitulo 7.htm

2. ONU - Declaraçăo universal dos direitos humanos [ texto na Internet] 2005 [citado 2005 dez 01]. Disponivel em:

http://www.unesco.org.br/publicacoes/copy of pdf/decunivdireitoshuma nos.pdf

3. ONU - International Humanitarian Law and Human Rights [texto na Internet] 2006 [citado 2006 jan10]. Disponível em:

http://www.ohchr.org/english/about/publications/docs/fs13.htm

4. ONU - Organização das Nações Unidas. As Grandes Conferências das Nações Unidas [texto na Internet] 2006 [citado 2006 jan10]. Disponivel em: http://www.unicrio.org.br/Textos/onu 20b.htm

5. ONU - Organização das Nações Unidas. IV Conferência Mundial sobre a Mulher. Apresentado em: Conferência Mundial sobre a Mulher, Beijing, 1995. (Série Conferências Mundiais das Nações Unidas). Rio de Janeiro: Fundação Oswaldo Cruz; 1996.

6. OMS - Organização Mundial da Saúde. Manual da classificação estatística intereacional de doenças e problemas relacionados à saúde: $10^{\mathrm{a}}$ revisão. São Paulo:Edusp; 1997.

7. Aldrovandi A, França DG. A reprodução assistida e as relações de parentesco. Disponivel em: http://jus2.uol.com.br/doutrina/texto. asp?id=3127 
8. Almeida LMM. A medicina moderna da procriação no direito de família e de sucessões. Trabalho apresentado no XXI Congresso da União Internacional do Notariado Latino: Berlim; 1995.

9. Ciocci D. Direito Penal e Reprodução Assistida - Tese apresentada à Comissão da Faculdade de Direito da Universidade de São Paulo para o titulo de Doutor - USP- 2005.

10. Wilson EE. Assisted reproductive techonologies and multiple gestations. Cl. Perionatology 2005, 32:315-28.

11. Steptoe PC, Edwards RG. Birth after reimplantation of human embryo Lancet. 1978; 2(8085):366.

12. Passos EP. Assisted reproduction: lesson learnt and future challenges. Rev gynaecol pract. 2004; 4:199-202.

13. Fernandez E, Zegers F, Hess R, Roblero, L; Ortiz, ME; Guadarrama, A. et al. Transferencia intratubaria de gametos (TITG, GIFT): comunicación del primer embarazo. Rev Chil Obstet Ginecol. 1985; 50(5):356-62.

14. Franco JR, Wheba S. I Registro brasileiro sobre o uso das técnicas de reprodução assistida: 1992. Reprodução. 1994; 9 (3):199-202.

15. Palermo G, Joris $H$, Devroey $P$. Van Steirtegehm AC. Pregnancies after intracitoplasmatic injection of single spermatozoon into oocyte. Lancet. 1992; 340(8810):17-9.

16. Jones G. First human clone bid planned. [texto na Internet] 2006 [citado 2006 jan10]. Disponivel em: <http://archives, cnn.com/2001/WORLD/europe/08/06/clone.doctor/>

17. Franco Jr JG, Petersen CG, Mauri AL, Baruffi RLR, Freitas, EF, Ursolino $\mathrm{G}$. Tratamento do fator masculino grave em infertilidade pela injeção intracitoplasmática de espermatozóides. Primeiras gestações 
obtidas com a coleta de espermatozóides do testículo. Rev Bras Ginecol Obstet. 1995;17(10):967-76.

18. Wilmut I, Schnieke AE, McWhir J, Kind AJ, Campbell KHS. Viable offspring derived from fetal and adult mammalian cells. Nature. 1997; 385: $810-3$.

19. Thomson JA, Itskovitz-Eldor J, Shapiro SS., Waknitz MA, Swiergiel JJ, Marshall VS, Jones JM. Embryonic stem cell lines derived from human blastocysts. Science. 1998; 282: 1145-7.

20. Pereira LV, Kerkis AY, Sukoyan MA, Kerkis IE, Merkel C, Mello MRB. Células tronco embrionárias e a geração de modelos animais para doenças genéticas humanas. Rev Biotecnol.Brasília. 2001;20: 10-20.

21. Assisted Human Reproduction (Section 8) Regulations. Gazette du Canada, Ottawa 2005. Partie I: 3165-85. [texto na Internet] 2006 [citado 2006 jan10]. Disponivel em:

<http://canadagazette.gc.ca/part//2005/20050924/pdf/g1-13939.pdf>

22. Al-Sunaidi M, Tulandi T, Holzer H, Sylvestre C, Chian RC, Tan SL. Repeated pregnancies and live births after in vitro maturation treatment. Fertil Steril. 2007;87(5):1212 e9-12.

23. CDC-Centers for Disease Control. Assisted Reproductive Technology. 2007. [texto na Internet] 2006 [citado 2006 jan10]. Disponivel em: <http://www.cdc.gov/art/>

24. IBGE Instituto Brasileiro de Geografia e Estatística. Sidra - Tabela 2466 - pessoas de 10 anos ou mais por estado civil, situação de domicilio, condição de convivência e grupos. [texto na Internet] 2006 [citado 2006 jan10]. Disponivel em $<$ http://www.sidra.ibge.gov.br/bda/tabela/listabl.asp?z=t\&c=2466> 
25. CDC - Centers for Disease Control. National Survey of Family Growth (NSFG). [texto na Internet] 2006 [citado 2006 jan10]. Disponivel em: http://www.cdc.gov/nchs/nsfg.htm

26. Glina S, Borges SJ, Antunes N. Reprodução Humana-Infertilidade Feminina. In: Segre CAM. Perinatologia. São Paulo: Sarvier. p.3-8.

27. Menezes A. Pesquisa vincula excesso de peso e má qualidade de vida a doenças hormonais. Cienc Cult. 2005; 57(1):15-6.

28. WHO - World Health Organization. Technical Report Series. Recent Advances in Medically Assisted Conception. 1992; 820: 1-111.

29. Segre CAM. Informações Perinatais: relatório de atividades. São Paulo: Hospital Israelita Albert Einstein; 1999.

30. Glina S, Soares JB, Meirelles, Borges J, Conceição AJ, Antunes Jr N. Relatório da Reunião de Diretrizes Básicas em Infertilidade Masculina da Sociedade Brasileira de Urologia \& II Consenso Brasileiro em Infertilidade Masculina da Sociedade Brasileira de Urologia. Int Braz J Urol. 2003; 29 (Suppl5) 59 p.

31. Olmed B, Chllik $C$, Kopelman $S$. Definición y causas de la infertilidad. Rev Colomb Obstet Ginecol. 2003; 54(4):1-3.

32. Borges Junior E. Técnicas de Reprodução Assistida de Baixa Complexidade. In: I Consenso Brasileiro - Indução da Ovulação em reprodução assistida. São Paulo: Ed. Cultural; 2000. p. 1-13.

33. Glina, S, Soares JB, Meirelles AJC, Antunes Jr A. Reprodução humana. In Segre CAM. Perinatologia. Fundamentos e prática.-São Paulo: Sarvier; 2002.p. 3-14.

34. Wright VC, Shieve LA, Reynolds MA, Jeng G. Assisted reproductive technology surveillance. MMWR 2005/ 54 (SSO2); 1-24. [texto na 
Internet] 2005 [citado 2005 mar10]. Disponivel em:

http://www.cdc.gov/mmwr/preview/mmwrhtml/ss5402a1.htm

35. CDC - Centers for Disease Control and Prevention - Division of reproductive health national. [texto na Internet] 2006 [citado 2006 jan10]. Disponivel em: http://www.cdc.gov/reproductivehealth/

36. Glina S, Fragoso JB, Martins FG, Soares JB, Galuppo AG, Wonchockier RA. Percutaneous epididymal sperm aspiration (pesa) in men with obstructive azoospermia. International Braz J Urol. 2005; $29(2): 141-6$.

37. Orvieto R, Ben-Rafael Z, Ashkenazi J, Yoeli R, Messing B, Perri T et al. Outcome of pregnancies derived from assisted reproductive technologies: IVF versus ICSI. J Assist Reprod Genet. 2000;17(7):3857.

38. Kansal-Kalra S, Milad MP, Grobman WA. In vitro fertilization (IVF) versus gonadotropins followed by IVF as treatment for primary infertility: a cost-based decision analysis. Fertil Steril. 2005; 84(3):600-4.

39. Kallen B, Finnstrom O, Nygren KG, Olausson PO. In vitro fertilization (IVF) in Sweden: infant outcome after different IVF fertilization. Fertil Steril. 2005; 84(3):611-7.

40. Gissler M, Klemetti R, Sevon T, Hemminki E. Monitoring of IVF birth outcomes in Finland: a data quality study. BMC Med Inform Decis Mak. $2004 ; 4(1): 3$.

41. Pinborg AP, Loft A, Rasmussen S, Andersen AN. Hospital care utilization of IVF/ICSI twins followed until 2-7 years of age: a controlled Danish national cohort study. Hum Reprod. 2004; 19(11): 2529-36.

42. Andersen AN, Gianaroli L, Nygren KG. The European IVF-monitoring programme (EIM) for the European Society of Human Reproduction and Embryology (ESHRE). Assisted reproductive technology in Europe, 
2000. Results generated from European registers by ESHRE. Hum. Reprod. 2004; 19(3): 490-503.

43. Hull MGR. Infertility treatment: Relative effectiveness of conventional and assisted conception methods. Hum Reprod. 1992; 7(6):785-96.

44. Zegers-Hochschild F. El impacto de la diversidad cultural y fatores en la práctica global de técnicas de reproducción asistida. Taller general Mar del Plata- Argentina 27 a 29 de abril de 2007. 116

45. Pasqualotto FF. Os três fatores genéticos mais frequentemente relacionados à infertilidade masculina. [texto na Internet] 2006 [citado 2006 jan10]. Disponível em <http://www.scielo.br/pdf/rbgo/v29n2/08.pdf>

46. Glina S. Ainda existe infertilidade masculina? [texto na Internet] 2006 [citado 2006 jan10]. Disponivel em: <http://www.portalmedico.org.br/jornal/jornais1999/0299/urologia.htm>

47. ESHRE - European Society of Human Reproduction \& Embriology [texto na Internet] 2006 [citado 2006 jan10]. Disponível em: http://mww.eshre.com/emc. asp?pageld=195

48. CDC-Centers for Disease Control. Assisted Reproductive Technology. 2007. [texto na Internet] 2007 [citado 2007 jan10]. Disponível em: $<$ http://www.cdc.gov/art/>

49. Schieve L, Wilcox LS, Zeitz J, Jeng G, Hoffman D, Brzyski R, et al. Assessment of outcomes for assisted reproductive technology: overview of issues and the U.S. experience in establishing a surveillance system. In: Vayena E, Rowe PJ, Griffin PD (editors). Current practices and controversies in assisted reproduction: report of a meeting on "Medical, ethical and social aspects of assisted reproduction Geneva. 2002, p.363-76. 
50. Benirschke K, Kim,CK. Multiple pregnancy. N Engl J Med. 1973; 288(24):1276-84

51. Martin JA, Hamilton BE, Sutton PD, Ventura SJ, Menacker F, Munson ML. Births: Final data for 2001. Natl Vital Stat Rep 2003.17;52(10):1113.

52. Beiguelman $B$, Franchi-Pinto $C$, Krieger $H$ and Magna LA. Twinning rate in a Southwesten RN Brazilian population. Acta Genet Med Gemellol. 1996; 45(3):317-24.

53. Kiely JL, Kiely M Epidemiological trends in multiple births in the United States, 1971-1998. Twin Res. 2001; 4(3):131-3.

54. Colletto GMDD, Segre CAM, Beiguelman B. Twinning rate in a Southeastern Brazilian population with a high standard of reproductive care. São Paulo Med J. 2001;119(6):216-9.

55. IBGE - Instituto Brasileiro de Geografia e Estatística. Sidra - Tabela 214 - Nascidos vivos ocorridos no ano por lugar de residência da mãe e número de nascidos por parto. [texto na Internet] 2006 [citado 2006 jan10]. Disponivel em $<$ http://www. sidra.ibge.gov.br/bda/tabela/listabl. asp?z=t\&c=214>

56. Colletto GMDD, Segre CAM, Rielli STRC Horácio MR. Multiple birth rates according to different socioeconomic levels: an analysis of four hospitals from the city of Sao Paulo, Brazil. Twin Res.2003; 6(3): 177 82.

57. Lambalk CB; De Koning $\mathrm{CH}$; Braat DD The endocrinology of dizygotic twinning in the human. Mol Cell Endocrinol. 1998;145(1-2):97-102.

58. Loraine E, Wilkins I. Multiple Gestations. Clin Perinatol. 2005; 32(2):301-3. 
59. Porter TF, Dildy GA, Blanchard JR, Kochenour NK, Clark SL. Normal values for amniotic fluid index during uncomplicated twin pregnancy. Obstet Gynecol. 1996; 87(5):699-702.

60. Revenis ME, Johnson-Robins LA. Multiple gestations. In Avery ME, Fletcher M, MacDonald MG (ed) Neonatology, pathology and management of the newborn. (5th ed.). Philadelphia: Lippincott 1999. p.473-82.

61. Katalinic A, Rosch C, Ludwig M. German ICSI Follow-Up Study Group. Pregnancy course and outcome after intracytoplasmic sperm injection: a controlled, prospective cohort study. Fertil Steril. 2004;81(6):1604-16.

62. Mayer A, Lunenfeld E, Wiznitzer A, Har-Vardi I, Bentov Y, Levitas E. Increased prevalence of gestational diabetes mellitus in in vitro fertilization pregnancies inadvertently conceived during treatment with long-acting triptorelin acetate. Fertil Steril. 2005;84(3):789-92.

63. Maman E, Lunenfeld E, Levy A, Vardi H, Potashnik G. Obstetric outcome of singleton pregnancies conceived by in vitro fertilization and ovulation induction compared with those conceived spontaneously. Fertil Steril. 1998; 70(2):240-5.

64. Hansen M, Bower C, Milne E, de Klerk N, Kurinczuk JJ. Assisted reproductive technologies and the risk of birth defects - a systematic review. Hum Reprod. 2005;20(2):328-38.

65. Gunby J, Daya S. IVF Directors Group of the Canadian Fertility and Andrology Society. Assisted reproductive technologies (ART) in Canada: 2001 results from the Canadian ART Register. Fertil Steril. 2005;84(3):590-9. Erratum in: Fertil Steril. 2006;85(1):272.

66. Reddy UM, Wapner RJ, Rebar RW, Tasca RJ. Infertility, assisted reproductive technology, and adverse pregnancy outcomes: executive 
summary of a National Institute of Child Health an Human Development workshop. Obstet Gynecol. 2007; 109(4): 967-77.

67. Jones KL. Smith's recognizable patterns of human malformation. 6 th ed. Philadelphia: Elsevier Saunders; 2006.

68. Schinzel AA, Smith DW, Miller JR. Monozygotic twinning and structural defects. J Pediatr. 1979; 95(6):921-30.

69. Katagiri Y, Shibui Y, Nagao K, Miura K, Morita M. Epigenetics in assisted reproductive technology. Reprod Med Biol. 2007; 6(2): 69-75.

70. Klip H, Burger CW, de Kraker J, van Leeuwen FE. Risk of cancer in the offspring of women who underwent ovarian stimulation for IVF. Hum Reprod. 2001;16(11):2451-8.

71. Lerner-Geva L, Toren A, Chetrit A, Modan B, Mandel M, Rechav G, Dor $\mathrm{J}$. The risk for cancer among children of women who underwent in vitro fertilization. Cancer. 2000; 88(12):2845-7.

72. Bruinsma $F$, Venn $A$, Lancaster $P$, Speirs $A$, HealyD. Incidence of cancer in children born after in-vitro fertilization. Hum Reprod. 2000; 15(3):604-7.

73. Moll AC, Imhof SM, Cruysberg JR, Schouten-van Meeteren AY, Boers $M$, van Leeuwen FE. Incidence of retinoblastoma in children born after in-vitro fertilisation. Lancet 2003; 361(9354):309-10.

74. Brinton LA, Lamb EJ, Moghissi KS, Scoccia B, Althuis M, Mabie J, Westhoff $C$. Ovarian cancer risk associated with varying causes of infertility. Fertil Steril 2004; 82:405-14.

75. Burkman RT, Tang MC, Malone KE, Marchbanks PA, McDonald JA, Folger SG, et al. Infertility drugs and the risk of breast cancer: findings from the National Institute of Child Health and Human Development 
Women's Contraceptive and Reproductive Experiences Study. Fertil Steril. 2003; 79(4):844-51.

76. Jackson RA, Gibson KA, Wu YW, Croughan MS. Perinatal outcomes in singletons following in vitro fertilization: a meta-analysis. Obstet Gynecol. 2004; 103(3):551-63.

77. Schieve LA, Meikle SF, Ferre C, Peterson HB, Jeng G, Wilcox LS. Low and very low birth weight in infants conceived with use of assisted reproductive technology. N Engl J Med. 2002; 346(10):731-7.

78. Källén $B$, Finnström $O$, Nygren $\mathrm{K}-\mathrm{G}$, Otterblad, Olausson $\mathrm{P}$. In vitro fertilization in Sweden: Child morbidity including cancer risk. Fertil Steril. 2005; 84(3):605-10.

79. Soderstrom-Anttila V. Pregnancy and child outcome after oocyte donation. Hum Reprod Update. 2001;7(1):28-32.

80. Bonduelle M, Ponjaert I, Steirteghem AV, Derde MP, Devroey P, Liebaers I. Developmental outcome at 2 years of age for children born after ICSI compared with children born after IVF. Hum Reprod. 2003;18(2):342-50.

81. Ratzinger JC, Bovone A. Instruction on respect for human life in its origin and on the dignity of procreation replies to certain questions of the day. Congregation for the doctrine of the faith.1987.

82. Warnock M. Report of Committee of inquiry into human fertilization and embriology. London: HMSO; 1984.

83. CFM - Conselho Federal de Medicina. Normas éticas para a utilização das técnicas de reprodução assistida. Resolução no 1.358, de 11 de novembro de 1992. Diário Oficial da União; Poder Executivo, Brasília, DF, 19 nov. 1992. Seção 1, p. 16053. 
84. Goldim JR. Bioética e Reprodução Humana. [texto na Internet] 2006 [citado 2006 jan10]. Disponivel em:

$<$ http://www.ufrgs.br/bioetica/biorepr.htm>

85. Perin Junior $E$. Aspectos jurídicos da reprodução humana assistida em face do meio ambiente ecologicamente equilibrado. 1998. [texto na Internet] 2006 [citado 2006 jan10]. Disponível em:

<http://jus2.uol.com.br/doutrina/texto.asp?id=3510>

86. Brasil. Congresso Nacional. Constituição da República Federativa do Brasil. 1988.

87. Diniz D. A Medicina Reprodutiva no Brasil: tecnologias reprodutivas, ética e gênero: $O$ debate legislativo brasileiro. Série Anis Bioética 2000.

88. Brasil. Câmara dos Deputados. Deputado Luiz Moreira. Projeto de Lei n. 3.638. 1993.

89. Brasil. Câmara dos deputados. Projetos de Lei e Outras Proposições. [texto na Internet] 2006 [citado 2006 jan10]. Disponivel em: http://www2.camara.gov.br/proposicoes

90. Brasil. Ministério da Saúde - Secretária de Ciência, Tecnologia e Insumos Estratégicos. Regulação da Reprodução Humana Assistida. Jun 2004. Diário Oficial da União, Brasília, 8(3): 1515-17.

91. Brasil. LEI No 11.105, DE 24 DE MARÇO DE 2005. D.O.U. de 28 março 2005. Disponivel em: http://www.planalto.gov.br/CCIVIL/ Ato20042006/2005/Lei/L11105.htm

92. Brasil. Ministério da Saúde - Secretaria de Atenção à Saúde Departamento de Ações Programáticas Estratégicas. Direitos sexuais e direitos reprodutivos uma prioridade do governo. Normas e Manuais Técnicos. Cad 1. Brasilia - DF 2005. 
93. Brasil. Ministério da Saúde Portaria no 388 de 06 de julho de 2005 Secretária de Atenção à Saúde, http://dtr2001.saude.gov.br/sas/PORTARIAS/Port2005/PT-388.htm

94. São Paulo. Conselho Regional de Medicina do Estado de São Paulo. Reprodução assistida para portadores de HIV. [texto na Internet] 2006 [citado 2006 jan10]. Disponivel em: http://uww.crmsp.org.br/?siteAcao=Revista\&id=184

95. São Paulo. Conselho Federal de Medicina. Polêmica- Fertilização in vitro. J Medicina. 2005. [texto na Internet] 2005 [citado $2005 \mathrm{dez} 01$ ]. Disponível em:

http://www.portalmedico.org.br/index.asp?opcao=bibliotecaJorecémnascidoalmaijuniul2005\#

96. Rede Lara - Rede Latino-Americana de Reprodução Assistida. Registro Latino-americano da. [texto na Internet] 2006 [citado 2006 jan10]. Disponivel em: http://www.redlara.com/REGISTRO.ASP

97. Melamed RMM, Borges E, Laconelli A, Rossi-ferragut LM. Expectativas e reações emocionais dos casais submetidos a técnicas de reprodução assistida. J Bras Reprod Ass. 2005; 9(2).

98. Andersen AN, Goossens V, Gianaroli L, Felberbaum R, Mouzon J, Nygren KG. Results generated from European registers by The European IVF-monitoring (EIM)* Consortium, for the European Society of Human Reproduction and Embryology (ESHRE). Hum. Reprod. 2007; 22(6): 1513-25.

99. Collins J; Graves $\mathrm{G}$. The economic consequences of multiple gestation pregnancy in assisted conception cycles. Hum Fertil. 2000, 3(4): $275-$ 83.

100. Statistic Program StatSoft (SPSS). [computer program]. Version 9.0. Tulsa: Statistica/Mac; 2000. 
101. DATASUS (Departamento de Informática do SUS), 2006. SINASC Sistema de Informação sobre Nascidos Vivos. Disponível em: <http://www.datasus.gov.br>

102. Kidd SA, Eskenazi B, Wyrobek AJ. Effects of male age on semen quality and fertility: a review of the literature. Fertil Steril 2001; 75:237

103. Lass A. The fertility potential of women with a single ovary. Hum. Reprod. Update. 1999, 5, 546-550.

104. Silva JLP, Bahamondes L. Reprodução assistida como causa de morbidade materna e perinatal. Rev. Bras. Ginecol. Obstet. 2005, 27(12): 759-67.

105. Shevell T, Malone FD, Vidaver J, Porter TF, Luthy DA, Comstroch CH et al. Assisted reproductive technology and pregnancy outcome. Obstet Gynecol. 2005.106:1039-45.

106. Grant A, Glazener CM. Elective caesarean section versus expectant management for delivery of the small baby Cochrane Database Syst Rev 2001;(2):CD000078

107. Blondel B, Kogan MD, Alexander GR, Dattani N, Kramer MS, Macfarlane A, Wen SW. The impact of the increasing number of multiple births on the rates of preterm birth and low birthweight: an international study. Am J Public Health. 2002 ;92(8):1323-30.

108. Martin JA, MacDorman MF, Mathews TJ. Triplet births: trends and outcomes, 1971-94. Vital Health Stat. 1997; 47(21):21-55.

109. Bertagnon JRD. O recém-nascido de baixo peso. [tese]. São Paulo. Universidade de São Paulo;1991.

110. Kazaura M, Lie RT, Skjaerven R. Paternal age and the risk of birth defects in Norway. Ann Epidemiol 2004; 14:566.. 
111. Andersen AMN, Wohlfahrt J, Christens P, Olsen J, Melbye M. Maternal age and fetal loss: population based register linkage study. BMJ 2000; $320: 1708$

112. Thacker PD. Biological clock ticks for men, too: genetic defects linked to sperm of older fathers. JAMA 2004. 291:1683

113. Auroux M. Age of the father and development. Contracept Fertil Sex 1993. 21:382.

114. Zhu JL, Madsen KM, Vestergaard, M. Paternal age and congenital malformations. Hum Reprod 2005. 20:3173.

115. Lian ZH, Zack MM, Erickson JD. Paternal age and the occurrence of birth defects. Am J Hum Genet 1986. 39:648.

116. Yang $Q$, Wen SW, Leader A. Paternal age and birth defects: how strong is the association? Hum Reprod 2007; 22:696.

117. Stutchfield P, Whitaker R, Russell I. Antenatal betamethasone and incidence of neonatal respiratory distress after elective caesarean section: pragmatic randomised trial. BMJ 2005. 331:662 